Università degli Studi di Genova

DISEFIN - Series of Economic Working Papers

16126 Genova - via vivaldi 5 - Fax +39010 2095223

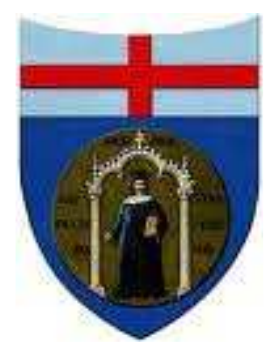

The Italian Tradition in Public Finance: an Annotated Bibliography of Mauro Fasiani

Amedeo Fossati

wp n. 1

January 2012 
"DISEFIN Working Papers on line"

series of economic working papers

published online by

Research Doctorate in

Public Economics

Ph.D School in New technologies and Social Sciences

University of Genoa

Founder:

Amedeo Fossati

Editor-in-Chief:

Marcello Montefiori

Editorial Board:

Paul De Grawe

Francesco Figari

Amedeo Fossati

Luca Gandullia

Eric Gaspérini

Andrea Monticini

Carlo Perroni

Web site:

http://www.disefin.unige.it/ 


\title{
The Italian Tradition in Public Finance: an Annotated Bibliography of Mauro Fasiani
}

\author{
Amedeo Fossati \\ University of Genoa, Italy
}

\begin{abstract}
This paper is directed to the enhancement of the scientific figure of MauroFasiani. In fact, he still does not occupy the proper place in scientific debate, either in Italy or abroad. Following his untimely death in 1950, his high reputation has not paid adequate historiographical interest. The aim is not to discuss Fasiani's scientific thought, but only to draw it to the attention of the international scholars by letting known the content of his work. This is done by scaling down the over 3 thousands pages of his original works to the just overl hundred pages of this paper.
\end{abstract}

Keywords: Italian tradition in Public Finance; Mauro Fasiani Jel Classification: $B 2, H O O$ 


\section{Introduction}

Mauro Fasiani's scientific figure still does not occupy the proper place in scientific debate, either in Italy or abroad. Following his untimely death in 1950, his high reputation has not paid adequate historiographical interest. The enhancement of the figure of Fasiani therefore presents a very significant scientific interest, in order to finally put into perspective his contribution to the evolution of the theory of public finance not only in the Italian tradition, but in the international context also. This requires the recognition of his scientific work and an adequate critical discussion of the topics that he studied in the light of contemporary literature, to highlight his originality, depth of thought and relevance today.

To that end is directed the present paper within its obvious limits. In fact, the aim is not to discuss Fasiani's scientific thought, but only to draw it to the attention of the international scholars by letting known the content of his work. This is done by scaling down the over 3 thousands pages of his original works to the 1 hundred pages of this paper. The hindrance is that between Fasiani and my readers there is still the wedge of my intelligence: I do hope that only few misunderstandings will occur.

Mauro Fasiani (Turin, 1900 - Genoa, 1950), young veteran of World War I, had graduated in law at the University of Turin in 1924 with Luigi Einaudi and under his leadership had worked in the Laboratorio Cognetti De Martiis for a decade as an assistant professor and then as professor in both the R. Politecnico and the R. Istituto Superiore di Scienze Economiche in Turin. Winner of the university chair of Public Finance at Messina in 1932, he was called at the end of 1933 at the R. Istituto Superiore di Scienze Economiche in Genoa, where he has spent the last part of his life. On 15 July 1948 he was appointed associate of the Accademia Nazionale dei Lincei. He was elected Dean of the Faculty of Economics, University of Genoa in 1936, when the Istituto Superiore was merged into the University of Genoa and remained in that position until his death on 20 July 1950.

After Einaudi, namely in the last generation of the Italian tradition of public finance, Fasiani is certainly the most prominent scholar. 
His scientific work can be compared with that of the great masters of the Italian tradition, as De Viti de Marco, Pantaleoni and Einaudi. His scientific activity can be considered as the highest point in the evolution of the Italian tradition of the general theory of public finance. His approach is purely economic, as opposed to the sociological one followed by Borgatta, first pupil of Einaudi. His scientific effort differs from that of Einaudi, especially because of his strictly logic approach, from the assumption of hypothesis trough the development of reasoning, to the identification of uniformities.

In regard to the late Italian tradition in public finance, Fasiani was the scholar who received the Paretian heritage in the most critical but beneficial way. He did not belong to the sociological school - so a clear break is evident between Fasiani and the Paretians like Sensini and Borgatta. In fact, he endorsed Pareto's scientific methodology as regards the need for a clear separation between science and politics, morals and arts. He explored specific fiscal topics basing on economic assumptions only, using a Paretian economic methodology, from the general equilibrium approach to the choice theory. But Fasiani's research programme also extended to offering a general theory of public finance, building on the definition of cooperative, monopolistic and tutorial states, intended as polar cases, based on Paretian maxima for and of the community.

This paper is organised as follows. Section 2 groups all Fasiani's works on the general topic of taxation, partitioned in Methodology for tax analysis, Time and intermediate equilibria and Effects of taxation. Section 3 reports on the essays on Fiscal illusions, section 4 on the double taxation of savings, and section 5 on Business cycles. Then, section 6,7 and 8 are devoted respectively to the essays on Corporative economy, Pubblic Debt and on the History of economic thought. Section 9 reports on the works concerning the dispute with Einaudi and section 10 is devoted to the manual Principii di Scienza delle finanze. Finally, section 11 reports on the minor works, which complete the review of the entire known works of Fasiani. The list of the works of Mauro Fasiani and a bibliography about Mauro Fasiani conclude the paper. 


\section{Works on the general topic of taxation}

\subsection{Works on the methodology for tax analysis.}

Fasiani did not write any papers devoted to methodology entirely, but had often discussed methodological points in his essays. Among them, here I think it appropriate to consider specifically six article, i.e.: On a divergence in opinions among some public finance scholars (1931); Theoretical structures and fiscal "exponibilia" (1932); On the appropriateness of the assumption of the hail-tax assumption in the analysis of tax shifting (1943); The taxation of capital gains (1946); Tax distribution and Pareto's law in a recent theoretical study (1949); The equivalence between income taxation and inheritance taxes (1950). However, important points are discussed in his Manual "Principii di Scienza delle Finanze" (Principles of Public Finance) (1941) and in other essays .

The general idea that ordered the selection of the articles is the prominence or the importance of the methodology. In point of fact, the specific method used in this paper is not to discuss Fasiani's methodologies, but to let that the reader directly face how Fasiani tackled his topics with the specific methodology that he had considered appropriate to his ends.

As regards the first essay above mentioned: A proposito di una divergenza di opinioni fra alcuni scrittori di finanza (On a divergence in opinions among some public finance scholars) (1931), it is an "arbitrage" between different theoretical statements about the expediency to tax the surplus or the extra income (Hobson ${ }^{1} \&$ Griziotti $^{2}$ ) rather than the "normal" income in the sense of Einaudi ${ }^{3}$. In general,

\footnotetext{
${ }^{1}$ Hobson, J. A.: The taxation of unearned income. London: King, 1909; Hobson, J. A.: The industrial system : an inquiry into earned and unearned income, London: Longmans, Green, 1910; Hobson, J. A.: Taxation in a New State, London: Methuen, 1919

${ }^{2}$ Griziotti, B.: Le imposte sugli incrementi di valore, in Giornale degli economisti, 1910; Griziotti, B.: Le imposte sugli incrementi di valore nei capitali e sulle rendite nei redditi, Caserta: Tip. della libreria Moderna, 1912

${ }^{3}$ Einaudi, L.: Osservazioni critiche intorno alla teoria dell'ammortamento dell'imposta e teoria delle variazioni nei redditi e nei valori capitali susseguenti all'imposta/note del socio nazionale residente Luigi Einaudi, in "Atti della Reale accademia delle scienze di Torino ", vol. 54, 1918-1919, Torino: Bocca, 1919; Einaudi, L.: La terra e l'imposta, in "Annali di
} 
the discussion reaches a high level of dialectic sophistication (see $\S 8$ \& 9), although perhaps the discussion boils down more to a difference in settings than a difference of opinions. Einaudi starts from the assumption that savings must be exempted, while Hobson and Griziotti assume to tax the ability to pay, defined as that exceeding the production cost, represented by wages, interest and profits.

Fasiani states that the economic expediency concerns certain principles accepted a priori and therefore the problem is to compare, from the perspective of those principles, the effects of alternative taxes founded on different tax bases. As regards the position of Einaudi, it is tautologically true that by taxing the earned income also savings are taxed. Then, there is no doubt that if one wants to encourage savings in view of its beneficial effects on the expansion of the economic system, savings should be exempted from taxation. To this end, Einaudi assumes that the earners of "normal" income do not save, while savings are made by the earner of supra-normal incomes, at least basically. It follows that the objective of exempting savings may be achieved by taxing the "normal" income.

Hobson's argument is that taxation should be based on ability to pay and that the latter exists only above a certain minimum, which in a sense represents the cost necessary to ensure continued use of the factors of production. Therefore, ability to pay exists only in the surplus of income, because the cost should be exempted. Griziotti, similarly, believes that only the extra income may be taxable (at least as far as real taxes are concerned), because the "normal" income lacks any ability to pay.

Fasiani first notes that a large part of the difference among the approaches depends on the different concept of income used by Griziotti and Hobson compared to that used by Einaudi. In fact, all authors agree that rents must be taxed. According to Hobson, the cost of production of income is not part of ability to pay, because it is the normal compensation needed to the productive factors, and does not contain any kind of rent which instead should be taxed. For Hobson, the earned surpluses are not taxable because they are part of the costs, while the not earned surplus should be taxed. Similarly, Ein-

economia", Università Bocconi, Milano, 1924; Einaudi, L.: Contributo alla ricerca dell'ottima imposta, in " Annali di economia “, Università Bocconi, vol. V , Milano, 1929 
audi suggests to tax the normal income, which includes such rents. Actually, Hobson, Griziotti and Einaudi all agree that rents should be taxed. The bulk of the difference lies in the fact that Hobson and Griziotti do not consider the "cost" of production of income as part of the tax base, while according to Einaudi it should be taxed because it is part of the "normal" income.

The fact is that, according to Einaudi, the tax is part of the cost of production of income because the state is a factor of production. On the contrary, the other two authors are thinking under the assumption of hail-tax. Then, Fasiani argues that Einaudi's framework is logically correct only because the tax is the price of productive public services. However, even under the assumption that public services are factors of production, Fasiani recalls that "the production cycle of the tax" may not coincide "with the shortest cycle in which income is accruing" and therefore it might be convenient taxing the unearned surplus. And again, this expediency could also arise directly from the fact that this might increase income more rapidly, because the costs of production will be reduced. It is clear, however, that probably there would rise problems, because such a narrow tax base may be insufficient to grant the necessary tax income.

Another difference stems from Einaudi's assumption that savings are done by the ultra 'normal' taxpayers, as this hypothesis seems very far from reality. The final difference that Fasiani detects is that according to Hobson, savings are playing a less important role in the development of economic systems, as it only affects the formation of physical capital, while his economic systems are largely based on the development of human capital, due to costs of education, health, etc..

In the second essay: Schemi teorici ed "exponibilia" finanziari (Theoretical schemes and fiscal "exponibilia" (1932), Fasiani moves from the observation that semantics is very important and in particular that many economic theories are in fact examples of propositions exponibiles. Such Latin word means propositions intended in the particular sense of statements that are not necessarily true or false. Thus, the problem is to ascertain how much truth there is in each of them and to identify the circumstances from which their degree of truth depends. 
From this angle, the theoretical propositions of Graziani, Einaudi and Puviani ${ }^{4}$ are discussed. Each of them seeks to explain the phenomenon of taxation basing on his own explanatory principle "although often they arrive to conclusions only in part consistent". For Graziani, the explanatory principle is the marginalism. According to Einaudi, the explanation is to be found in the unconscious attempt of the law-makers to avoid double taxation of savings. For Puviani, the phenomenon of taxation is based on trying to maximize the fiscal illusions.

For Graziani, the decreasing marginal utility of income justifies: a) progressive taxation, b) tax exemption of the minimum income, c) qualitative discrimination of income (because labour income is only temporary), d) taxation of personal income, e) taxation on any transfer outlays, including taxes on consumption. According to Einaudi, "the fiscal systems" are explained because the state hits with taxes the consumption in all possible ways, including considering the earned income as a tax base. When earned income is taxed, it is exempted that part of income "that the law-maker deems earned" (quote from Einaudi ${ }^{5}$ ). The progressivity stems from the "reasonable" presumption that the need for savings is growing less than proportionally with the increase of savings. Likewise, the qualitative discrimination of income is explained considering that labour incomes are temporary. And so the property tax is "a technical tool moulded to meet ... the exemption of savings" (quote from Einaudi $^{6}$ ). For Puviani, taxes on transfers and on consumption are certainly destined to the exploitation of the fiscal illusions, but Fasiani points out that even the tax progressivity, the minimum income exemption and qualitative discrimination can be traced back to certain types of fiscal illusion.

Fasiani has no doubts that Puviani and Einaudi have made some "attempts to interpret these phenomena as results of a set of actions

\footnotetext{
${ }^{4}$ Graziani, A.: Istituzioni di scienza delle finanze, Torino: Bocca, 1897, quoted in the edition: Torino: Utet, 1929; Einaudi, L. (1912) Intorno al concetto di reddito imponibile e di un sistema di imposte sul reddito consumato, in Memorie della R.Accademia delle scienze di Torino,, serie II, Tomo LXIII, 1912; Puviani, A., Teoria della illusione finanziaria, Palermo : Remo Sandron Edit., 1903.

${ }^{5}$ Intorno al concetto di reddito imponibile...,cit., p.263

${ }^{6}$ Intorno al concetto di reddito imponibile..., cit., p.65-66
} 
that are "non-logical" in the Paretian meaning. In other words, the phenomena are explained by aspects that are not expected and (or) not desired from those individuals who decides the fiscal measures (p.498). However, he argues that also Graziani's attempt can be interpreted in the same way as a non-logical result. Thus, he may accept part of the explanation offered, while rejecting the "implicit benefit doctrine". The coexistence of the results emerging from the three schemes depends on considering the results as non-logical. Thus, one can accept the part of truth that there is in each. For example, the quantitative discrimination of income seems better explained by Graziani's framework compared to those of Einaudi and Puviani. Qualitative discrimination seems to be explained by the setting both of Graziani and of Einaudi, but not by that of Puviani. On the contrary, the particular specificities of taxes on transfers can be explained only in the setting of Puviani. The conclusion is not "to decide what is the schema corresponding to reality, but rather to determine the extent to which each schema does really show an attitude to explain the formal distribution of taxes" (p.514).

In my opinion, in this analysis, a major concern seems to be the meaning of action non-logical in the Paretian meaning, upheld by Fasiani, according to which the results are not expected or desired by the agent (p.498, note). For example, it is only due to "the character non-logical of the actions that lead to the exemption of savings from taxation" that Fasiani is able to understand Einaudi's statement that "while aiming to the opposite purpose, we are led, by the force of circumstances, to realizing unconsciously that result". Then, it would seem that the "explanation" is intended as the simple observation of the uniformity that "savings is exempted irrespective of the actions taken by the law-makers", while the further question "why does this happen?" remains unanswered.

However, I maintain that it is very important Fasiani's opinion that "in reality the fiscal phenomenon does not follow a single tendency, captured by this or that schema, but rather a number of tendencies that, in various ways, with varying intensity, in different circumstances, act on it" (p.483, emphasis in original). In other words, starting from the idea of exponibilia, Fasiani seems to land to a sort of scientific relativism, at least in the theory of public finance. 
As regards the third above mentioned essay: Sulla legittimità dell'ipotesi di un'imposta-grandine nello studio della ripercussione dei tributi (On the legitimacy of the hail-tax assumption in the analysis of tax shifting) (1943) Fasiani points out that the fact of taking into account the expenditure of the tax-income in the study of the effects of taxes, "can be ascribed to the glory of De Viti" (p. 261), even if there are precedents, including Sensini (1917) and Einaudi (1918-19), who had already provided applications consistent and in depth, before $\mathrm{De} \mathrm{Viti}^{7}$ (p. 262). However, since the complexity of the links among the markets makes it difficult and unpromising the analysis using the general equilibrium approach, it seems important to identify cases in which the simple assumption of hail-tax may be used. To that end, Fasiani distinguishes between direct or immediate effects of public expenditure, and indirect or mediated effects. The direct effects relate to the fact that, by taxing, the State affects the demands for the goods, either directly or due to the decrease in the income of the citizens. Those indirect "include the fact that the services provided by the state can now make convenient certain activities ... and other activities even more convenient" ( $\mathrm{p}$. 264).

Then, he recalls that he (Fasiani 1940a) ${ }^{8}$ had stated that the hailtax assumption is sensible in four cases only: 1) when one wants to do a partial study, 2) if the tax revenue is small and comes from one market only, while it is spent in all the markets, 3) when the demand of the state is merely substitutive of the private demand (the state purchases the very goods, that individuals no more demand), 4) when the new tax revenue will be used to finance an increase in spending "due to other dynamic changes"(p. 264-65). The rest of the article is devoted to discuss the criticism that Da Empoli (1941) had raised to these four Fasiani's propositions.

On the first case, Fasiani recalls that Da Empoli thinks that "to state that the case legitimates the assumption of hail-tax it is a bit 'forced', while Fasiani has no doubt that the point is simply to choose "a field of research", and believes that there is no contrast of

\footnotetext{
${ }^{7}$ See, however the precedent recalled in Fasiani (1936c), $\S 6$ below.

${ }^{8}$ See below, $\$ 2.3$.
} 
substance with Da Empoli in this regard, but only a different use of the terms "legitimate" and "scientifically correct".

In the second case Da Empoli had argued that it is not easy to ascertain when the effects on other markets are insignificant, and anyway an ad hoc research is always necessary. Fasiani's replication is that, although the objection is formally founded, however, economic research can not help but using a certain degree of lack of precision, and recalls that the same Da Empoli speaks of "significant influence" on prices, which is equivalent (in terms of vagueness) to Fasiani's "negligible effect" on the other markets.

Da Empoli's criticism of the third case is interpreted by Fasiani as the assertion that this is not a hail-tax because the state spends the tax revenue to replace the private demand. If so, for Fasiani "there is no substantial difference" between them.

Fasiani recognizes that Da Empoli's critique of the fourth case is correct. However, he states: "I did not mean to refer to the legitimacy of the hypothesis of a hail-tax with regard to the direct effects of public spending, but rather, and only, to its indirect effects" (p. 273, emphasis in original), where the direct and indirect effects are understood in the sense described above.

The remaining five pages are devoted to a deep discussion regarding the mediated or indirect effects: Fasiani's conclusions are that in the cases 1) \& 2) the possibility of hail-tax is legitimate as regards both the direct and indirect effects. In case 3 ) it is legitimate only as regards the direct effects and in case 4) for the indirect effects only.

The fourth paper: L'imposizione degli incrementi patrimoniali (The taxation of capital gains) (1946) is a 24 A4 pages essay, printed on two columns. It was addressed to the Italian Constituent Assembly, and covers the basic aspects of ordinary taxation of capital gains, in reference to the Italian tax system at the time, and to the economic system to which the tax system had to be applied. Fasiani's basic assumption is that the taxes must be informed by some general principles of taxation accepted by all political parties. According to him, at the times such general principles were :

a) all the wealth should be taxed only above a certain minimum; 
b) wealth qualitatively and quantitatively equal should be taxed equally;

c) wealth qualitatively and quantitatively different should be taxed differently;

d) the choice between the different tax systems that allow the desired qualitative or quantitative discrimination must take account of their disposition to:

1) providing the necessary revenue;

2) achieving such discrimination;

3) disturbing the economic activity;

4) causing costs of assessment and collection;

5) securing other technical advantages (flexibility, sensitivity, etc..).

Firstly, Fasiani warns that the taxation of capital gains should not be aiming at achieving qualitative discrimination, because its precise nature is not to discriminate between labour and capital incomes, but instead that of discriminating between the capital incomes that obtained (or not) some increase in value. Secondly, he discusses as to whether it should be taxed the increase in the value of the assets or the increase in assets, and concludes that it seems reasonable to tax the increase in the value of the assets. Finally, he distinguishes, and deals with separately, the following categories of increase in value:

A) nominal increase due to inflation;

B) real increase due to income increases corresponding to increases in the value of the asset;

C) real increase due to a fall in the real interest rate;

D) nominal increase due to a fall of the rate at which certain income are capitalized;

E) increase that are either income or can not be distinguished from income.

Regarding the increases of type A, namely due to currency depreciation, it would seem at first glance that there are no grounds for taxation, yet one can find some justifications, from the elasticity of the revenue to the fact that inflation do "tax" certain assets (fixed income securities, mortgages, etc.) while exempting other (real estate assets), who have escaped taxation because their monetary values have risen owing to the money depreciation. Taxing the correspond- 
ing increases in values, therefore, could be justified from the standpoint of fairness.

About the increases of type B, which are due to income growth, Fasiani first observes that indeed their taxation implies a double taxation, which must have some justification. In fact, Fasiani suggests two reasons that might justify it: a) the existence of widespread "feelings of dislike for unearned income increases", b) the "exploitation of the phenomenon of 'fiscal illusion' (p.436, left column). However, it does follow that the "earned" income increase should be exempted, i.e. the increase due to "application of labour, whether intellectual or material" should be tax free (p.437, left column).

The increases of type $\mathrm{C}$ are due to decrease in the rate of interest. According to Fasiani they should go substantially untaxed: in case of sale of the asset, in fact, it is true that the realized value is greater, but if it is intended to be reinvested it will ensure still the same income. One can think to tax these increases in value, therefore, only accepting a legal-accounting definition of income: indeed, if the realized asset is used for consumption, taxation would not imply any double taxation.

About the increases of type D, they are due to a fall in the rate at which are capitalized certain specific earnings: the example given is the appreciation of the value of a property due to inflationary expectations. In this case the increase is not a gain, but the prospect of avoiding a loss, and therefore the conclusion of Fasiani is that there is no "more reason for taxing these capital gains than there is to tax increases due to a devaluation of the currency already in place" (p.439, left column).

Finally, with regard to increases of type E, i.e. for those that are not distinguishable from income, in general Fasiani concludes that taxation does not seem reasonable ${ }^{9}$. The first provisional conclusion is, therefore, that the tax may be recommended as regards a limited use of fiscal illusions. In fact, the tax would hit the high income groups, and could balance the many fiscal illusions that affect the

\footnotetext{
${ }^{9}$ Fasiani's specific example is speculation in the construction activity. However, his point of view seems far from the present one, in fact, the reasoning of Fasiani is as follows: if a speculator buys a plot of land and holds it for ten years without getting any income, when he will sell the land making a surplus, the latter replaces the income lost the last ten years.
} 
low income groups. In addition, to meet the widespread feeling of aversion against not earned income, the tax could be set for the increase of type $\mathrm{C}$, but not for the others types. Finally, to hit the wealth that has escaped to inflation, the tax could be extended to types $\mathrm{B}$ and $\mathrm{F}$, at least as long as inflation remains modest.

In practice, however, the tax cannot but hit all types of increases in value. Thus, two main reasons are playing in favour of the tax, namely: a) the fact that the burden can be attenuated by the phenomena of illusion mentioned above, b) the apparently widespread sentiment against "new income, increasing income or super-normal incomes" (p.441, left column). In fact, Fasiani recalls that Meda's project of tax reform had justified the tax on capital gains with the motivations: "nor it can be ... too surprising, in a time when many believe that private property is only a transient phase of social organization" (p .441, right column).

Two other secondary reasons of a technical nature are: c) if the income tax is not assessed every year, these increases in value may correspond to the income that has not yet paid any tax, so that there would be no double taxation; d) the mere existence of this tax can correct errors of assessment or evasion of the standard tax on capital.

If really the tax is to be introduced, a decision must be taken whether to give it a "real" character or a "personal" character. In this regard, Fasiani recalls that: "even if for reasons in part open to discussion, the general opinion is that personal taxation is the more rational method" (p.442, right column, italics in the original). With regard to the taxpayer, Fasiani suggests that the juridical persons should not be taxed, in order to avoid double taxation, and then discusses whether individuals or families should be taxed, and considers the latter as the most reasonable solution.

In order to determine the value increase to be taxed, after recalling that in 1913 the German tax had assessed all increases every three years, Fasiani suggests to tax only the increases of values realized in the selling price at the time of the sale.

Fasiani suggests a personal tax (and not a real tax). Thus, he suggests the deduction of capital losses, as in the Meda tax reform project. Particular problems arise when the increase in the value of capital has the very character of income (see above). To that end, Fasiani recalls: i) that the tax on the movable wealth (tassa di ricchezza mo- 
bile) had taxed the capital gains realized by the traders, but had exempted those made by other taxpayers; ii) the solution proposed in the Meda's project (according to which, for example, the business goodwill of a company would not be considered income derived from a commercial activity, and thus would be taxed as capital gain).

Then, Fasiani discusses the idea of the Meda's project to consider the capital value increases as part of the ordinary income tax, and to graduate the tax liability depending on the number of years in which the increase is produced. Regarding the first point, Fasiani does not think it is correct, because the type of discrimination to be achieved by taxing the increase has nothing to do with the discrimination practiced by the income tax, and in particular, can not be implemented by the same rates. About the graduation of the tax liability depending on the year, Fasiani notes that the increases are not uniform in time, and therefore the formula of dividing the increase in respect of the number of years does not seem advisable.

About the effects of the tax on the increase in the capital value, Fasiani points out that the two main questions are: i) whether the tax is actually paid by the taxpayers affected, and ii) whether the tax "may result in alterations in the equilibrium, that may involve destruction or loss of wealth" (p. 446 right column). In this regard, he believes that: a) while being personal, the tax can not but be capitalized, at least partially; b) the tax discriminates against the more risky investments; c) tends to reduce the supply of savings, without that the rate of interest be necessarily affected, because it simultaneously decreases the demand of savings. However, the decrease in savings implies an increase in consumption, resulting in an increase in the price of goods, and in a change in the structure of capital, which tends to decrease wages. These effects would be of little importance, however, in the case that the tax is sufficiently moderate.

Finally, he points out that taxing capital gains is mainly a political problem, based on an ideology which is largely devoid of any sound economic basis.

The fifth essay: La distribuzione dell'imposta e la legge di Pareto in una recente indagine teorica (Tax distribution and Pareto's law in a recent theoretical study) (1949) was originally published with an 
English translation. Fasiani draws on a paper by Crosara ${ }^{10}$, which "belongs to a category ... that is on the boundary of the true science" because is based on "an evaluation of good and evil, whose foundation eludes a science of means, such as ours" (p.301). The discussion, however, refers only to a point of Crosara's paper, that is the latter's proposal of a certain type of progressive income tax, called "rational" on the basis of the Pareto law of incomes distribution. However, the discussion does not apply to judgments of value of Crosara, but only to the logical correspondence between the objectives of Crosara and its results.

Crosara's assumption is that Pareto's law of distribution of incomes is a statistical uniformity "natural" 11 . Thus, he proposes a progressive tax that exempts the minimum income, and "at the same time preserves the proportions among individual incomes" (p.306) ${ }^{12}$. Compared to a proportional tax of equal tax-revenue, the progressive tax identifies a taxpayer that is 'indifferent', i.e. to whom the two alternative taxes subtract the same amount of income. Thus, taxpayers with incomes lower than the taxpayer indifferent: "will be favored for the amount that taxpayers with higher incomes are overloaded" (p.306).

Fasiani interprets Crosara's proposition in the sense that the progressive tax which preserves the proportions among the incomes, is the only rational or "natural" tax, even if exempts a minimum level of income. Fasiani's analysis focuses on the rationality of that ap-

\footnotetext{
${ }^{10}$ Crosara, Il concetto di reddito indifferente, Padova: Gregoriana, 1948

${ }^{11}$ Fasiani recalls that, for $\mathrm{N}=$ number of taxpayers with incomes greater than $\mathrm{x}$, for Pareto, "the real curve is interpolated with a straight line whose equation is $\log \mathrm{N}=\log \mathrm{A}$ $\alpha \log \mathrm{x}$, which can probably be traced to the $\log \mathrm{N}=\log \mathrm{A}-\alpha \log (\mathrm{x}+\mathrm{a})$ " (p. 303). Then, he notes that Crosara "brings a change in the formal Paretian expression, resorting to the coeffficient $\rho$ that would be the reciprocal of $\alpha$ " (p. 303). Therefore, also $\rho$ is constant along the curve, just as the coefficient $\alpha$, which is the elasticity, i.e. expresses how the percent number of individuals with incomes greater than $\mathrm{x}$ changes with respect to a percentage change of $\mathrm{x}$. According to Crosara, $\rho$ "is the difference between any given income ... and the average of all incomes that are not lower than the average ... ... The meaning is clear ... by putting a number of order $\mathrm{n}$ (i.e. $1 \mathrm{st}, 2 \mathrm{nd}$, 3rd, 4 th degrees, etc.) to each of the $\mathrm{N}$ rentiers, in the descending order of income" (p. 303).

${ }^{12}$ Fasiani does not enter into the merits of this claim, because his goal, basically, is to use Crosara's formula of the progressive tax in his polar case of cooperative state. In fact, he believes that the feature to preserve the proportions of individual incomes, can conform to the general principle of the cooperative state, in which the ruling class tends to a maximum of utility for the community in the Paretian meaning of the expression (p.315).
} 
proach: he discusses the thesis of Crosara to determine whether it is logically consistent with the premises on which it is based. This discussion involves the solution of two questions, namely: 1) whether it is true that the tax proposed by Crosara does not change the distribution of "natural" income, 2) whether the fact of not changing this distribution be sufficient to demonstrate the necessity of the proposed $\operatorname{tax}($ p.310).

Regarding the first question, Fasiani provisionally accepts that the tax does not change the ex ante distribution of income, that is to say that the tax is not being shifted, so that the tax "does not result in changes in the "natural' distribution of gross incomes and ... also ensures a Paretian distribution of the net incomes" (p.310).

Regarding the second question (whether to justify its adoption it is sufficient that the tax does not disturb the 'natural' distribution of incomes) Fasiani raises some doubts, related to: A) what is the value attributable to the law of Pareto; B) if "the supposed 'naturalness' of the Paretian distribution may be sufficient to prefer a change in the coefficient of the line that represents it, to a change in the structure of the distribution", C) if such a preference may arise from a principle typical of a polar case, D) if the problem of the difficulty of practical application is merely a pretext for the ruling class for not introducing such a tax.

At point A, after extensive discussion Fasiani concludes that the law of Pareto is not completely reliable for Crosara's ends. At point $\mathrm{B}$, Fasiani does not see "why [the Paretian distribution] is to be regarded as 'natural', or why it should be preferred to another" (p.315). In addition, he is not convinced that the result of: "perfect preservation of the existing proportion among individual incomes" has to be preferred to other possible objectives, such as: "encourage the production of savings" or "minimize unemployment of labour", etc.. In conclusion, Fasiani doubts that the "Pareto's Law will dictate, by itself, a criterion that can be said ... more scientifically correct than other criterions which are offered continuously" (p.315).

About point C, Fasiani remarks that, in the polar case of the cooperative state, the feature of the tax proposed by Crosara might seem in accord with the fundamental principle of this polar case: "no benefit to anyone, which may cause expense to others". So, should a pro- 
gressive tax be implemented, Crosara's tax would seem preferable to other progressive taxes.

Finally, point D regards essentially the difficulties of assessment, which according to Fasiani are greater than that Crosara claims, because progressive taxation is necessarily personal, and therefore presents greater assessment difficulties than direct taxes at the source. In addition, one has to consider also political, historical and practical problems, like the high tendency to evade that characterizes the Italian context

In the sixth essay: Sull'equivalenza fra imposte sui redditi e imposte di successione (The equivalence between income taxation and inheritance taxes) (1950) Fasiani explores the limits of the validity of the traditional statement (e.g. Pigou ${ }^{13}$ ), that an income tax is equivalent to a tax on wealth and thus to a tax on transfers in general, and in particular to an inheritance tax. The study had been widely commented by Cosciani ${ }^{14}$. First, Fasiani notes that, in his earlier works, had already pointed out some limitations. Then, he lists his basic assumptions, that are: a) he does not consider the economic effects of such taxes, b) public expenditure is not considered, c) no tax shifting is assumed, d) as regards inheritance taxes, the only tax basis considered, is the entire assets of the testator.

The body of the paper is devoted to the discussion of three cases in which the equivalence between the inheritance tax and the income tax may not be realized. These cases are: A) when the assets are considered as entities in their own right, regardless of the people who will own them later, B) when the point of view of the taxing body is considered and C) when the wealth is considered from the point of view of the subsequent owners.

In case $\mathrm{A}$, when the assets are treated as entities in their own right, Fasiani distinguishes two cases: a) the society is completely static even in the very long run, b) some changes occur in the society. Assuming full statics, the limitations to the equivalence between an income tax and an inheritance tax are two, the main one being that the

\footnotetext{
${ }^{13}$ Pigou, A. C., A study in public finance, London: Macmillan, 1928

${ }^{14}$ Cosciani,C.: Ancora sull 'equivalenza fra imposte sui redditi e imposte di successione, in "Studi in memoria di Gino Borgatta", Istituto di cultura bancaria, Arti Grafiche Spa, Bologna, 1953, pp.111-126.
} 
equivalence holds only "on average", because upon death, the assets are transferred at intervals very different ${ }^{15}$. The second limitation concerns the "graduation of rates" (p.160), if the tax is progressive. Here, Fasiani remarks using a simple numerical example, that equivalence can not be set in a static context, because it might imply absurd rates on the assets. In fact, the reasoning implicitly would assume that the income tax is paid by reducing the consumption, i.e. dedicating a portion of annual income to pay the tax, while the property tax is paid by reducing the assets. Thus, if the rational taxpayer of an inheritance tax will pay by decreasing his consumption, the corresponding savings would lead to capital formation, which contradicts the hypothesis of static economy.

In the case of non-static economies, Fasiani remarks that we can expect much greater limitations. Using the same numerical example, he is able to state that the equivalence would imply changes of tax rates on the assets in inverse proportion to the possible changes in interest rates, which leaves him baffled. In fact: "in any given moment, there will be a certain income tax, that is equivalent to the specific inheritance tax ... but it is a tax which is equivalent only if the interest rate does change no more" (p.165 italics in the original). His concern increases when considering that "the interval between two successive transfers of assets" varies, and the context is also dynamic owing to the variability of incomes over time (p.165). Moreover: "the meaning of the concept of equivalence seems more uncertain" under the assumption that a new wealth is accumulating (p.167). In fact, we do not know whether, and to what extent, the taxes are paid with part of the savings or of the assets. What is more, we do not know which is the periodic increase in the assets due to possible new savings: we do not even know if the inheritance tax increases (Dalton $^{16}$ ) or decreases the savings (Pigou $\left.{ }^{17}\right)(\mathrm{p} .168)$.

\footnotetext{
${ }^{15}$ In a footnote, however, there is a reference to [Fasiani $1935 \mathrm{c}$ ], which states that the equivalence does not even exist in that case, since there are insurances against the inheritance tax. Since the normal taxpayer is risk averse, if he resorts to the insurance it is clear that he does not consider the two taxes as equivalent.

${ }^{16}$ Dalton, H.: Some aspects of the inequality of incomes in modern communities, London: Routledge, 1929

${ }^{17}$ Pigou, A Study... cit.
} 
In case B, Fasiani takes into account the point of view of the state: even if the taxpayers consider equivalent the taxes, as regards the state it might not even exist any equivalence. To begin with, the inheritance taxes imply a fiscal illusion, which can be exploited by the tax authorities, as was usually done in the past. In addition, acceptance of the taxes depends on prevailing political ideology: Fasiani recalls that according to Jannaccone ${ }^{18}$, both socialists and liberals had favoured inheritance taxes, albeit with opposite reasons. Still, there may be psychological effects on taxpayers, that the IRS can not ignore, like the tendency to evade taxes and the feeling of the taxpayer that the inheritance tax rates are too high than those of an "equivalent" income-tax.

In case $\mathrm{C}$, Fasiani analyzes whether the equivalence can fail when the assets are considered in relation to subsequent owners. If, as was done above, property is considered an entity in itself, it is assumed implicitly that there is "a continuity of interests between the successive generations who come into possession" (p. 174). In fact, those who pay the two taxes are by definition two different subjects, who may not have continuity of interests. Here Fasiani draws on Bastable, Seligman and De Viti ${ }^{19}$. "The hearth of the matter ... is to investigate whether and in what sense it is true ...... that the inheritance tax is paid at the end of life." (p. 176, italics in the original). De Viti, in particular, believes that the inheritance tax is "a debt of the deceased in favour of the state" paid by the heir (p.177), and therefore constitutes an arrears income tax at the time of death of the testator. However, even apart from the assumption of state-factor of production, De Viti's thesis is wrong, because the inheritance tax, in fact, could be anticipated by some taxpayers and postponed by other taxpayers: see [Fasiani $1935 \mathrm{c}$ ] and [Fasiani $1936 \mathrm{a}$ ]. Therefore: "the issue is not so simple as the theory of De Viti seems to assume, nor it can have a unique solution" (p. 179). In fact, Fasiani distinguishes four cases: 1) when the assets existed prior to the introduction of the inheritance tax, and there is continuity between the testator and his heir; 2) when the assets existed before, but there is no continuity between testator

${ }^{18}$ Jannaccone, P.: L'imposta di successione e i valori mobiliari, in Rivista Bancaria, 1923.

${ }^{19}$ Bastable, C.F. Public Finance, London: Macmillan, 1903; Seligman, E.R. ,Essays in taxation, London: Macmillan, 1905; De Viti de Marco, A.: Principii di economia finanziaria, Torino: Einaudi, 1934 
and heir; 3) when the assets are the result of new savings, and there is continuity between testator and heir; 4) when the assets are the result of new savings, but there is no continuity between testator and heir (p. 180).

In the first case (pre-existing assets, and continuity between testator and heir), the conclusion is that the inheritance tax "is not necessarily an income tax deferred," but it is advanced or delayed depending on when the assets fall in succession (p.183, italics in the original). So it seems likely that the inheritance tax may imply a fate very different for each property, "which may be reason for diversity ... [among taxes that are] 'equivalent' as regards every other points" (p.183). Therefore, there is no reason for preference for inheritance tax, as it would be if the tax had been actually postponed.

In the second case (pre-existing assets and no continuity between testator and heir), the discontinuity between the testator and the heir can be due both to the assumption that the former is not worried about the second and to the assumption that the heir is endowed with a limited economic horizon. Under the first assumption Fasiani concludes that, in principle, the testator prefers the inheritance tax to the income tax, and vice versa for the heir, unless the testator does not use the assets to pay income tax. In this case, the two taxes are indifferent to the testator, while as regards the heir, all depends on the time when the succession takes place. In the second case of discontinuity, when the heir has an economic period of limited duration, the heir prefers the income tax to the inheritance tax.

In the third case, when there is a continuity of interest, but at the time of the introduction of the tax the assets do not yet exist, because they are the result of new savings: "the inheritance tax affects only the income devoted to increase the assets, when the latter falls in succession". By contrast, "the income tax entails double taxation of savings, so that the inheritance tax should be preferred (p.188). However, "if the assets increase over time and the inheritance tax is progressive," inheritance tax "will tend to become less convenient for individuals, the longer is the interval between the introduction of the tax and the transfer of property upon death" (p.188).

In the fourth case the wealth is the result of new savings, but there is no continuity of interest. The situation is very similar to that of the second case: "if the testator tends to accumulate money, and the heir 
to spend it" the heir prefers the inheritance tax to the income tax ( $\mathrm{p}$. 189).

\subsection{Time and intermediate equilibria}

Under this subheading, I think it appropriate to consider specifically four articles, i.e.: Materials for a Theory of the Duration of the Process of Tax shifting (1929); Velocity in the changes in demand and supply, and stable and unstable equilibrium points (1932); An elementary problem regarding time and some related fiscal applications (1936); About a phenomenon of friction (1932). The fact is that the first three essays compose a trilogy about time in economics, which, together with the fourth essay, constitute an important "attempt to help ... to moving from the theory of final positions to the theory of intermediate positions" (Fasiani, 1932d, p.42). In other words, it is a contribution to build a theory of the economic forces acting in the short run, or of the closely interrelated phenomena which concern: a) the rapidity of change in demand and supply, b) the phenomena of friction, d) the role of expectations (Fasiani, 1932d, p.43).

The first essay: Elementi per una teoria della durata del processo traslativo dell'imposta in una società statica (Materials for a Theory of the Duration of the Process of Tax shifting) (1929), was translated in English with small variants by A. P. Lerner \& Ursula K. Hicks in the thirties ${ }^{20}$. As regards the variants of that translation, here I recall only that the original $\S 17$ has been entirely omitted. This omission is explained in the draft of an undated letter, handwritten in Italian, which I had the venture to find in an offprint of Fasiani's article: "Elementi per una teoria della durata del processo traslativo..." among Fasiani's books in the Library of the Bocconi University. The transcript of the letter is as following:

\footnotetext{
${ }^{20}$ Fasiani, M.: Materials for a Theory of the Duration of the Process of Tax shifting, in "The Review of Economic Studies", February 1934, pp. 81-101, and February 1935, pp. 122-37.
} 


\section{Carissimo,}

I have found some copies of my old writing ... in the two successive editions in Italian and in English, and I send them to you as per your kind request. Perhaps you might be interested in the mystery of the small formulas on pp. 20 et seq. in the Italian offprint. Their story is pretty complicated. The study was published in the emergence of the next deadline for submission of titles for my Libera docenz ${ }^{21}$, and as often happens in such circumstances, I had worked in part on the third proofs. In the early formulation, as it resulted from my manuscript, for a certain end I wanted to take into account of the changes in the [deleted: overall] total cost of marginal units, in successive time units. Therefore I used these expressions: $K=$ total cost of the marginal units per unit of time;

$t=$ sum of the unit of time

$c=$ unitary cost

$n_{x}=$ units of goods $x$ produced per unit time.

In the simplest case, I had assumed that $K$ [underlined] had been constant, namely that the same amount had been spent in each unit of time.

This fact has led to the equality $c=K / n_{x} t$ (Incidentally, I have never been able to have the $n x$ [underlined] rectified in $\left.n_{x}\right)$.

Then, in the proofs, I have removed this way of approaching the problem, and also some consequences that I drew, and about which I had some doubts. From that, a mess had originated. [Written at the bottom, with a call sign: largely due to my dislike, dare I say "physical", to correct, materially, the proofs when / deleted: I do not have / the problem studied no longer interests me. In addition], a round of proofs had been lost, and Mortara ${ }^{22}$ printed the first part of the study not adjusted [deleted: in accordance with] in line with that of the new formulation. Hence an argument in letters, which had the consequence that I did not publish any more on the Giornale

\footnotetext{
${ }^{21}$ The Libera docenza corresponded to the university teaching qualification.

${ }^{22}$ A.Mortara was the editor of the Giornale degli economisti
} 
degli economisti. In the English edition, [deleted: this cheat] the cheating of formulas is of course correct.

Does not seem to doubt that the draft relates to the present Fasiani's work and is likely to be addressed to Paul Rosenstein Rodan, a close friend of Fasiani who spoke Italian. About the date, the reference to an "old writing" implies a date some years after its publication in the Review of Economic Studies, that is, some years after 1935. Another useful information is that Fasiani "did not publish any more on the Giornale degli economisti", which let fix the date prior to 1940, the date of publication on the GdE of (Fasiani 1940a). At any rate, Mortara had been obliged to leave the GdE in 1938 owing to the racial persecutions. Ultimately, however, any date between 1938 and 1950 is still possible.

Coming back to Fasiani's essay, it is an excellent study that addresses a topic ignored by the literature. Fasiani tries to bring the neoclassical Marshallian setting nearer to the reality of economic systems. The methodology includes the examination of a large number of assumptions and involves a complex casuistry as well as much work.

Fasiani considers the shifting of taxes in comparative statics, and he studies those phenomena that delay shifting, since it takes time to completing the tax shifting process. In other words, assumes the amount of tax shifting and focuses on the period of time between the percussion and the moment of the final shifting. The methodology used is that of successive approximations, i.e. he starts from certain assumptions, and then he studies the role played by each of them. The assumptions are: a) the equilibrium in a static economic system is considered as a starting point, b) competitive markets, c) the tax does not induce new businesses, d) the hail-tax assumption, e) the assumption of the special tax and f) closed market. Moreover, he assumes a sales tax that affects the manufacturer with a fixed amount for each unit of product and that the manufacturer shifts the tax on the buyer. Furthermore, Fasiani assumes in first approximation that the shifting process consists in a fall in supply, followed by a rise in price and then by a decline in demand, ignoring more complex sequences. In particular, the analysis is conducted in the Marshallian equilibria, and not in the general equilibria. 
The hearth of the analysis is the fact that the tax-induced increase in the marginal cost influences the capital employed in the taxed sector. The increase in marginal cost induces the marginal producers to change the use of their funds or simply to stop reinvestment, which still implies an additional cost. This is because the production processes takes some times to be completed, while capital can be used in many subsequent processes. For either the company expects to have recovered its investment despite the marginal cost increase, or change the destination of the invested capital (for example, machines). In all case, firms must bear an additional cost.

As a first approximation, the cost of the change of use depends on the ratio fixed capital/variable capital. However, Fasiani distinguishes three categories of capital: 1) those that can be processed at no cost, 2) those that can be used in other production lines at a cost which can vary greatly between "their after-tax price in the old destination and their price in the new destination", 3) those that can not be transferred. In each category, Fasiani distinguishes two subgroups, namely: A) those that are only used in one production process like raw materials and wages, B) those, like machinery and capital assets, that are used for many productive processes. In turn, the subgroups can be distinguished: $\alpha$ ) if they are acquired continuously as long as the production proceeds, $\beta$ ) if they are all purchased at once at the start of production. Since not only in the productive processes, but also in individual firms, the capital employed "could belong to different extents to the various categories" (p.87), Fasiani successively analyzes a number of polar cases. The first polar case $(\S 12-\S 23)$ is the $3 \mathrm{~A} \alpha$, i.e. when capital can not be transferred, it is only used in one production process and is acquired continuously as the production process proceeds. In $\S 13$, Fasiani provides an analysis of first approximation, valid under the assumptions: that the duration of the production process be the same for all firms, that the firms sell the product at the time in which the production process ends, and that the marginal firm is the one with the higher marginal cost. Thus, if the duration of the production process is the same for all firms, the cost (defined as the amount of capital including interest and profits) will start from zero at the time when the production process begins, will increase as long as the production proceeds, reaching the maximum at the time when the production process ends. That is, at the time 
when the firm recovers both the invested capital and its profit through the sale of the product.

Under these conditions, the duration of the shifting process depends on the variables: a) the duration of the process of production, b) the marginal cost in each subsequent moment of the production process, c) the time when the tax is introduced, d) the amount of the tax, e) the time interval between the end of a production process and the next one (this regards the existence, at any time, of different production processes in various states of progress). If the tax is introduced right at the beginning of the production process, marginal firms exit from the market because their marginal cost increases, and therefore they are not involved in the production process that begins at that time. However, as a result of this exit the market supply will be diminished only at the end of the production process. Therefore, the market price of the goods produced can be increased only after a time equal to the duration of the production process. In that case, the duration of the shifting process is equal to that of the production process.

If the tax is introduced in an intermediate time between the beginning and the end of the production process, the firm must consider whether the marginal loss owed to the tax-increased cost is greater or smaller than the loss that it would meet if leaves the process of production, i.e. the capital invested at that date. In the first case, the decline in supply will only be felt at the end of the production process. In the case where the tax is lower, the marginal firm will complete the production process under way, and the decrease in supply will come at the end of following production process. And if at the time of introduction of the tax, the marginal firm has implemented a number of processes simultaneously, it will leave all those processes for which the tax is greater than the cost of capital invested to that date, and will complete the others.

$\S 14$ focuses on the relationship between the end of the production process and the time in which the sale takes place. To that effect, Fasiani remarks that firms may: i) sell and deliver immediately at a price $\mathrm{P}$, ii) sell right away and collect the price $\mathrm{P}$ ' after a certain time, iii) collect the price $\mathrm{P}$ " immediately, but deliver the product after a certain time, iv) deliver the product at the price P" after a certain time. $\S 15$ is devoted to the problem of the length of time needed to 
sell the entire product at the date of termination of the production process. In $\S \S 16-21$ the assumption that the duration of the production process is the same for all the firms is released, considering the existence of only two firms. Then, Fasiani considers cases in which the firm that has the longer process of production produces an amount of product that is respectively: 1) equal to that of the other firm, 2) greater and 3) smaller. In $\$ 20$ Fasiani defines "determinant production process" as the one during which the marginal production of a firm is abandoned. Then, he is able to point uniformities regarding the duration of the shifting process for the case 1), i.e. when the two firms produce the same amount of product. In this case: a) if production is all sold at the end of each production process, the shifting will occur at the end of the first "determinant production process" that finishes after the introduction of the tax, b) if the sale occurs in a variable period of time for which the total supply is the sum of the supply of the firms, the completion of the tax shifting can only occur when the production of the last unit of marginal product has ended for all the firms. Then, in $\S 21$ Fasiani examines cases 2) and 3) while in $\S \S 22-23$ he considers respectively the influence of simultaneous production processes in the same firm, and of different cost curves for each firm. The polar case in which the capitals are of a type 3B, namely when capital can not be transferred and is used in more than one production process, is considered in $\$ 25$ and $\$ 26$. In $\$ 27$ it is considered in the simultaneous existence of capital $3 \mathrm{~A} \alpha$ and $3 \mathrm{~A} \beta, 3 \mathrm{~B}$ and $3 \mathrm{~A} \beta, 3 \mathrm{~A} \alpha, 3 \mathrm{~A} \beta$ and $3 \mathrm{~B}$. In $\S 28$ are considered capital of type 1 , namely those that can be processed at no cost. $\S 29$ concerns the capital of type 2, namely those that can be used in other production lines with variable costs. Finally, $\S 30 \& \S 31$ are devoted to clarifications of the identification of marginal production. In the sections from $\S 32$ to $\S 42$ (which is the last) Fasiani discusses about the assumptions. However, he really does not abandon his assumptions, which would be a second degree of approximation. Plays only a "cursory and short examination of the assumptions in order to test their relative importance" (p. 124). In particular, in $\S 32$ discusses the possibility of the existence of an equilibrium at the time of introduction of the tax. In $\S$ $\S 33$ and 34 respectively, discusses the idea of competition and a static economy. In $\S 35$ mentions the possibility that the tax does not 
cause any new activities, while in $\S 36-38$ Fasiani considers the taxes that finance productive public spending.

In particular, in $\S 37$ he considers the productive sectors in the later stages (see Clark ${ }^{23}$ ) and in $\S 38$, other sectors not taxed, which in some way can benefit from the spending of income tax. In $\S 39$ Fasiani considers the possibility of abandoning the assumption of the special tax, and in $\S 40$ starts releasing the assumption that the tax is uniform on each unit of output. Then, he considers, in particular, a tax that affects revenues or profits. Due to a printing error there are two sections 40, and in the second of them Fasiani is primarily concerned with other directions of movement: backwards, oblique, etc.. In $\S 41$, he returns on the temporal sequences "reduction in supplyprice increase-decrease in demand" rather than price increasedecrease in demand-reduction in supply. In the last section ( $\S 42)$ Fasiani: i) briefly mentions the hypothesis that the tax is levied on the buyer instead that on the seller, ii) considers the process of shifting, iii) neglects the effects on the general equilibrium. Finally, he concludes by expressing the hope that his work can be used to indicate the road, citing Quesnay: "to have a good book ... one has to tolerate that bad books are made."

The second essay: Velocità nelle variazioni della domanda $e$ dell'offerta e punti di equilibrio stabile e instabile (Velocity in the changes in demand and supply, and stable and unstable equilibrium points) (1932) addresses another topic "virtually unexplored" (p. 5), i.e. the influence of the velocity of change in supply and demand on the determination of intermediate positions in the unstable equilibria that characterize comparative statics. Takes its cue from what has been observed in (Fasiani 1931a) that comparative statics analysis ignores the essential fact that we need to investigate the sequence of intermediate equilibria.

First, Fasiani defines the velocity of change of an economic quantity as the ratio between the change itself and the time necessary in order that the change may take place. Then, he assumes: a) that the velocities of supply and demand are independent of each the other, b)

${ }^{23}$ Clark, J.B.: Essentials of Economic Theory, New York: Macmillan, 1909; Clark, J.B.: The distribution of wealth, New York: Macmillan, 1899. 
that they are uniform, c) that the subsequent demand curves are concentric, d) that each change regarding supply and demand begin at a different time. Following an exogenous change in demand, it results crucial the role of the relative velocity of supply $\left(V_{S}\right)$ and of demand $\left(V_{D}\right)$. Only if the ratio of the velocities $V_{D}$ and $V_{S}$ maintains a particular value, the subsequent unstable equilibria may remain along the supply curve. In general, however, the path of the successive temporary equilibria lies outside the supply curve. In that regard, Fasiani notes that as long as it is $V_{D} / V_{S}>1$, the price decreases; until it is $V_{D} / V_{S}<1$ the price increases. The price does not change for $V_{D} / V_{S}=1$ (p.13).

The analysis becomes more laborious and complex by introducing expectations and forecast errors and then releasing such assumptions. In fact, as usual, Fasiani's approach is to take a number of assumptions that delineate a scheme from which, by pure logics, the conclusions follow. Here, his reasoning is highlighted and illustrated by graphs, and, at least in part, resolve itself in showing the path that connects the equilibrium ex ante to that ex post. Therefore, any criticism can only be raised to the assumptions and to the possibility that other changes may interfere with the developments highlighted ${ }^{24}$. Above all, this is due to the fact that Fasiani goes on assuming interdependent velocities of demand and supply. Moreover, he assumes that the firms are engaged in subsequent production processes, so that, contemporarily, there are many production stages, like in Fasiani (1929c) and Fasiani (1934-35). It is possible to reach interesting conclusions (see $\S 43$ ). Among them:

a) "that the points of (partial) unstable equilibrium (which are successively reached) are determined by the ratio of the velocity of change in demand and supply. The phenomenon tends to take [a particular trend] depending on the ratio",

b) that "for the same change in price, the length of time it takes, is shorter the more the rate of change [in demand and in supply] is far

\footnotetext{
${ }^{24}$ Specifically, it is perhaps worth noting that the velocities $V_{D}$ and $V_{S}$ do not seem strictly uniform, although I am not clear how this fact can modify his treatment. In fact, if we assume a change in the demand curve with respect to a constant supply curve - like Fasiani does - the rapidity of the demand concerns the process of shifting of the curve. By contrast, Fasiani's rapidity of the supply curve concerns movements along the same supply curve.
} 
away from 1, and the more decreasing are the successive demand curves,

c) that "in the absence of deviations produced by expectations, the greater the rapidity in the change in demand and the more slowly costs are growing in the production processes, the more the velocity of change in the supply is likely to increase",

d) that "the errors in forecasting can modify the relationship between $V_{D}$ and $V_{S}$, but it does not seem possible to determine their influence exactly",

e) that "if the offer shrinks and forecasts are accurate, the demand starts rising. Then, the progress of the offer will follow. However, it is the velocity of change in supply that determines the rapidity of change in demand",

f) "the same reasoning can be repeated, mutatis mutandis, if the supply moves upward, or if supply and demand move together",

g) "these conclusions are valid even if one does not know the initial and terminal positions of the stable equilibrium".

The third essay: Di un elementare problema di tempo e di alcune sue applicazioni finanziarie (An elementary problem regarding time and some related fiscal applications) (1936) analyses the time horizon of the consumer, and applies it to the problem of the double taxation of savings ${ }^{25}$.

The primary problem of time that Fasiani is concerned with in this essay stems from the idea that each individual considers his plan for consumption within a certain time horizon, while his fixed incomes may have a different timing. In the economic system the equilibrium interest rate is determined when, given the consumers' time preferences, all the consumers determine their optimal consumption plan within the considered time horizon.

Given the equilibrium interest rate, a temporary income and a perpetual one are valued equally, if they have the same present value ${ }^{26}$.

\footnotetext{
${ }^{25}$ About the double taxation of savings see below, $\S 4$.

${ }^{26}$ Fasiani's numerical example is only a first approximation. Since the interest rate is $5 \%$, it is true that a $£ 5,000$ perpetuity corresponds to a capital of $£ 100,000$. However, a $£ 10,000$ annuity, temporary for ten years, only after 10 years of accumulation at zero interest corresponds to a $£ 100,000$ capital. Taking into account the rate of $5 \%$, it takes ten annual instalments of approximately $£ 7,950.457$ to obtain a $£ 100,000$ capital.
} 
Thus, assuming that all the consumers have an unlimited time horizon and that they distribute their consumption evenly in time, it follows that the holder of a temporary income must save in order to get a perpetual income, that is to say that he must sell part of his temporary annual income to buy future incomes ${ }^{27}$.

If it happens that an individual, (either with a perpetual income or with a temporary income) has his time horizon shortened, his equilibrium will change. In fact, for all future periods within his new time horizon shortened, his constant annual income will be increased. To this end, he will proceed to exchange his expected future consumption which is over his new horizon, with consumption included in this narrower horizon. If his consumption is an infinitesimal part of the consumption of the community, the interest rate remains unchanged and thus his consumer's surplus will increase: with unchanged prices the demand for present consumption shifts upwards.

Fasiani labels this increase in consumer's surplus as "bachelor's rent". In his numerical example the interest rate is $5 \%$. Thus, a $£ 15,000$ annuity for ten years corresponds to a $£ 5,000$ perpetuity. Then, if the time horizon of the consumer is reduced to 10 years, he consumes all his incomes in ten years and find himself enriched with $£ 10,000$ a year, which is the monetary value of his "bachelor's rent". In other words, the bachelor's rent is represented by the "advantage" enjoyed by the consumer with a time horizon limited to ten years.

\footnotetext{
27 In other words, to decrease the current consumption in order to increase future consumption. It is, however, clear that this can happen only if there are individuals with the opposite problem (turning the future consumption into current consumption). It is also clear that the exchange occurs when the MRS between current consumption and future consumption is equal to the interest rate for both traders, and that both traders have a Marshallian consumer surplus.
} 
Tab. 2.2.1: Fasiani's numerical example-interest rate (general): 0,05; interest rate applied to savings: 0,00

\begin{tabular}{|c|c|c|c|c|c|c|c|c|c|c|c|c|}
\hline \multirow[b]{2}{*}{ tim } & \multicolumn{3}{|c|}{ Normal individual } & \multirow[b]{2}{*}{$\begin{array}{c}\text { present } \\
\text { value of } \\
\text { savings }\end{array}$} & \multirow[b]{2}{*}{$\begin{array}{l}\text { back- } \\
\text { elor's } \\
\text { rent }\end{array}$} & \multicolumn{4}{|c|}{ Bachelor } & \multirow[b]{2}{*}{$\begin{array}{l}\text { present } \\
\text { value of } \\
\text { savings }\end{array}$} & \multirow[b]{2}{*}{$\begin{array}{l}\text { back- } \\
\text { elor's rent }\end{array}$} & \multirow[b]{2}{*}{$\begin{array}{l}\text { present } \\
\text { value of } \\
\text { backelor's } \\
\text { rent }\end{array}$} \\
\hline & $\begin{array}{l}\text { in- } \\
\text { come }\end{array}$ & $\begin{array}{l}\text { con- } \\
\text { sumes }\end{array}$ & $\begin{array}{c}\text { annual } \\
\text { savings }\end{array}$ & & & $\begin{array}{c}\text { pre- } \\
\text { sent } \\
\text { value of } \\
\text { back- } \\
\text { elor's } \\
\text { rent }\end{array}$ & $\begin{array}{l}\text { In- } \\
\text { come }\end{array}$ & $\begin{array}{l}\text { con- } \\
\text { sumes }\end{array}$ & $\begin{array}{c}\text { annual } \\
\text { savings }\end{array}$ & & & \\
\hline 1 & 150 & 500 & $10 \cap 0$ & $10 \cap 00$ & חก & ח & 150 & 100 & 5000 & 5000 & 5000 & 5000 \\
\hline 2 & 15.0 & 5.00 & 10.00 & 20.000 . & 0.00 & 0.00 & 15.0 & 10.0 & 5.000 & 10.00 & 5.000 & 10.00 \\
\hline 3 & 15.0 & 5.00 & 10.00 & 30.000 , & 0.00 & 0.00 & 15.0 & 10.0 & 5.000 & 15.00 & 5.000 & 15.00 \\
\hline 4 & 15.0 & 5.00 & 10.00 & 40.000 , & 0,00 & 0.00 & 15.0 & 10.0 & 5.000 & 20.00 & 5.000 & 20.00 \\
\hline 5 & 15.0 & 5.00 & 10.00 & 50.000 & 0.00 & 0.00 & 15.0 & 10.0 & 5.000 & 25.00 & 5.000 & 25.00 \\
\hline 6 & 15.0 & 5.00 & 10.00 & 60.000 & 0.00 & 0.00 & 15.0 & 10.0 & 5.000 & 30.00 & 5.000 & 30.00 \\
\hline 7 & 15.0 & 5.00 & 10.00 & 70.000 . & 0.00 & 0.00 & 15.0 & 10.0 & 5.000 & 35.00 & 5.000 & 35.00 \\
\hline 8 & 15.0 & 5.00 & 10.00 & 80.000 , & 0,00 & 0.00 & 15.0 & 10.0 & 5.000 & 40.00 & 5.000 & 40.00 \\
\hline 9 & 15.0 & 5.00 & 10.00 & 90.000 & 0.00 & 0.00 & 15.0 & 10.0 & 5.000 & 45.00 & 5.000 & 45.00 \\
\hline 10 & 15.0 & 5.00 & 10.00 & 100.00 & 0.00 & 0.00 & 15.0 & 10.0 & 5.000 & 50.00 & 5.000 & 50.00 \\
\hline 11 & 5.00 & 5.00 & 0.00 & 0,00 & 0.00 & 0.00 & 2.50 & 2.50 & 0,00 & 0.00 & 0,00 & 0.00 \\
\hline 11 & 5.00 & 5.00 & 0,00 & 0,00 & 0,00 & 0,00 & 2.50 & 2.50 & 0,00 & 0,00 & 0,00 & 0.00 \\
\hline
\end{tabular}


This advantage is actually represented by the difference between his own estimate of a perpetual income, and the corresponding estimation of the market (p.86). In the following table 2.2.1 is reported the original Fasiani's numerical example. Similarly, if there is an extension of the horizon of a consumer, his Marshallian consumer's surplus will rise, but the name of "bachelor's rent" is reserved for subjects with shorter time horizon. According to Fasiani, in fact, the unlimited time horizon is typical of those included in family, while celibacy is somehow typical of a person "atypical" with respect to individuals "normal" that have an unlimited time horizon (p. 78, p.81, p.87).

The identification of "normal" with the unlimited time horizon is based on Einaudi's idea that a "normal" income belongs to the entrepreneur "normal" or "marginal. According to Einaudi" ${ }^{28}$, "the taxpayer is the one that does not undo the marginal land, nor he does it. $\mathrm{He}$ is the one who does not grow the endowment in capital goods, nor he let decrease his endowment". n fact, "although [Einaudi] does not deal with this problem, implicitly assumes that the normal economic agent considers an unlimited time horizon" (p.89).

The argument put forward by Fasiani is that lawmakers have a subconscious tendency to tax the "bachelor's rent". This tendency might explain the problem of the qualitative discrimination of income and the true role both of transfers and of the inheritance taxes and of some personal taxes (p.90).

In sections 17 to 24 he discusses the qualitative discrimination of income seen as a problem that involves temporary incomes in respect to permanent incomes, that is to say labour income vs. capital income. It is clear that the issue of double taxation of savings is involved $^{29}$ : "I do not want to revive the old and now tedious dispute about the so-called problem of double taxation of savings, but it seems to me that to regard at it from the point of view just stated, will serve to make known the contents and clarify many of the misunderstandings born around it" (p.97).

\footnotetext{
${ }^{28}$ Einaudi, L.: Contributo alla ricerca dell'ottima imposta, in “ Annali di economia “, Università Bocconi, vol. V, Milano, 1929.

${ }^{29}$ As regards the double taxation of savings see below, §4.
} 
In $\S 17$ Fasiani summarizes the controversy about the double taxation, from the statement of the Actuaries, James Mill \& $\mathrm{M}^{\prime} \mathrm{Culloch}{ }^{30}$ that temporary incomes should pay lower taxes because they have a lower capital values, to J. Stuart Mill's assertions ${ }^{31}$. The latter had stated: i) that if one capitalizes incomes, then also taxes should be capitalized and therefore the tax rates must be equal, ii) that the supposed savings (to provide for the future) should be exempted. Then, Fasiani recalls that Fisher and Einaudi "did not add much to the reasoning of Mill and that Graziani has introduced the idea of diminishing marginal utility which however implies a comparison between the utilities of different individuals (p. 94).

Fasiani remarks that (net) perpetual annuities can be compared with temporary annuities that are either: a) net unearned income, b) earned income, c) gross unearned income (p. 94).

As for the comparison a), Fasiani notes that the positions of the various scholars can be related to the different "length of the economic period considered by each economic subject" (p.96). In fact, to consider incomes from an objective point of view, amounts to "treat them as received by individuals with unlimited time horizon" (p.96). Thus the statements of the Actuaries and M'Culloch, under the assumption that normal individuals have an unlimited horizon, can be considered as following: "if one wants to distribute the wealth available within an unlimited period, so that at any time one can expend the identical amount of income, those two incomes are equivalent" (p. 97, italics in the original).

As regards J.S.Mill, he oscillates between the consideration of a limited time horizon, and an unlimited time horizon. His criticism of the Actuaries, that if the flow of incomes is capitalized, than also the flow of taxes should be capitalized, implies considering as normal the individuals that have a limited time horizon. By contrast, when Mill, for allegedly "sentimental reasons" proposes to exempt from taxation the expected savings, i.e. a share of savings certainly lower than that is necessary to ensure consumes perpetually uniform, im-

${ }^{30}$ Mill, J.: Elements of political economy, London : Baldwin, Cradock, and Joy, 1821; McCulloch, J. R. Principles of Political Economy: (1825), 4th ed. Edinburgh : A. and C. Black; London : Longman, Brown, Green and Longmans, 1849.

${ }^{31}$ Mill, John Stuart, Principles of political economy: with some of their applications to social philosophy, 2nd ed. London : J.W. Parker, 1849. 
plicitly is considering people endowed with "two superimposed plans: one with an unlimited time horizon, and the other with a limited time horizon"(p.99). Thus, Fasiani concludes that such a system ends up hitting both consumption and bachelor's rent. For example, if one assumes that a consumer with a $£ 15$ temporary annuity for ten years consumes in that period of time only $£ 10$ and saves $£ 5$ which will provide a perpetual annuity of $£ 2.5$, we may infer that his "bachelor's rent" is $£ 5$. According to Mill's suggestion the tax would be levied on $£ 10$, i.e. both on the $£ 5$ corresponding to the perpetuity plus the $£ 5$ of the bachelor's rent.

The same conclusion can be extended to the comparison b) (p.100), whereas the comparison c), which concerns gross unearned incomes that are temporary, is used to extend the argument to inheritance taxes and to taxes on transfers in general. Indirectly, the result of taxing the "bachelor's rent" can be obtained "by adding to the direct taxes and to the taxes on transfers, taxes affecting consumption which, albeit imperfectly, are weighting on the mentioned "bachelor's rents" realized through gross income" p.109).

In the fourth essay: Di un fenomeno di attrito (About a phenomenon of friction) (1932) Fasiani makes an attempt to justify the economic analysis in partial equilibrium, not necessarily competitive $\mathrm{e}^{32}$, in respect of the more correct general equilibrium analysis ${ }^{33}$.

Specifically, he highlights a friction mechanism that limits, in fact, the interconnections between the markets, making the Marshallian scenario closer to reality than that of Pareto's general equilibrium. Starting from the idea of Pantaleoni regarding the markets stickiness, Fasiani identifies the discontinuity of Marshallian supply curves as the responsible mechanism, following the idea of intermediate equilibria. In fact, he assumes that the supply curve is not continuously adapting to changes in demand, which are seen as exogenous shocks.

\footnotetext{
32 The fact remains that the reasoning of Fasiani can still be referred to oligopoly or imperfect competition markets, although it is not always easy to navigate in the tangle of his cases and arguments.

${ }^{33}$ This topic may seem coincident with that of the legitimacy of the hail-tax assumption or of neglecting the expenditure of the tax revenue in the analysis of tax shifting) (Fasiani, 1943a) and (Fasiani, 1940a), reported above respectively in $\$ 2.1$ and $\$ 2.3$. However, the fact is that here Fasiani is concerned with the more general topic regarding economic analysis, and not fiscal analysis only.
} 
In other words, for adherence to reality, Fasiani assumes that market supply curves present discontinuities:

By definition, we are accustomed to consider the Marshallian supply and demand as continuous curves. Thus, we may be surprised by Fasiani's statement that "the current assumption of continuity in the supply curve, obtained within productions at increasing costs, instead of ... being the normal case, it appears to me rather an extreme case, quite unlikely in practice. New firms are not formed for the slightest increase in demand, and firms do not increase their production per the slightest increase in price" (p.13).

As usual, Fasiani considers a wide-ranging casuistry based: a) on the idea that, after the initial displacement, the demand curve remains constant (in the terminology of Fasiani: the demand is inelastic), or that it can adapt to the successive changes in the supply (the demand is elastic), b) on the causes of discontinuity of the supply curves.

In particular, the discontinuity of supply can alternatively be determined by the fact that: 1) at a given price change, the offer will not change (absolute rigidity of supply), 2) the supply changes because new firms enters the market, but the firm are not efficient (i.e. they are not at their minimal cost), or the new firms are efficient even if producing a sub-optimal quantity (relative inelasticity of the supply).

Following Clark ${ }^{34}$, Fasiani considers a scenario where the productive sectors comprise several successive stages, so that firms that produce the final good (at the final stage) need inputs produced by the firms operating at the previous stages, where the first stage is the one corresponding to the raw material. At each stage, however, can be used as inputs also goods produced in other sectors. In this way, the absolute and relative rigidity of the supply of inputs will generally be different at each stage, from that of the final product. Therefore, a change in the price of a final product may not have an impact on the prices of some inputs or affect some goods only. For Fasiani "the exact determination of the cases and of the limits regarding the phenomenon of friction can be obtained only by successive approximations" (p.17). Actually, using appropriate assumptions about op-

\footnotetext{
${ }^{34}$ Clark, J. B., Essentials of economic theory: as applied to modern problems of industry and public policy, New York: MacMillan, 1909
} 
timal firms and then releasing such assumptions, he is able to make interesting statements regarding the different possible casuistries.

\subsection{Effects of taxation}

This section is devoted to seven essays regarding different topics related to the effects of taxation, from the excess burden of indirect taxes, to the risk taking behaviour, from imperfect competition to individual labour supply. They are: On a Particular Aspect of Consumption Taxes (1930); The effects of exempting the new built houses from taxation (1931); A contribution to some aspects of the theory of tax shifting as regards taxes on profits and incomes (193132); Risk and taxation (1935); A review of a recent book on the effects of income taxes (1940); Tax shifting in a case of imperfect competition and in a corporative regime (1942); Some critical notes regarding the theory of the effects of taxation on the individual labour offer (1942).

The first one is: Di un particolare aspetto delle imposte sul consumo (On a Particular Aspect of Consumption Taxes) (1930), that was translated in English in the fifties ${ }^{35}$. The analysis seems very pioneering as compared to the modern discussion of the optimal tax in a second best setting, but suffers from non-analytical methodology. First, Fasiani refutes the statement of Gobbi and Pantaleoni ${ }^{36}$ that the direct and indirect taxes cause the same sacrifice, by drawing on the previous Borgatta's reasoning and on the proof of Barone of the excess burden of indirect taxes ${ }^{37}$. In particular, the criticism raised against Pantaleoni constitutes a literary proof of the theorem of the excess burden of indirect taxation using the equilibrium condi-

35 Fasiani, M.: On a Particular Aspect of Consumption Taxes, in International Economic Papers, vol.6, 1956.

${ }^{36}$ Gobbi, U.: Un preteso difetto delle imposte sui consumi, in "Giornale degli economisti”, April 1904, pp.296-306; Pantaleoni, M.: L'identità della pressione teorica di qualunque imposta a parità di ammontare e la sua semiotica, in "Giornale degli economisti", March 1910, pp.293-324.

${ }^{37}$ Borgatta, G.: Intorno alla pressione di qualunque imposta a parità di prelievo, in "Giornale degli economisti", August 1921, pp.290-297; Barone, E.: Studi di economia finanziaria, in "Giornale degli economisti", April-May 1912, pp.309-353; June 1912 pp.469505; July-August 1912, pp.1-75. 
tion that the marginal utilities of goods are proportional to their prices. Then, he presents two cases of identity of sacrifice between direct and indirect taxes, dependent on specific assumptions about the indifference curves, which now seems quite unrealistic.

He then goes on to discuss the issue of how the diversity of the consumers' tastes influences individual burden of direct and indirect taxation. In particular, he investigates the role of the income elasticity of the demand for the taxed goods and shows how, with the same sacrifice, the difference in the tax income between the direct and indirect tax is minor when taxing the goods with a more rigid demand. Having to resort to a distortionary tax (i.e. in second best), this implies that the tax is less inefficient when hitting the goods with a demand more inelastic to income changes. The proof is based on the assumption of indifference curves with "the same tendency" 38 , and then it is extended to indifference curves without this condition, in which case the difference in the tax income tends to disappear the more the tendencies differ ${ }^{39}$. Finally, considering the indirect tax which affects two goods, Fasiani notes that the first best entails the identical tax rate. The second best is achieved by zero-taxing the good with the demand more elastic with respect to income. In the third best (different tax rates for each goods), the goods with a demand more elastic with respect to income should be taxed at a lower tax rate.

In the second essay: A proposito degli effetti dell'esenzione dall'imposta delle case di nuova costruzione (The effects of exempting the new built houses from taxation) (1931) Fasiani proceeds to rebut some statements of Fubini which were, anyway, in conflict

\footnotetext{
38 The definition of indifference curves with "the same tendency" is a critical point, in so far as it does not seem easy to attach an economic meaning to it.

${ }^{39}$ Some doubts might be raised by the claim that in Figure II the point C' (that lies on the indifference curve CC') is simultaneously tangent to the two different budget lines AP \& A'B'. In fact, the criticism of Bordin (Bordin, A.: Differenze tra l'imposta sul reddito e l'imposta sul consumo, in "Economia", August 1930, p.125) is referred to this very point. Bordin recalled that the two curves can not have "a common tangent". Fasiani had answered in (Fasiani 1932d, p. 18, footnote) stating that he really just wanted to say that the equilibrium point is always at the point $C^{\prime}$, with both budget constraints. This is possible, since one of them is a side equilibrium.
} 
with what was previously said by $\mathrm{Bachi}^{40}$. These statements regard the effects of exempting the new houses from the income tax. Secondly, Fasiani draws on Bachi's contribution, enlarging the latter's framework. He makes explicit Bachi's assumptions and then proceeds to distinguish two different cases: i) that the income tax had already been shifted prior to the introduction of the exemption (Case A) and ii) that before the introduction of the tax exemption the income tax was not yet shifted (Case B) ${ }^{41}$.

Therefore, the discussion covers the following five points: 1) in case $\mathrm{A}$, if following the tax exemption the rents do not decrease or can not decrease by an amount equal to the tax, 2) still in case A, both in the short and in the long run, whether the tax exemption is an incentive to build new houses, 3) if such an incentive is different from the one that would result from a fall in the building cost of houses, 4) if such an incentive may exist in the case B, 5) if any difference exists between the case of abolition of the tax and the case in which the tax is suspended only for a certain period.

The discussion proceeds in point of logics, including the use of detailed case studies. About point 1) the conclusions are that: a) the rents decrease by an amount equal to tax in case the latter had been entirely shifted to the tenants. The rents may have an even higher decrease in case the building cost decreases; b) the rents remain unchanged if the tax had been transferred entirely on the factors of pro-

40 R.Fubini: Sugli effetti dalla esenzione dell'imposta sui fabbricati per le case di nuova costruzione, in La Riforma sociale, 1931, gen-febb. p.14; R.Bachi: Sugli effetti della esenzione dall'imposta sui fabbricati per le case di nuova costruzione, in Economia politica contemporanea: saggi di economia e finanza in onore del prof. Camillo Supino, Padova : CEDAM, 1930 vol. 2.

${ }^{41}$ The economic system is considered "progressive" in that both the population and the stock of houses are increasing. However, the rent is fixed in order to match the constant level of the cost of building new houses. All the other economic variables remain unchanged: see the list of Fasiani's hypothesis. For example, the national income increases, but average income does not increase. I do not understand then how Fasiani may consider a possible decrease in the tax shifting due to the presence of rising costs in the production of new houses due to growth of demand (p. 342). It seems to me that the costs must be constant, because "the whole system of equilibrium prices" has been assumed invariant (p.340). More generally, in a "progressive" economic system, a temporary tax exemption must have an impact on intermediate equilibriums, through acceleration or deceleration in demand and supply, and the correspondent temporary rent variations. Moreover, I am not clear in what sense one can speak of rigidity of the demand for rentals: certainly not in the long-run equilibrium, in which by definition the price does not change. 
duction; c) the rents decrease, but less than the tax, if the latter had been shifted in part (p.347).

About point 2) Fasiani concludes that Fubini was wrong: in general the exemption is a "particular and lasting incentive to build new houses" (p.348). Point 3) leads to the conclusion that the fall in input prices is closely analogous to the tax exemption. About point 4 ), relating to the case $\mathrm{B}$, the effects of the exemption are similar to those of case A in case the owners are temporarily affected. However, the assumption that the tax permanently affects the owners (as Fubini does) is incompatible with his other assumptions, because the final impact on the owners requires, in the long run, a complete block of building activity.

The discussion of point 4) involves an elaborate casuistry. Thus, the effects "may differ considerably" (p. 355). Finally, Fasiani extends the inquiry basically to the case of new types of houses, and then he releases important assumptions, including the hypothesis of a special tax, and of the analysis in partial equilibrium.

In the third essay: Contributo ad alcuni punti della teoria della traslazione delle imposte sui "profitti» e sui «redditi» (A contribution to some aspects of the theory of tax shifting as regards taxes on profits and incomes) (1931-32), Fasiani analyses the shifting of taxes on profits and on incomes in a scenario involving the role of time and of intermediate equilibria. The starting point is the contribution of Seligman $^{42}$ and Coates ${ }^{43}$ to the Report of the Colwyn Committee ${ }^{44}$. Firstly, Fasiani warns that he is interested only in relative price changes, in particular following Cassel's framework ${ }^{45}$. Secondly, he clarifies what may be considered as profit, showing in particular that for Coates profit encompasses both the surplus and the interest on capital. This makes Coates's approach not comparable with that of Seligman, unless the interest rate is zero. What matters most, how-

\footnotetext{
${ }^{42}$ E.R. Seligman, Income Tax and the price level, in Colwin Report, cit, Appendix XII pp.119-121

${ }^{43}$ Coates, Memorandum on the incidence of Income Tax and the price level, in Colwin Report, cit, Appendix XI, pp.90 ff.

44 Great Britain, Treasury, Report (Cmd. 2800) of the committee on national debt and taxation, London, 1927 (Colwyn Report).

${ }^{45} \mathrm{G}$. Cassel, The treatment of price problems, in The Economic Journal, December 1928, pp.589 ff.
} 
ever, is that the inclusion of the interest into the surplus, makes undetermined the equilibrium in competitive markets. In fact, if the marginal entrepreneur is not the one who has zero profit, but a person who "makes an indeterminable amount of loss", it is impossible to determine the equality between price and cost of the marginal entrepreneur.

Then, Fasiani, under the assumptions both of a special tax and of a hail-tax, critically discusses the theory of Seligman, according to which the tax on profit (defined as surplus) is not shifted. This is so because the marginal firm (whose cost determines the price) has zero profit and therefore it is not paying any tax. Thus, the marginal firm can not change the quantity produced, so that the market price does not change. Fasiani's scenario is a competitive market in which infra-marginal and marginal firms co-exist, but in which the tendency toward equilibrium is only virtual, because he is particularly interested in intermediate equilibria. Thus, Fasiani's criticism to Seligman is based on the fact that the marginal producer, defined as the one that has the highest cost, can not exit (or enter) the market immediately. It follows that the equality between the price and the highest cost, might not be verified at every time.

According to Fasiani, this would mean to confuse the "normal" cost with the market price toward which it tends in a given time (p.18). In fact, the market comprises, in addition to the firms which are normally efficient, also firms whose efficiency is subnormal. Thus, the market price will tend to conform to the normal cost, but this level can only be achieved through the elimination of the subnormal firms. In this way, at each moment of time, the price may be higher or lower than the normal cost. In addition, each market is different from the others in the sense that if in a market the price is higher than the normal cost, in another it may be lower. Finally, it is not true that in the long run, cost price and normal cost coincide, because the normal cost is subject to continuous changes. The conclusion is that, as regards the shifting of taxes in general, it is not sufficient to look at the effects on the highest cost, or on the price temporarily equal to it, or even on the normal cost. It is necessary to watch out at the effects of all these costs. This is true both in the short and in the long run (p.23). 
However, the very distinction between the short and the long run does not appear significant, in so far as the long run coincides with the reaching of the market equilibrium. In other words, the analysis in comparative statics does not seem satisfactory. In fact, it neglects the essential fact that with the passing of time, new forces are involved, which shift all the trajectories. What is important instead is the sequence of intermediates equilibria.

In order to pursue the discussion on the special tax, at this point Fasiani finds it necessary to analyze the nature of the surplus defined as the difference between cost and price. For this purpose he distinguishes between: a) unearned surplus, which does not increase the production (it would seem identical to a Ricardian rent), b) surplus earned coming from speculation (which depends on the demand), c) surplus earned from an invention or from efficiency (which causes a decrease in the cost of production). Both surpluses b) \& c) have the effect of increasing production. Indeed Fasiani shows that the shifting of the special tax (which affects the surplus that is obtained in a particular use) may occur in higher or lesser degree depending on the fact that the tax hits the surplus in the sense a), b) or c).

Then, Fasiani analyses a general tax that hits the surplus and shows that the results obtained in the special tax case are valid also for the general tax. However, in addition, one should consider also the effects on the rate of interest and on the demand \& supply for savings. The main conclusions regarding the general tax are: a) in the short run the general tax tends to change the surpluses less than a special tax and then to cause a lower amount of shifting, b) both a progressive tax and a proportional tax on surpluses may alter the attractiveness of alternative uses and then to shift temporarily, c) in so far as it affects the earned surplus, the general tax tends to induce a lower demand and supply in savings, and slower and slower investments, so that the price of goods decreases less quickly.

Then, Fasiani considers the general tax on income (which hits not only the surplus). The concept of general income tax is ambiguous and thus he considers a tax with a wide field of taxation as a first approximation (p.73). At any rate, a "real" general tax is assumed, that is a tax that affects income at its sources. Fasiani considers the ap- 
proach of De Viti de Marco very important and highly original ${ }^{46}$. In fact, he recalls that only after a long time Kendrich ${ }^{47}$ has presented a special case comparable to De Viti's general one. The Devitian setting is partially accepted, but Fasiani uses the hail-tax assumption. The reason is that in this case he does not think it appropriate to consider the effects of the tax spending, because this would imply to neglect both time and intermediate equilibria, although the tax may be productive through spending. As mentioned, Fasiani accepts and develops the other setting of De Viti de Marco, according to which the tax can produce changes in the demand curves. A further difference with the approach of De Viti is that the latter starts from a point of equilibrium and considers the effect in comparative statics, while Fasiani starts from a position in which positive or negative surpluses may occur according to the different productive uses. From that position the movements are directed towards an equilibrium in which any surplus disappear. In this way the theory is extended from the Devitian comparative statics, to the analysis of dynamic phenomena that occur in limited periods of time.

Thus, the introduction of the tax may have very different consequences depending on all the circumstances that may occur. Therefore, Fasiani takes on three assumptions to simplify the analysis. These assumptions are: a) there is a direct relationship between interest rate and supply of savings, starting with a positive amount of savings corresponding to the interest rate zero, but there is also a maximum possible amount of savings, b) in a first approximation the tax does not have any direct effects on the supply of savings, c) the equalization of profit in all the markets is acting not only through the modification of the flow of new employments, but also through the shifting of investment from one market to another, when the threshold between surpluses realized elsewhere and losses due to the transfer has been trespassed. At the light of these premises, Fasiani examines six typical cases according to the sectors in which - before of

\footnotetext{
${ }^{46}$ De Viti de Marco, A., I primi principî dell'economia finanziaria, Roma: Sampaolesi. 1928. English translation of a later edition as First Principles of Public Finances, LondonNew York: Jonathan Cape-Harcourt Brace \& Co., 1936.

${ }^{47}$ Kendrich, M.S. Public expenditure in the tax incidence theory, in The American Economic Review, June 1930. By contrast, De Viti's approach can be traced back in his lessons to the early years of the century.
} 
the tax - there occurs a surplus or a loss, related to the sectors over which the tax leads to an increase or decrease in the demand.

Here is considered only the first of these cases, in which the demand increase (decrease) involves different sectors than the ones that verify the surplus or loss. Thus, not only the sectors that make a loss, but also areas in surplus, will tend to shift the tax because their prices fall less rapidly. On the other hand, demand for savings tends to increase in the sectors in which the demand increases and to decrease in sectors in which the demand decreases. The interest rate can therefore increase or decrease, causing a further impact on the sectors considered.

Fasiani has considered a tax that directly affects the business (as long as the tax is not shifted), but whose burden is expected to affect the individuals to which the distributed income accrues. According to him, the object of taxation is the income of the firms defined conventionally, so that the cost of interests is included but not that regarding the interest paid on equities, as stated by Coates. The reasoning of Fasiani highlights that the reaction of the firms is not uniform, depending on the type of surplus enjoyed (not earned, or earned out of speculation or invention).

The consideration of intermediate equilibria is an important element, typical of the theoretical construction of Fasiani. However, since the analysis is based on the assumption that competition is priced on marginal cost, it seems to leave room for uncertainty with respect to the succession of intermediate equilibria. In the second part of the essay, Fasiani considers a general tax on income, starting from a De Viti's scenario. Nonetheless, the coherence with the analysis of the first part is ensured by the fact that he does not consider a general tax on personal incomes, but a real tax, since it affects incomes at the source. The taxpayers are still the firms (not the individuals) and Fasiani's analysis is directed to ascertain the reaction of the firms. For example, among the "three premises" that Fasiani assumes, one is that the supply function of savings is not changed. This assumption is reasonable only if the investigation relates to the conduct of business and not to the reaction of the individuals. 
The fourth essay: Imposta e rischio, (Risk and taxation) (1935) starts from both historical precedents ${ }^{48}$ and the current literature on risk $^{49}$, and begins with solving problems of definition concerning risk, uncertainty and the event of risk. Specifically, it distinguishes between cases in which: $\alpha$ ) the probability of occurrence of the adverse event is known, but the amount of loss is unpredictable; $\beta$ ) both the occurrence of the event and the assessment of its economic effects are loosely foreseen; $\gamma$ ) it is possible to know only generally that there are certain types of unpredictable events. According to the Pareto approach, Fasiani distinguishes between unpredictability in the objective sense and in the subjective sense, and then only considers the latter kind of unpredictability. In particular, he assumes a normal individual, representative in the Marshallian sense.

The tax can be considered either ${ }^{50}:$ A) an adverse event that constitutes a risk, and then it can be distinguished in the three mentioned cases $\alpha, \beta, \gamma ; \mathrm{B})$ a source of adverse events in so far as it leads to price changes more or less easily predictable; C) an event capable of changing the firm's willingness in risk-taking; D) an event that could reduce risk by limiting adverse events when the expenditure of the tax revenue is considered; E) the object of risk, considering the variability of the tax-revenue and its consequences.

48 Smith, A., An inquiry into the nature and causes of the wealth of nations, Dublin: Whitestone, 1776; Hume, D.: Essays and treatises, (1753) Essays and treatises on several subjects, A new edition London: Printed for A. Millar, ... and A. Kincaid and A. Donaldson, at Edinburgh, 1760; Verri P., Meditazioni sulla economia politica, 1771. Edition Custodi, "Scrittori classici italiani di Economia politica", Tomi XV-XVII, Milano: Destefanis, 1804; Rossi, P., Cours d'économie politique, Paris: Guillaumin, 1854; Pufendorf, S.: Le droit de la nature et des gens, ou Systeme général des principes les plus importans de la morale, de la jurisprudence, et de la politique Nouv. éd. Ed. 3a, emendatior, Basle 1771; Montesquieu, C., De l'esprit des loix, Leyde: Chez les libraires associés, 1749; Necker, J.: De l'Administration des finances de la France, 1785; Mercier de La Rivière, P.P.F., L'ordre naturel et essentiel des sociétés politiques, Paris : Desaint, 1767.

${ }^{49}$ Lavington, F., The English capital market, London:Methuen \& co. 1td., $2^{\text {nd }}$ ed.,1929; Knight, F. H., Risk, uncertainty and profit, Boston: Houghton Mifflin, 1921;Pigou, A.C., A study in public finance, London: Macmillan, 1928; Stamp, J. The fundamental principles of taxation in the light of modern developments, Newmarch lectures for 1919; Åhman, Sven, Uncertainty-Bearing and the Income-Tax , in The Economic Journal, 1929, Vol. 39, No. 154, pp. 288-291.

${ }^{50}$ Fasiani's casuistry is quite detailed, but at least some of his reasoning is essentially based on the extension of the effects of taxation, to the effects of expectation, which means that he assumes to have resolved any uncertainty about the effects of taxation. 
In $\S \S 5 \& 6$, the case $A \alpha$ is considered, that is typical of the inheritance taxes. This tax is considered comparable to an income tax but only under the assumption that there is a continuity of interests between successive generations. The equivalence holds on average, but involves also unknown factors which could be resolved by insurance. This reasoning implies that the inheritance tax that gives the same tax income is more burdensome to the taxpayer, because it presents an additional cost due to the risk which, knowing the probability, can be insured. In addition, there is still another form of uncertainty due to the fact that one can not exactly determine future tax liability, because it can vary the interest rate, or simply the tax rate in an asymmetric fashion, i.e. only in the future.

In $\S 7$ attention is drawn to the fact that in certain circumstances one can expect an increase in the tax burden, but it is not possible to predict neither its size nor its modalities. These are events that fall within the $A \beta$ case, since the risk can not be determined. However, the resulting uncertainty can have very large effects on the economy, in particular by delaying all possible business and inserting a wedge between the seller's price and the buyer's price, i.e. the cost of the risk. $\S 8$ is devoted to historical precedents and in particular shows the reasoning of Mercier de la Rivière ${ }^{51}$ who "sets out the general concepts of the theory of the consequences of the uncertainty of taxes" according to which the use of the factor that Pigou ${ }^{52}$ calls "uncertainty-bearing" becomes necessary in every production. Thus, this fact implies a change in the set of inputs and the closing down of some productions. "In other words, the uncertainty ... ... acts as a decrease in the productivity of [aggregate] savings ... and at the same time as a decrease in the supply of savings" (p.23).

To develop this insight, Fasiani begins with studying the effects of introducing a tax on the market of capitals. He uses a graph taken from Jarach ${ }^{53}$ in which the aggregate supply and demand of savings determines the equilibrium rate of interest. The introduction of a hailtax determines a different equilibrium, because the demand curve shifts towards the abscissa. $\S 9$ is devoted to expand this reasoning.

${ }^{51}$ L'ordre naturel..., cit.

${ }^{52}$ A study...cit.

${ }^{53}$ Jarach, C.: Gli effetti di una imposta generale ed uniforme sui profitti : Nota R. Accademia delle scienze di Torino, Torino: Tip. V. Bona, 1911 
Considering the general equilibrium approach still in the case that capitals are considered material goods (according to the Austrian school) it seems likely that the supply curve is shifted up, because the distribution of incomes has changed due to the new prices of the inputs, induced by the tax. This implies that the increase in the rate of interest is no longer certain: it may also decrease or remain constant, but it can be stated that savings are dwindling.

In $\S 10$ it is pointed out that the effects of an "expected" tax can be analyzed in the same way by assuming that changes are occurring in the demand and supply of savings. However, here there is a degree of uncertainty that may be analysed by considering the two polar cases of catastrophic or optimistic forecast, assuming respectively a maximum and a minimum possible shifting of the curves. In $\$ 11$ Fasiani introduces the Wicksellian approach that the tax lengthens the time of the production processes and consequently reduces wages. In this case, however, the cost of risk increases with the increase of the production period, and this would have an effect contrary to that stated by Wicksell ${ }^{54}$. In every way, contrary to what expected by Wicksell, the capital can not remain constant.

In $\S 12$ the assumption is outlined that there are some dynamics in the system; in $\S 13$, still for the same case $A \beta$, the special tax on wealth established in Italy in 1919 is briefly examined, because it presented large features of institutional uncertainty. In $\S 14$ the cases of A $\gamma$ type are briefly considered, which are similar to those of the previous case, only with a greater degree of uncertainty.

In $\S \S 15$ and 16 cases of type B are studied, where the risk comes from the fact that the tax causes price changes that are more or less predictable depending on the type of tax and on inter-relationships between markets.

In $\S \S 17-20$ Fasiani analyzes cases of type $C$, i.e. when the tax is capable of changing the propensity in risk-taking of the firms. He considers "actual" risks, i.e. risks that affect different businesses differently, so that "capital and labour are driven away from higher risk

${ }^{54}$ Wicksell, K., Finanztheoretische Untersuchungen nebst Darstellung und Kritik des Steuerwesens Schwedens, 1896, Italian translation as Saggi di finanza teorica, in "Nuova collana economisti stranieri ed italiani”, vol. IX, G. Borgatta ed., Torino: Utet, 1934, pp. 1133. A discussion of Wicksell's thought is in Webb, U.K. Taxation and production. The Wicksell analysis, in Review of Economic Studies, 1934, pp.18 ff. 
business" (p.40). Here Fasiani uses graphs with probability distributions of returns for two alternative investments with different dispersion, that are indifferent because the investment with the greater dispersion also has a higher average return.

He points out that the tax lets the curves shift, but at the same time decreases their dispersion. Hence the premium for the risk is reduced by the same proportion in which the deviations of the two investments are reduced. Fasiani finds that generally the tax induces entrepreneurs to take either a higher or a lower risk depending on their utility curve with respect to profit.

In $\S \S 21-28$ he analyzes cases of type $\mathrm{D}$, i.e. when the tax decreases the risk by limiting adverse events since the tax spending is "useful" for the community. Three sub-cases are possible: a) the expenditure of the tax revenue reduces adverse events somehow, b) allows the cost of risk to be redistributed among the individuals, c) transfers the costs of the risk from one part of the community to a different one.

Finally, §29 is devoted to the risk associated with changes in tax revenue and thereby, inter alia, with the cyclical sensitivity of taxes. In that case, Fasiani considers the risk that taxes generate against the state. The latter, however, reacts by shifting the cost to taxpayers through higher taxes or la ower spending.

The fifth essay: A proposito di un recente volume sull'incidenza delle imposte (A review of a recent book on the effects of income taxes) (1940) is a review article of a book by Duncan Black ${ }^{55}$, from which Fasiani takes its cue for discussing again some topics that he had already treated and on which he shall return later ${ }^{56}$. These are: a) the methodological problem of when it is allowed to neglect the expenditure of the tax revenue in the analysis of the effects of taxes, b) the effects of taxation on labor supply, c) the relationship between taxes and population movement, d) the productivity of taxes, e) the double taxation of savings.

Point a) is the consideration that, when trying to highlight the intermediate positions between the initial and the final equilibrium in

\footnotetext{
${ }^{55}$ Black, D., The incidence of income taxes, London: Macmillan, 1939

${ }^{56}$ Fasiani (1926); Fasiani (1928a); Fasiani (1931b) Fasiani (1941, Appendix VII) ; Fasiani (1942c); Fasiani (1942d); Fasiani (1943a);
} 
comparative statics, it appears that partial equilibrium is closer to reality than it may be the general equilibrium . From this, it follows that the assumption of hail-tax is legitimate. In other words, it seems reasonable not to consider the expenditure of the tax income. Fasiani does not entirely agree with Black and propose the legitimacy of hail-tax assumption only in four cases ${ }^{57}$.

On point b) (effects of taxation on labour supply) Fasiani focuses primarily on the analysis with indifference curves, which allows Black to show that the tax could either increase or decrease the supply of work. In this contex, recalling Pantaleoni's approach, Fasiani states that the difference between the two theories is purely formal (p.12), because it is possible to imagine marginal curves of utility and of painfulness of work which may lead to increase, decrease or leave constant work-related efforts (p. 11) ${ }^{58}$. In addition, Fasiani comments on the possible consequences of considering also the tax-revenue expenditure, and of the plausibility of assuming that workers can actually vary their labour supply.

In dealing with taxes and population movement (point c), according to Black both the tax and the expenditure of the tax-revenue tends to make certain classes of annuitants more rich and to impoverish other classes, so that ultimately there will necessarily be an impact on the birth rate and on the mortality rate. The latter will show a tendency to decrease, while the birth rate will rise in the short run, but probably will decrease in the long run. Fasiani recognizes to Black the merit to have attempted the analysis of the relations between taxation and demography, but thinks that Black's thesis are more convincing as assumptions than as conclusions.

About point d) (the productivity of taxation) Fasiani summarizes the analysis of the effects of taxation on the quantity of capital. According to Black a reduction of capital and an increase in the rate of interest are likely to occur "in the long run". These findings are in contrast with those of Einaudi and De Viti ${ }^{59}$. According to Black, this is due to the fact that they consider the tax useful to the community,

57 The topic was considered specifically in Fasiani (1943a): see above, $\$ 2.1$.

${ }^{58}$ The problem is then taken up in detail in (Fasiani 1942c) and also in (Fasiani 1941).

59 Einaudi, L. Intorno al concetto di reddito imponibile e di un sistema di imposte sul reddito consumato, Torino: Bocca, 1912; De Viti de Marco, A., I primi principî dell'economia finanziaria, Roma: Sampaolesi, 1934.. 
or "productive", but in his view the tax could be productive only if the state does a more productive use than the privates, or if the tax causes a net increase in investments, but this seems extremely unlikely. Really, according to Black the tax is only productive if it is "directed to uses in which only a government, not individuals, can be productive" (p.16), i.e. investments in education and public health.

Fasiani recalls that he does not belong "to the group of those who believe that the tax is normally productive" ${ }^{60}$, but notes that: 1) the activity of the state could save overhead costs, 2) productivity of capitals should be considered over a certain period of time, but the "public" time rarely coincides with the "private" time, 3) productivity is a concept that must be weighed against the "political" ends of the state, 4) not only the expenditures in health and education can be productive, but also every expenditure related to indivisible services (p. 17).

Finally, about the point e) (double taxation of savings) Fasiani considers a numerical example of Black and notes that Black's argument is not dissimilar to the one that Ricci presented and which Fasiani had discussed in (Fasiani 1928a): see below, §4. Then, he presents a further criticism against that argument.

The sixth essay: La traslazione dell'imposta in regime di concentrazione industriale e in regime corporativo (Tax shifting in a case of imperfect competition and in a corporative regime) (1942) is devoted to imperfect competition, effects of taxation and market regulation. This essay has been considered here, and not in the section regarding Corporative economy, because the reference to the corporative regime is not particularly important, since here Fasiani intends only the ordinary possibility of the state to control some prices. In fact, Fasiani considers a case of imperfect competition, drawing on a previous Amoroso's work ${ }^{61}$. A big firm co-exists with a large number of small businesses. The big firm knows the curve of the overall market demand and thus it is able to derive its 'partial' demand curve, which is negatively sloped. Thus, the big firm maximises its profit by set-

\footnotetext{
${ }^{60}$ In (Fasiani 1931b) a Fasiani's work on the productivity of taxation is mentioned as being in press, of which, however, there are no other news. The argument is, nonetheless, resumed in (Fasiani 1942d).

${ }^{61}$ Amoroso, Luigi, Principii di economia corporativa, Bologna: Zanichelli, 1938
} 
ting the (market) price that equals its marginal cost to its marginal revenue. Small businesses provide the quantity that make equal the market price to their marginal costs; the remaining amount is provided by the big firm, so that the market is in equilibrium. Given the productive costs, this scenario is thus based only on the reaction of consumers (market demand curve), and on the reaction of the small business which determines the demand for the big firm.

To come closer to reality Fasiani tries to justify the coexistence of a big firm with a number of small business $(\S 6-\S 8)$. His reasoning relates to possible agreements between producers, to gentlemen's agreement in the industry, to transportation costs and to fixed capital; thus, this case is somewhat different from that of Amoroso, which was instead used by Fasiani in the second edition of his Principii (Fasiani, 1951). At any rate, such reasoning makes it difficult to identify the demand curve for the big firm, even if it does not seem to affect Fasiani's real treatment of taxes, except for generating some uncertainty: "that affects the amount of shifting to an extent which can not be determined a priori" (p. 11, italics in the original) .

Under the hail-tax assumption, Fasiani introduces a special excise tax and graphically shows that the tax increases the equilibrium price and reduces the quantity. Therefore, it causes a partial forward shifting, even if smaller than in a monopoly market ${ }^{62}$.

The remaining of the essay is formally devoted to build a theory of public policy under imperfect competition in the corporative economy. However, Fasiani assumes that the corporative regime is denoted only by the possibility of fixing prices, with the objectives of favouring either the consumers or the workers employed in the production. Thus, it follows that his reasoning really concerns a state controlled economy ${ }^{63}$.

\footnotetext{
${ }^{62}$ In the graphic representations the shifting of the partial demand curve is correctly represented, but Fasiani does not draw the corresponding marginal revenue curve. It follows that his new equilibrium relating to the big firm is not correct. Probably Fasiani refers to this error when writes: "I am grateful to D'Albergo... to have pointed out the shortcomings of my wording... to which I have tried to remedy at present" (Fasiani 1951, p. 244, footnote 5).

${ }^{63}$ I would like to highlight just three points: i) price control is considered a tool even in modern economics, ii) in order to fix prices one must have adequate information on the costs, which seems very difficult, iii) as regards the ability of the state to set prices, Fasiani's confidence may seem excessive, even in the Italian corporative state.
} 
The state, in fixing the price of the goods, wants to pursue certain public goals. Fasiani considers as goals of the state the following three: 1) general fairness, which may be obtained by fixing alternatively the price of the goods or the price of labour, 2) that the state wants to seize all the profits of the firm or, alternatively, only its surplus, 3) that the state wants to favour all consumers, or only the workers.

In the first polar case, the state wants to redistribute income to all consumers by way of setting the price. If the state wants to seize only the surplus, there is no problem. It is sufficient just to set the price equal to the marginal cost. Conversely, if the state wants to seize all the profit, it would not be sufficient to set the price equal to the average cost. The goal, notes Fasiani, can not be achieved by using only the price, because when the price equals average costs, to the big firm the demand curve would appear as a line parallel to the $\mathrm{x}$-axis. Therefore, the new marginal revenue curve would coincide with that of average revenues, and the big firm will respond by reducing the amount of its production. In the market, there would be an excess demand and thus, the state would need other tools in order to reach his aims.

Then, Fasiani discusses the introduction of an excise tax when the price is equal to the marginal cost, and to the average cost. He concludes that in both cases a tax shifting occurs. If the price is equal to the marginal cost, the producer retains the rent: it follows that further redistributive measures to restrict the remaining tax shifting are possible.

Finally, Fasiani considers the introduction of a tax under the assumptions that the state sets wages either at the level to seize either all the profits, or the rent only.

In the seventh essay: Appunti critici sulla teoria degli effetti dell'imposta sull'offerta individuale di lavoro (Some critical notes regarding the theory of the effects of taxation on the individual labour offer ) $(1942)^{64}$, Fasiani first discusses the current economic

\footnotetext{
${ }^{64}$ Fasiani had addressed this issue in the review article regarding Black [Fasiani 1940 a]: see above, the fifth essay of this section. Then, he briefly resumed it in [Fasiani 1941] and [Fasiani 1951].
} 
theory of labour supply $(\S 1-\S 11)$, especially with regard to the question whether taxation increases or lowers productive efforts ${ }^{65}$. Then, from $\S 12$ to $\S 30$ he introduces, in addition to the working time, as a variable, the 'intensity of the work effort' and examines how the traditional results are modified accordingly. In $\$ 31$ he considers also the technical reintegration of the instruments of labour. In $\$ 32$ Fasiani devotes to issues related to the psychology of the worker and to the presence of goods that are complementary to leisure. From $\S 33$ to $\S 42$ he analyses the problem in the context of the firm, because he no longer considers an isolated worker, but many workers in single productive process. The last two sections contain some final considerations. Three appendices follow, respectively on the use of marginal utility curves instead of total curves, on the construction of the curve of the disutility of work when both the duration and the intensity of work are considered and finally on some "doubts" regarding whether the tax may affect the utility curve

In the first point $(\S 1-\S 11)$, Fasiani attempts to show how the traditional approach of Pantaleoni - based on marginal curves of the utility of income and disutility of work effort - can be reconciled with the indifference curves approach used by Black. The fact is that the first approach necessarily implies that the tax increases effort and decreases the net income. By contrast, Black's approach may allow either an increase or a decrease in the productive effort. The 'reconciliation' obtained by Fasiani (in particular, that a lump-sum tax may imply an increases in leisure also in the framework with utility and disutility curves) depends on two assumptions: a) that "considering leisure as an asset with a positive utility is just a different way of considering work as having a negative utility" (p. 154), b) that the marginal utility of income may also be increasing $(\S 7)^{66}$.

\footnotetext{
${ }^{65}$ Pantaleoni, M., Teoria della pressione tributaria, Roma: Pasqualucci, 1887; Robbins, L., On the Easticity of Dmand for Income in Terms of Effort, in Economica, No. 29 pp. 123129, 1930; Black, D., The incidence of income taxes, London : Macmillan, 1939; Hicks, J. The theory of wages, London: Macmillan, 1932, ; Frish, R..

${ }^{66}$ However, according to Black - who is consistent with the neoclassical hypothesis marginal utilities of both income and leisure are both decreasing. Thus, Fasiani's approach remains quite distinct from Black's, and still near to that of Pantaleoni. Moreover, Pantaleoni's approach with marginal curves of utility and disutility is implicitly based on the assumption that the rate wage is normalized to one in order to set on the $\mathrm{x}$-axis both the time of work and the income. Thus, the equilibrium is given by that level of income (or
} 
Then, Fasiani briefly recalls the approach of Robbins ${ }^{67}(\S 10)$ and of Frisch $^{68}(\S 11)$.

After a thorough discussion of the problem $(\S 12-\S 22)$, Fasiani introduces the quality of the work using isoquants between working hours and intensity of work. These isoquants identify the combinations which correspond to a fixed quantity of product (\$23). Then, to that system of isoquants Fasiani overlaps the system of indifference curves that identify combinations with the same level of disutility of work $(\S 24){ }^{69}$. In this way, Fasiani obtains an expansion path regarding production, and to such a path, a curve regarding the disutility of

work) for which it is $U m g_{\text {income }}=-P m g_{\text {work }}$. Fasiani's assumption that leisure is work with negative utility, might be interpreted that he assumes $U m g_{\text {leisure }} \equiv-P m g_{\text {work }}$ and then that the equilibrium is given by $U m g_{\text {leiswre }}=U m g_{\text {income }}$.

In the approach with indifference curves, at the point of equilibrium it is SMS $=w$ , i.e. $U m g_{\text {income }} / U m g_{\text {leisure }}=w$, where $\mathrm{w}$ is the wage rate. For $\mathrm{w}=1$ the same point of equilibrium is identified in both the two approaches, but only on the assumption that the wage rate does not change, that is until it is $w=1$. This fact was already pointed out in Goetz, C., La discriminazione qualitativa dei redditi: riesame di una famosa discussione, in Giornale degli economisti, 1965, pp.763-779.

In order to understand the links between the traditional approach and the one with the indifference curves, I present the following general approach, which consists in addressing the following problem of maximum:

$\operatorname{Max} U(y, r, \ell) ; U_{y} ; U_{r}>0 ; U_{\ell}<0 ; y=$ income; $r=$ leisure; $\ell=$ work; $w=$ wage rate, constrained to $\bar{K}=r+\ell ; \quad w \bar{K}=y+w r$, which leads to the condition of equilibrium $w=\left(U_{r}-U_{\ell}\right) / U_{y} \quad$ or $S M S_{\text {net leisure, income }}=w$. Thus, if work is not painful, it is $U(y, r)$ and the condition reduces to that of Black. Alternatively, if it is zero the utility of leisure, it is $U(y, \ell)$ and the condition coincides with Pantaleoni's one. In point of fact, Black's model boils down to this general model if his utility of leisure is considered as utility of leisure net of the disutility of the corresponding work effort. Note, however, that this utility of leisure (net of work) is negative for the lower level of leisure, and positive for the higher levels of leisure. This depends on the assumptions that disutility increases more than proportionally with the work effort and that utility of leisure increases less than proportionally with leisure. Thus, the corresponding net marginal utility is always positive but decreasing.

${ }^{67}$ See Robbins, L., On the Easticity..., cit.

${ }^{68}$ Frisch, R., New methods of measuring marginal utility, Tübingen : Mohr, 1932.

${ }^{69}$ It appears that Fasiani, accustomed to consider graphs where the negative sign of the disutility is considered only implicitly, draws the indifference curves convex rather than concave, and does not realize that the path of expansion of production is identified by the tangency between isoquants and indifference curves (see his fig. 10). Fasiani draws also some indifference curves that 'end' on isoquants, that are of uncertain meaning (see his fig. 10 a). For a similar construction see [Fasiani 1930]. 
the work corresponds. In $\S 25$ and $\S 26$ Fasiani discusses of "daily paths", which suggests that time plays also a different role, but, perhaps, such paths are only peripheral to the core of Fasiani's reasoning. The curve of disutility of the work is then inserted in the marginal approach of Pantaleoni and the equilibrium is given by equating marginal disutility of effort and marginal utility of income. The difference is that "in the current theory the rising curve of the effort is a thing which one hopes to have a meaning, but for us it has an unequivocal meaning' (p. 179), italics in original.

Moreover, Fasiani introduces the possibility of changing the techniques of production and also the way of working, so that to each technique corresponds a different curve of disutility of effort. Thus, multiple equilibria are possible, including the one that presents the higher utility.

In $\S 31$, Fasiani shows that if one takes into account the cost of the equipment used for working, this fact has an impact on the determination of the maximum net utility. In $\$ 32$ Fasiani is concerned about the psychological effects of taxation, using long quotations from Pantaleoni and Hicks ${ }^{70}$. Besides, he mentions the fact that the tax could change the utility curve of income, referring to his Appendix II.

In $\S 33$ - $\S 37$, he considers a worker within a firm, in which, however, both the amount of work and the corresponding intensity do not affect the other workers: the only consequence is that the entrepreneur sets, for all the workers, the same working time. Here, Fasiani believes that this circumstance leads to a new curve of disutility of labour, higher than the old one. In fact, the worker (who can not change his working time) changes the intensity of his work, so that the equilibrium point is shifted to the left, corresponding to a lower level of income.

In $\S 38$ and $\S 39$ Fasiani considers the problem of the entrepreneur, who must set an equal time of work for all the workers, each of whom would prefer a different time. The solution may be obtained by maximizing the sum of the production of each worker with respect to the time of work, since in each time of work, each worker responds by choosing his own level of intensity, which corresponds

${ }^{70}$ Pantaleoni, Teoria della pressione..., cit; Hicks, The theory of wages, cit. 
to a different quantity of produced goods. In $\S 40$ Fasiani advances some considerations about the effects of a tax, in the remaining $\S 41$ $\S 44$ he further comments about the applicability to the reality of the approach. Finally, Appendix I on the relationship between and total and marginal utility/disutility, seems quite trivial; and Appendix II on the curve of disutility does not seem straightforward. Appendix III regards the fact that the tax changes the utility, and raises questions regarding the utility of goods that are complementary to leisure.

\section{Fiscal illusions.}

Fasiani had devoted to illustrating and developing the original $\mathrm{Pu}-$ viani's idea of fiscal illusion: i) the 1929 essay "Some notes on an aspect of the theory of fiscal illusion", ii) 14 pages of his exposition of the Italian tradition in public finance ${ }^{71}$ (Fasiani 1932-33), iii) 110 pages of his Manual (Fasiani 1941). As regards specifically the Manual, it is possible here only to note that he was able to use the concept of fiscal illusion, together with some Paretian sociological notions, to build a viable framework for his economic analysis of public finance.

Here, the reference is only to Fasiani's first essay regarding fiscal illusions, i.e.: Riflessioni su di un punto della teoria dell'illusione finanziaria (1929), which was translated into English in $1998^{72}$. In that occasion, fiscal illusion was used for discussing the double taxation of savings, and the short and long run. The initial assumption is that a specific category of Puviani's fiscal illusions ${ }^{73}$, i.e. the illusion due to the painful sensation, may be construed as an implementation of Marshallian consumer's surplus ${ }^{74}$. In fact, the consumer's surplus increases when the price of goods decreases, and can be used "for the purchase of a larger quantity of the same good or for the purchase of certain quantities of different goods" (Fasiani, 1929a, p.335). Thus,

\footnotetext{
${ }^{71}$ See below, $\S 8$.

${ }^{72}$ Fasiani, M. Some notes on an aspect of the theory of fiscal illusion, in Pasinetti, L (Ed.). Italian Economic Papers, Il Mulino/Oxford University Press, 1998, vol. III, pp.89-97.

${ }^{73}$ Puviani, A., Teoria della illusione finanziaria, Palermo: Remo Sandron Edit., 1903.

${ }^{74}$ Marshall, A., Principles of economics, Edition 4,1898; Cannan, E., "Total Utility" and “Consumer's surplus", in Economica, No.10 pp.21-26, 1924.
} 
the surplus increases even in case that, at a certain moment, the consumer is willing to pay a higher price for a certain asset, which is exactly what fiscal illusion does.

Fasiani assumes that the demand curve is not known. However, knowing the quantity purchased and the change in the price, one can get some information about the surplus ${ }^{75}$. The problem is that, in general, the comparison of the utility of the subject is done in different moments of time, so that the evaluation in different times may be different.

To overcome this difficulty, Fasiani considers two groups of goods, the first of which is somehow "predetermined" in so far as it corresponds to the standard consumption related to the social group to which the consumer belongs. By contrast, he second group of consumes should be rather casual: in these conditions, one can assume that the elasticity of demand in the first group is rigid, while in the second group is elastic ${ }^{76}$. Thus, Fasiani analyzes the change in the consumer's surplus with respect to changes in prices both for the elastic goods and the inelastic goods, in the cases that the consumer's income remains constant or changes. In the latter case Fasiani distinguishes the short from the long run.

The conclusions are that when the income does not change, a change in price of goods in the first group increases the consumer surplus, while the same can not be said for the goods of the second group. If the income increases, the conclusions are the same, at least after a sufficiently long period of time. However, with the passage of time, the surplus tends to disappear.

According to Fasiani, these conclusions imply that the burden of a hail-tax may be considerably different, depending on the moment at

\footnotetext{
75 The example of Fasiani is: we know that an individual acquires the amount $\mathrm{A}$ at price of 14 and that, by raising the price to 20 , he will consume the amount $\mathrm{B}<\mathrm{A}$. Thus, since A-B $=\mathrm{C}$ we can say: $\mathrm{i}$ ) that at price 14 the consumer would enjoy a surplus of at least $£ 6$ for the quantity $\mathrm{A}$, ii) for the quantity $\mathrm{C}$, he enjoys a surplus between $£ 6$ and 0 .

76 This classification is inspired by Angell, J,W. Consumers' demand, in The Quarterly Journal of Economics, Vol. 39, No. 4, 1925.

${ }^{77}$ Menger's utility tables assume that the prices of all goods are normalized to one. Regarding the choice between present consumption and future consumption, Menger's tables may seem methodologically outdated as compared with an analysis by indifference curves. However, since the argument concerns the decrease in the utility of future good, at that time the approach with indifference curves might have seemed less immediate.
} 
which the tax is introduced. If this occurs immediately after the reduction of the price of the goods of the first group, the burden will be smaller, because the corresponding consumer's surplus is different. In addition, the occurrence of the consumer surplus can push the subject to increase the demand for public goods, which ends with the consolidation and may possibly lead to a negative illusion.

Finally, Fasiani suggests that the illusion described by Puviani "essentially represents a variation in the relative utility of present and future goods, which has the ultimate effect of lowering the level of marginal utility of income at a given moment" (p.341, emphasis in original). In this interpretation, monetary income and commodity prices remain unchanged but the "spending ability" (this is the original expression of Puviani) changes. Using two Menger's utility tables $^{77}$, Fasiani shows that the consumer tends to reach an equilibrium where the amount of the present goods has increased to the detriment of the quantity of future goods. Therefore, the decrease in marginal utility of income implies that a tax applied at that time would have less burden, causing a minor sacrifice. Thus, Einaudi's theory seems therefore confirmed, that it is likely that the state will tax more heavily consumption than savings.

\section{The double taxation of savings.}

As regards the Italian tradition, the theorem of the double taxation of savings was endorsed by L. Einaudi in 1912 and was the object of heated debate among Italian scholars ${ }^{78}$. Fasiani had participated in the debate with the three main works here reported: On the theory of tax exemption of savings (1926), On the double taxation of savings (1928a) and the review article on Irving Fisher's experience (1928b). Then, he revisited the problem by proposing an original reading of the double taxation problem in Fasiani (1936) (see above, §2.2). Finally, in a specific appendix of (Fasiani 1941), he partially rectified his opinion and acknowledged that no double taxation occurs, albeit

\footnotetext{
${ }^{78}$ For a modern discussion of this topic, see: Fossati, A., The double taxation of savings: the Italian debate revisited, Forthcoming in History of Political Economy, spring 2013 issue (vol. 44, no. 1)
} 
only under the strict assumption that the state is a factor of production. This opened a dispute with Einaudi (see below, §9).

The first essay: Sulla teoria dell'esenzione del risparmio dall'imposta (On the theory of tax exemption of savings) (1926) is the first work ever written by Fasiani ${ }^{79}$. It is dedicated to the topic of the double taxation of savings so dear to Einaudi ${ }^{80}$. In summary, according to Fasiani, the history of the double taxation of savings can be broken down as follows: a) as a postulate Mill ${ }^{81}$ had said that by taxing earned income, the income saved is taxed more than consumed income because the flow of fruits on savings will be subject to further taxation. Therefore, the hearth of the Millian problem was a matter of justice; b) for Fisher ${ }^{82}$ the problem was to prove the Millian postulate (see the distinction between flows and stocks by Borgatta, below); c) given the Millian assumption, for Einaudi the point is that state express a growing tendency to exempt savings from taxation, even unconsciously. Fasiani's essay is designed to strengthen the position as expressed above by Einaudi.

In the Introduction, Fasiani assumes at first the hedonic approach. Thus, there is a tendency to disrtibute the cost of public services so to equalize the marginal cost to the marginal benefit that each individual takes from public services. In this situation, if the savings are doubly hit by taxation, it is clear that there would be a contradiction with the hypothesis assumed for the allocation of costs of the public services. Thus, the tendency to restore the proper distribution would lead to correct this situation. For this reason, according to Fasiani, the state, openly or unconsciously, de facto acts as if it wanted exempting savings from taxation.

\footnotetext{
${ }^{79}$ Still, among Fasiani's books which are deposited in the Library of the Bocconi University, I have found a Fasiani's manuscript concerning the payments of war indemnities dated 1924, which possibly might be the thesis with which he graduated in 1924 at the University of Turin that, as far as I know, has been never published. However, Bresso states that the thesis was on the double taxation of savings: P.Bresso, Il Laboratorio di Economia politica negli anni della direzione di Achille Loria (1903-1932), in "Il pensiero economico italiano", XII, 2004.

${ }^{80}$ Einaudi, L., Intorno al concetto di reddito imponibile e di un sistema d'imposta sul reddito consumato, Torino, Bona, 1912.

81 Mill, John Stuart (1848), Principles of Political Economy, London: Longmans, Green\&co.

${ }^{82}$ Fisher, Irving, The nature of capital and income, New York: Macmillan, 1906
} 
After recalling some basic premises, the first part of the essay is devoted to show that taxation of earned income implies a double taxation on savings and a greater sacrifice for savings, and to rebutting the criticisms both "of the new wealth" and of "utility". The first criticism refers to the fact that some opponents of the double taxation of savings (in particular, Ricci ${ }^{83}$ ) argue that the fruits of savings are new incomes, produced in a different production cycle. Fasiani, by contrast, drawing on Borgatta ${ }^{84}$, considers that capital is a stock that corresponds exactly to a perpetual flow of income determined by the rate of interest. Thus, stocks and flows are two different aspects of the same economic reality. Savings are taxed firstly because they are part of the earned income, and secondly because they will be taxed further as fruits of the increase in capital, that correspond to the savings. This reasoning is illustrated by numerical examples and graphs taken from Fischer and Borgatta.

The second criticism is based on considering that savings have a utility of their own, distinct from that of the consumer goods. Fasiani is particularly critical of the position of Graziani ${ }^{85}$, according to which the fact that "lawmakers are moving away from the general principle of earned income" depends on the fact that they believe that the marginal utility of a perpetual income is a different thing from that of a temporary income. This claim is rebutted by Fasiani, who notes that the claim is based on the implicit assumption that the utility of saving is an entity different, from the utility of the fruits of savings. That statement is certainly false if we assume (with Borgatta) that the rate of interest determines the level of savings. However, Fasiani notes that the investor can have savings even in the case in which the rate of interest is equal to zero: in this case, the interests (the fruit of savings) would represent a net revenue (the postponer's rent of Gonner ${ }^{86}$ ) which could be taxed, justifying the double taxation of savings as a result of this increase in utility,

\footnotetext{
${ }^{83}$ Ricci, Umberto, Che cosa è il reddito?, in "Giornale degli economisti e rivista di statistica”, August 1913, pp.93. Ricci, Umberto, L'imposta unica sui consumi non necessari, in "Giornale degli economisti e rivista di statistica", October 1913, pp.293.

${ }^{84}$ Borgatta, Gino, Contributo critico alla teoria finanziaria, in "Atti della R. Accademia delle Scienze di Torino", vol.48, 1912-13

${ }^{85}$ Graziani,A.: Istituzioni di scienza delle finanze, Torino: Bocca, 1897.

${ }^{86}$ Gonner, E.C., Interest and savings, London: Macmillan, 1096.
} 
coming from savings. In principle, however, it would overlap with the compensation for risk, and anyway, we can assume that such a phenomenon has a very limited practical importance.

The second part of the essay is devoted first of all $(\S 20-\S 33)$ to showing that "at least as a tendency, the phenomenon of tax is based on the law of value" (p.2) and, secondly, to illustrate graphically the double taxation of savings ( $\$ 34)$. On the first point, Fasiani argues that the explanation of the phenomenon was attempted by two streams of thought: the economic ${ }^{87}$ and the political one ${ }^{88}$. After observing that both streams are based on the principle of the minimum means, it is argued that the economic rationale is that both politics and economics help to explain the reality, so that it should be irrelevant to start from the economic explanation and then to introducing the political element, or vice versa. In fact, having: "a close look, at the difference between the 'political' and the 'economic' approaches, the difference is in method rather than substance" (p.24, emphasis in original).

It is assumed that public goods are "all the goods that are produced at a given time by the State and the cost of which is distributed with taxing" (p.25, emphasis in original). Public goods may be either indivisible or not, and their unities are normalized so that all prices are set equal to one. It is assumed that all individual incomes are

\footnotetext{
${ }^{87}$ E.Sax, La teoria della valutazione dell'imposta, in Giornale degli economisti, May 1924, pp.276-312; De Viti de Marco, Il carattere teorico dell'economia finanziaria, Roma: Pasqualucci, 1888; Mazzola, U. I dati scientifici della Finanza pubblica. Roma: Loescher, (1890); . Pantaleoni, Maffeo Contributo alla teoria della distribuzione della spesa pubblica, in La rassegna italiana, 1883 Oct: 25-70; Graziani, Augusto (1897). Istituzioni di Scienza delle Finanze. Torino: Utet.; Ricca Salerno, G. Nuove dottrine sistematiche nella Scienza delle Finanze, in Giornale degli economisti, 1887. July-Aug., pp.375-402; Montemartini, Giovanni (1902). Municipalizzazione dei pubblici servizii, Milano: Societa editrice libraria; ,Einaudi, L., Corso di Scienza delle Finanze; Torino: Tip. E. Bono, 1914; Wicksell, K., Finanztheoretische Untersuchungen, Jena, 1896 1896; Lindahl, E., Die Gerechtigkeit der Besteuerung, Lund: Gleerup, 1919.

${ }^{88}$ Loria, A. Le basi economiche della costituzione sociale, Torino: Bocca, 1902; Conigliani, C., (1894). L'indirizzo teorico nella scienza finanziaria, in Giornale degli

Economisti, 1894, pp.105-29; Tangorra, Trattato di Scienza delle Finanze, Milano: Edit.Libraia, 1897; Sensini, G., Lo studio scientifico dei fenomeni finaziari, in "Rivista italiana di sociologia", 1917, pp.86-97; Labriola, A., Finanza ed economia, Napoli: Morano, 1924; Borgatta, G., Contributo critico alla teoria finanziaria, in Atti della R. Accademia delle scienze di Torino, vol. 48, 1912-13; Murray, R. Della soddisfazione dei pubblici bisogni, in Rivista italiana di sociologia, 1914, December; Lolini, La nozione dei così detti 'bisogni pubblici', in Giornale degli economisti, 1919, February, pp.189 ff.
} 
equal, and also that all the individuals have the same utility function, at least in a first approximation. In a graph where the $\mathrm{x}$-axis reports the quantity of goods (private and public), and the y-axis the correspondent marginal utilities, Fasiani shows that, according to the "economic" theory, the individual equilibrium point is given by those quantities for which marginal utilities of the two goods are equal. On the horizontal axis of the graph, by construction, individual income is the sum of the tax that he is willing to pay and the amount of the private $^{89}$.

When considering the political element we are confronted with the presence of coercion. Thus, when considering the monetary cost of coercion, we realize that the equilibrium departs from the previous ideal (efficient) equilibrium. In fact, if an individual is able to let the other pay a larger fraction of the cost of public goods, he gets a rent which is, however, lower than the loss inflicted to the other individual. At this point Fasiani generalizes, assuming that the utility of the two subjects is different as regards the public goods, but this may raise some concerns ${ }^{90}$. Finally, in $\$ 34$ Fasiani considers two individuals with the same level of income but qualitatively different, so that one of them shall dedicate a portion of his income to savings and therefore cannot consume like the other individual. In Fasiani's graph, under the assumption that the utilities are equal for both individuals and that utilities are separable, this case is represented simply by a lesser amount of income for the person who must save. In this way, while the same downward curve represents the marginal utility of the private goods for the two individuals, only for the saver the rising curve of marginal utility of public goods is shifted to the left. As a result, for the saver the equilibrium is identified by a lower

\footnotetext{
${ }^{89}$ The units of both the public and the private goods are normalized in order that both prices are set equal to one for both goods. Thus, the unit in the abscissa corresponds to a unit both of income and of each goods. The individual is in equilibrium where the marginal utilities of the two goods are equal. This implies utility both additive and separable, and actually does not rise objections if the public goods is rival in consumption, as indeed is considered by Fasiani (e.g. p.28). Therefore, when the public goods are indivisible it must be assumed that if the utility of the subjects is different, even the units of public goods are different, which means that the graph cannot be generalized.

${ }^{90}$ As stated above, the utility functions must be additive. However, in case public goods are indivisible (Samuelsonian), the assumption of different utility functions for each individual implies different individual prices, which in Fasiani's graph leads to different units of measure for the public goods regarding the two individuals.
} 
quantity both of private and public goods, than that of the other individual and, therefore, by a lower level of utility. Fasiani identifies this loss of utility (between the two equilibrium points) as the "fact highlighted by Graziani" (p.36). Then, he identifies an additional loss of utility for the saver in case he had to pay a "tax" equal to that of the other individual ${ }^{91}$.

In the second essay: Sulla doppia tassazione del risparmio (On the double taxation of savings) (1928a) it is once again discussed the statement of Mill-Fisher-Einaudi regarding the double taxation of saving. Specific object of the present paper is the criticism to Ricci ${ }^{92}$ who asserts that the statement of Fisher-Mill-Einaudi gives rise to two distinct problems. The first one is whether it is right to taxing savings. The second problem is to find out whether it is really true that savings is taxed twice when the tax base is the earned income. The first problem is quickly set aside by noting that it depends on the concept of justice assumed and that it has no bearing on the theory of Einaudi in any case. The second problem is dealt with, by reporting Ricci's argument which consists of a numerical example where the pre-tax interest rate (i.e. gross of the tax) is distinguished from the rate net of tax. These interest rates are used to shift from the new capital (the savings), to the evaluation of the corresponding flow of future incomes. In particular, the flow of income (gross of the tax that will hit in the future), valued at the pre-tax interest rate, tautologically coincides with the value of savings (new capital). Net of the $\operatorname{tax}^{93}$, the flow of future income (valued at the after-tax interest rate) provides the same identical value of the savings.

According to Ricci, this implies that taxing the fruits of savings does not imply a double taxation.

However, the (net) interest rate is decreased by effect of the tax. Therefore, Ricci believes that this fact induces a lower level of savings, and this will lead to a new equilibrium with a gross interest rate

91 Fasiani's reasoning is rather ruffled, because he follows Graziani in his ambiguous concept of relative utility. However, given his assumptions, it seems correct.

92 Ricci, Umberto (1927), La taxation de l'épargne, in "Revue d'économie politique", May-June, pp.860.

${ }_{93}$ In the case that the tax is a general one. 
higher than before. Then, the net interest rate increases, but still the new rate of interest is lower that the rate before the tax and in that case the value of the old capitals goes down, while the value of the new capitals goes up.

Fasiani's criticism consists in noting that Ricci changes the original Einaudi's assumption of constancy in the interest rate, which could really increase or decrease. According to the approach of Einaudi, if the state uses well the tax revenue, then the interest rate decreases, while if it is badly spent the interest rate increases. If the utility of public expenditure is equal to that of the replaced private expenditure, the interest rate remains constant. In order to show that this does not affect Einaudi's standpoint, Fasiani examines the three possible cases that he considers most likely: i) the interest rate remains constant, ii) its decrease is less than proportionally to the tax change and iii) its decrease is in proportion to the tax ${ }^{94}$. First of all, he concludes that, in principle, changes in the interest rate do not involve a refutation of the theory of Einaudi, nor any limitations in its applicability ${ }^{95}$. Secondly, the reduction in the interest rate is only one of the possible hypotheses. Finally, regardless of the capitalization or shifting of the tax, the double taxation is still present, both for the new and the old capitals. To that end it is immaterial that the interest rate remains

\footnotetext{
${ }^{94}$ Ricci had assumed that the rate of interest increases due to the decrease in gross savings. Fasiani talks of reductions in the rate of interest. The fact is that Fasiani rejects the formal separation between the gross and the net interest rate, and consequently his "reduction" coincides with what Ricci considers as an "increase" in the interest rate. In essence, the diminution in the interest rate to which Fasiani refers to corresponds to the "net rate" of Ricci. This is quite clear in the following Table 3.1 which shows the three cases of Fasiani, using his original numerical values. In the first case, Fasiani states that the rate remains constant at $5 \%$, in the second case that the rate decreases to $4.75 \%$ and that in third case that the rate decreases to $4.50 \%$.

In discussing the first case, Fasiani concludes that "Einaudi's theory is fully confirmed" (p.134). In the second case: "the phenomenon considered by Einaudi occurs at least in part" (p.135, emphasis in original). In the third case: "It therefore seems that ... Einaudi's theory does not apply" (p.135). However, for the second case he adds: "but neither is it true that double taxation occurs only in the cases, above mentioned, of partial capitalization and shifting of the tax". Then, he refers to the treatment of the third case. About the third case, Fasiani devotes two and a half pages (pp.136-138) to show the existence of double taxation for the cases where the tax is not capitalized or shifted. In this way, the final conclusions are: "the double taxation of savings still exists ... both in case the interest rate as a result of the tax remains constant, and in the cases in which it decreases in proportion to the amount of tax, or less than proportionally to the tax" (p.140).
} 
constant, decreases less than proportionally to the amount of tax, or decreases in proportion to the tax.

This paper has been criticized extensively by Fubini ${ }^{96}$. A first criticism (Fubini 1928, p.484 note) is the assertion that in the first case of Fasiani (constant interest), even the old capital could shift the tax. Secondly, (Fubini 1928, p.486-7) acknowledges that Ricci changes the rate of interest, but denies that Einaudi might have assumed the constancy of the interest rate as stated by Fasiani. According to Fubini, although Einaudi has always thought in terms of constant interest, but this was a mere expedient, and not

The third criticism (Fubini, 1928, p.486-7) is that - according to him - Fasiani says that: i) the double taxation increases, with the increase in the interest rate, ii) if interest rate lowers less than proportionally to the amount of the tax the phenomenon occurs in part (p.487). According to Fubini, this depends on the fact that Fasiani evaluates the capital "without regard to the burden that the tax has imposed on it. If Fasiani had taken account of this fact, he would easily have realized that to an increase or decrease in the value of the future annual tax, would correspond to an increase or decrease in the overall capital values"(p.487). Nonetheless, he admits that Fasiani somehow is not wrong. In Fubini's words: "I can not but agree with these arguments" (p.488), but then says: "I think that the mistake of Fasiani comes from wanting to think at all costs in terms of terms of trade" (p.488).

\footnotetext{
${ }^{96}$ Fubini, R.: Sulla tassazione del risparmio, in Giornale degli economisti e rivista di statistica, 1928, serie IV, pp.480-493;Fubini, R., Di alcuni problemi finanziari parzialmente analoghi al problema della tassazione del risparmio, in "Archivio scientifico del R.I.S. di Scienze economiche e commerciali di Bari, 1931-32, pp.21-43; Fubini, R.: Contributo allo studio degli effetti dell'imposta generale sul reddito, in Giornale degli economisti e rivista di statistica, giugno 1932, pp.365-404.
} 
Tab.3: Fasiani's three case: $£ 5,000-10 \%$ tax $=£ 4,500$ new savings

\begin{tabular}{|c|c|c|c|c|c|c|c|c|}
\hline \multicolumn{3}{|c|}{ 1st case: constant interest rate } & \multicolumn{3}{|c|}{$\begin{array}{l}\text { 2nd case: less than proportional de- } \\
\text { crease }\end{array}$} & \multicolumn{3}{|c|}{$\begin{array}{l}\text { 3rd case: decrease proportional to the } \\
\text { tax }\end{array}$} \\
\hline Annuity & \multicolumn{2}{|c|}{ Interest rate } & \multicolumn{3}{|c|}{$\begin{aligned} & \begin{array}{r}\text { an- } \\
\text { nuity }\end{array} \text { interest rate } \\
&\end{aligned}$} & annuity & \multicolumn{2}{|c|}{ interest rate } \\
\hline 250.00 & 0.0556 & Gross & 237.50 & 0.0528 & Gross & 225 & 0.0500 & Gross \\
\hline 225.00 & 0.0500 & Net & 213.75 & 0.0475 & Net & 202 & 0.0450 & Net \\
\hline $\begin{array}{r}4.500, \\
0\end{array}$ & \multicolumn{2}{|c|}{ capital value (gross rate) } & $\begin{array}{r}4.500 \\
0\end{array}$ & \multicolumn{2}{|c|}{ capital value (gross rate) } & $\begin{array}{r}4.5 \\
00,0\end{array}$ & \multicolumn{2}{|l|}{ capital value (gross rate) } \\
\hline $\begin{array}{r}4.500, \\
0\end{array}$ & \multicolumn{2}{|c|}{ capital value (net rate) } & $\begin{array}{r}4.500, \\
0\end{array}$ & \multicolumn{2}{|c|}{ capital value (net rate) } & $\begin{array}{r}4.5 \\
00,0\end{array}$ & \multicolumn{2}{|l|}{ capital value (net rate) } \\
\hline 25,0 & \multicolumn{2}{|c|}{ annual tax $=10 \%$ gross annuity } & 23,75 & \multicolumn{2}{|c|}{ annual tax $=10 \%$ gross annuity } & $\begin{array}{l}22, \\
50\end{array}$ & \multicolumn{2}{|c|}{ annual tax $=10 \%$ gross annuity } \\
\hline 25,0 & \multicolumn{2}{|c|}{ tax shifted on the borrowers } & 12,5 & \multicolumn{2}{|c|}{ tax shifted on the borrowers } & $\begin{array}{r}0,0 \\
0\end{array}$ & \multicolumn{2}{|c|}{ tax shifted on the borrowers } \\
\hline 450,0 & \multicolumn{2}{|c|}{$\begin{array}{l}\text { present value of the tax (gross } \\
\text { rate) }\end{array}$} & 450,0 & \multicolumn{2}{|c|}{$\begin{array}{l}\text { present value of the tax (gross } \\
\text { rate) }\end{array}$} & $\begin{array}{r}450 \\
, 00\end{array}$ & \multicolumn{2}{|c|}{ present value of the tax (gross rate) } \\
\hline 500,0 & \multicolumn{2}{|c|}{ present value of the tax (net rate) } & 500,0 & \multicolumn{2}{|c|}{$\begin{array}{l}\text { present value of the tax (net } \\
\text { rate) }\end{array}$} & $\begin{array}{r}500 \\
, 00\end{array}$ & \multicolumn{2}{|c|}{ present value of the tax (net rate) } \\
\hline
\end{tabular}


A further criticism is that according to Fubini the problem "only concerns the taxation of savings for self" (p.489, footnote 2). On the contrary, Fubini thinks that Fasiani is considering as an assumption the fact that firstly savings are taxed and then the fruits of savings are taxed in a second time. This criticism, however, seems purely formal.

The same criticisms are repeated in (Fubini 1932) ${ }^{97}$. In this paper, Fubini shows a singular fury against Fasiani and also adds other criticisms related to (Fasiani 1931a) and a charge of plagiarism. Specifically, Fubini states that Fasiani plagiarized Borgatta first and then Murray ${ }^{98}$. While it is true that Fasiani built on Borgatta, it is untrue that he had plagiarized him.

However, Fasiani had had nothing to do with Murray's work: the comparison between the texts of Murray and Fasiani shows that plagiarism is completely absent.

Fasiani's reply was very detached and self-controlled. He had simply noted that "for the purpose of personal controversy Fubini ascribes to me some statements that I have never done and certain contradictions that really I do not think I had fallen into" (Fasiani 1936, p.95, footnote $)^{99}$.

In the review article to Fischer's The income concept in the light of experience (1928b), Fasiani complains that Fisher had completely ignored the abundant Italian literature on the double taxation ${ }^{100}$, which Fasiani encloses in his review. Indeed, that literature is impressive: it occupies a page and a half, i.e. half the space occupied by the whole review article. Beside that, Fasiani presents in detail a Fisher's reasoning made "more effective, using a hypothesis which

\footnotetext{
${ }^{97}$ See Fasiani (1928a, pp.381-384).

${ }^{98}$ Murray: Principi fondamentali di Scienza pura delle finanze, Firenze, La voce, 1914, specifically, see pp.262 and following.

99 On the other hand, as I have reported above in $\$ 2.3$, Fasiani (1931-32) contains an important criticism of a work of Fubini, even if conducted with great serenity. I also recall that in the autumn of 1932 a competition was going on regarding the university chair of Messina, which ended with Fasiani winner with five votes and only the second with three votes Fubini.

100 The same complaints appears in the first lines of his essay on the history of the Italian tradition in public finance (Fasiani 1932-33).
} 
Tab. 3.2 - The Fisher-Fasiani numerical example revisited: tax rate 0.10 ; interest rate 0.05

\begin{tabular}{|c|c|c|c|c|c|c|c|c|c|c|}
\hline Time & 1 & 2 & 3 & 4 & 5 & 6 & 7 & 8 & 9 & 10 \\
\hline Tax rate & & 0,10 & & & & & & & & \\
\hline Interest rate & & 0,05 & & & & & & & & \\
\hline Capital & 4.000 & 4.000 & 4.000 & 4.000 & 4.000 & 4.150 & 4.000 & 4.000 & 4.000 & 4.000 \\
\hline Income & 200 & 200 & 200 & 200 & 200 & 207,5 & 200 & 200 & 192,5 & 200 \\
\hline Savings & & & & & 150 & -150 & & -150 & 150 & \\
\hline Taxable income & 200 & 200 & 200 & 200 & 50 & 357,5 & 200 & 350 & 42,5 & 200 \\
\hline Tax on consumption & 20 & 20 & 20 & 20 & 5 & 35,75 & 20 & 35 & 4,25 & 20 \\
\hline Income tax & 20 & 20 & 20 & 20 & 20 & 20,75 & 20 & 20 & 19,25 & 20 \\
\hline \multicolumn{5}{|c|}{ consumption with the consumption tax } & 45 & 321,75 & & 315 & 38,25 & \\
\hline \multicolumn{5}{|c|}{ consumption with the income tax } & 30 & 336,75 & & 330 & 23,25 & \\
\hline \multicolumn{5}{|c|}{ final value of the consumption tax time $5 \& 6$ or $8 \& 9$} & 0 & 41 & & $\mathbf{0}$ & 41 & \\
\hline \multicolumn{5}{|c|}{ Final value of the income tax time $5 \& 6$ or $8 \& 9$} & 0 & 41,75 & & $\mathbf{0}$ & 40,25 & \\
\hline \multicolumn{5}{|c|}{$\Delta \operatorname{tax}$} & & 0,75 & & & $-0,75$ & \\
\hline \multicolumn{5}{|l|}{$\Delta$ Income } & & 7,5 & & & $-7,5$ & \\
\hline \multicolumn{5}{|c|}{ Final value of consumption at time $5 \& 6$ or $8 \& 9$} & & 369 & & & 369 & \\
\hline \multicolumn{5}{|c|}{ Final value of income at a time $5 \& 6$ or $8 \& 9$} & & 368,25 & & & 369,75 & \\
\hline
\end{tabular}


Fisher mentions in passing" (p.293), which consists of a numerical example.

This numerical example is here worked out in the table 3.2, where columns labeled "time 5" and "time 6" correspond to Fasiani's original example. From that we can see that the income tax gives a higher tax-income than the corresponding tax on consumption. Really, by taxing the earned income, the savings used to postpone consumption are doubly taxed.

However, I think it interesting to note that it is possible to reverse the Fisher-Fasiani argument. In fact, I have assumed in the columns referred to as "time 8" and "time 9" of the table, that savings are not made in order to postpone consumption, but to anticipate it. Then, it appears that the tax on consumption has a tax revenue higher than the income tax. Thus, my reasoning boils down to the fact that savings are taxed twice over only if savings are used to postpone consumption. Conversely, if savings are used to anticipate consumption, the income tax gives a lower tax income than the tax on consumption, and savings are favored.

In Fasiani (1941), the double taxation problem was revisited in a specific appendix ${ }^{101}$, in which a synthesis of the discussion was offered. On that occasion, however, De Viti's thoughts are presented in a new light. In fact, Fasiani had revised his previous opinion and had acknowledged that there is no double taxation of savings, albeit only under the strict Devitian assumption that the state is a factor of production.

In fact, De Viti ${ }^{102}$ had assumed that public services are goods that necessarily enter in all the productive processes regarding the final goods that compose the real income, i.e. public services are true productive factors. Thus, every unit of produced income cannot but contain its share of the cost of public services jointly with the cost of the other factors of production such as labour or land. Taxation is the

\footnotetext{
${ }^{101}$ Appendix VII, Sul problema della doppia tassazione del risparmio, (Fasiani, 1941, pp. 275-304).

${ }^{102}$ De Viti de Marco, A., I primi principî dell'economia finanziaria, Roma: Sampaolesi. 1934. English translation as First Principles of Public Finances, London-New York: Jonathan Cape-Harcourt Brace \& Co., 1936.
} 
counterpart of the cost of public services in the same way as the salary is the counterpart of labour.

Fasiani had fully endorsed De Viti's point that, on the assumption that new public services are necessary to the productive processes, no double taxation occurs because the new tax is the counterpart of new public services (Fasiani, 1941, p. 294-296). On the contrary, when public services are not considered a factor of production, the allocation between consumption and savings becomes of crucial importance. In this case, taxing savings is taxing income twice (Fasiani, 1941, p. 299). Thus, the conclusion on the double taxation problem depends strictly on the assumption of whether public services are factors of production. However, Fasiani has rejected the idea that the state may be considered a factor of production, and then he has maintained his previous conclusion that saving is doubly taxed if the tax base is the earned income.

\section{Business cycles}

Fasiani analyzed business cycle control in a dynamic economy mainly in the three essays: Business cycles and the corporative economy (1935); Economic crises: general principles and possible policies to secure control (1937) and Potential labour force and the money (1942). ). In all these essays are contained suggestions regarding the regulated economies and hints concerning specifically the corporative economy, but the prominent interest of Fasiani is the business cycle and the correlated unemployment. For this reason it seemed appropriate to treat these essays jointly under the heading of business cycles instead of in the next section, which regards the corporative economy.

In the first of those essays: Fluttuazioni economiche ed economia corporativa (Business cycles and the corporative economy) (1935) Fasiani had considered the corporative economy as a regulated economy within the neoclassical paradigm. In fact, he started discussing methodological problems and quoted a long sentence from Pareto. He claimed to use the deductive method, as one among the many possible, in order to analyze the specific problem of business cycles. 
About this issue, Fasiani notes that his contribution is couched in neoclassical economics but could possibly be a fragment of a "general and systematic theory of corporative economy" at that times still premature.

Basing on the work of Del Vecchio and Fanno ${ }^{103}$, Fasiani devotes the second part to framing the theory of business cycle in the study of the transformations of capitalist economic systems. To begin with, Fasiani rejects the traditional view that crises constitute a pathological condition compared to normal economic system, as we read in Ferrara. On the contrary, Fasiani thinks with Del Vecchio that this: "is a special case, perhaps the most important, of the general case of the study of changes in the economic system" (p. 10). He accepts that "the fluctuations are an outgrowth of the development trends" and he can not help but "to note that trends are in turn influenced by fluctuations" (p.11). Therefore, on the economic systems, the point of view shared by Fasiani is that if you leave an equilibrium after an initial external shock there is no chance that the variables may compose again a static progressive equilibrium: "owing both to relations of interdependence that links all the variables and to the different speed of their changes" (p.13).

It follows that the forces freely operating in the capitalist system are causing oscillating trends. Thus, the study of trends is not possible regardless of fluctuations and fluctuations can not be considered deviations from the normal development of the capitalist economy (p. 14). Indeed, the fluctuations "are the main phenomenon of the normal system. However, this necessarily implies that the liberal capitalist system" contains within itself its own negation" (p.18, last line). This is the idea of the most influential authors, such as J.M Clark $^{104}$ and J.A. Hobson ${ }^{105}$, which can be summarized in the propositions: a) "that the forces freely operating in a capitalist society usually lead to oscillating trends", b) "that oscillating trends determine the spontaneous creation of specific institutions and private

\footnotetext{
${ }^{103}$ Del Vecchio: Le crisi e le teorie economiche, in C.Arena (Ed.), Storia delle teorie, Nuova Collana degli economisti, vol. 1, Torino: Utet, 1932; Fanno, Marco: Cicli di produzione, cicli di credito e fluttuazioni industriali, in Giornale degli economisti, 1931, pp.139.

${ }^{104}$ Clark, J. M.: Studies in the economics of overhead costs, Chicago : University of Chicago press, 1929.

${ }^{105}$ Hobson, J.A., The economics of employment, London: Allen \& Unwin, 1922.
} 
organizations, that are the negation of the system in which they arise". This implies that fluctuations lead to the end of market competition, as stated by J.M. Keynes ${ }^{106}$.

Thus, public intervention is essential to overcome "the normal economic disharmony" and that market competition can not but end up in the "regulated economy" (p.25). As for the corporative economy, it can be said: 1) it "does not aim to change a static equilibrium in a static society, but to address the problems of dynamic imbalances, 2) it is not only a regulated economy or a remedy to business cycles, "but it pursues goals far more extensive." The corporative economy pursues purposes that go far beyond "the problems that usually has been dealt with in the economic theory", but the fact remains that the control of the business cycle is one of the responsibilities of the corporative economy and can therefore be framed in it. In this way, Fasiani can fit the study of business cycles as a fragment of a study of corporate economic systems, still remaining well inside the neoclassical economic theory.

In the third part, the starting point is the observation that the business cycles depend on arrhythmias of the economic system, which in turn are caused by the speed with which the different elements of the system are moving, that prices are not able to harmonize. The traditional response is to not interfere with the role of prices, except for the regulation of credit. The "communist experiment" replaces the price mechanism with other instruments, while the "third way" is to combine the price mechanism with "other forces" and this can only be the path that corporative economy is expected to follow. Fasiani's proposal is to intervene on "industrial changes" (p.28), drawing on the work of $\mathrm{Masci}^{107}$. It is shown that the business cycles may arise from external shocks (e.g. increased demand for final goods) that induce movements of technical capital among possible alternative uses, which in turn lead to changes in prices. This leads to the production of new machines (technical capital), which switch on when the actual increase in demand is already satisfied, which decreases "the produc-

\footnotetext{
106 The reference is to: J. M. Keynes, The end of laissez-faire, London, L. \& Virginia Woolf, 1927.

${ }^{107}$ Masci, Guglielmo: Alcuni aspetti odierni dell'organizzazione e trasformazioni industriali in G.Masci (Ed.), Organizzazione industriale, Nuova Collana degli economisti, vol. VII, Torino: Utet, 1934.
} 
tion in the hope of raising prices, with the result to further reduce the demands. So the downturn of the cycle begins"(p.40).

Thus, the real problem is the distribution of economic activity over time. Such a problem may be addressed by government policies that interfere with the expansion in time of demand and production facilities. Public intervention can actually use the credit control through the operation of the discount rate, but it could use other tools as well, i.e. the direct control of prices. The latter, however, "does not seem enough to dominate the phenomenon even in the corporative state" (p.57). The intensity of the business cycle is naturally limited by the existence of untapped capacity. Thus, it is possible to operate effectively "essentially on the demand and supply of equipment" (p.57), at least in part by measures "aimed to transform into 'overhead costs' at least part of the labour costs that still retain the feature of being variable" (p.58), for example by considering a "taxable amount of work". In addition, it is suggested the use of "a controlled production plan" to replace the individual plans ${ }^{108}$.

The policies to control economic crisis are analysed in the second essay: Principii generali e politiche delle crisi (Economic crises: general principles and possible policies to secure control) (1937), which is the text of a conference held on 15 May 1936, presumably at the Bocconi University. It is a 87 pages essay, 73 of which are devoted to general principles of economic crises and 14 pages to possible remedies against crisis. The economic crisis is seen as part of the business cycle, like in the modern economic theory and the commitment of Fasiani is not the pursuit of a "good theory" to identify its causes, but rather the choice of some concepts around which to

\footnotetext{
${ }^{108}$ About this Fasiani's essay, it might seem appropriate to quote the report of the Commission that confirmed Fasiani's university chair (Professors Fanno, Zingali and Masci): "the study of the economic fluctuations and corporative economy, in which the Author has been able to use recent Italian research work especially regarding industrial changes, is an acute analysis that highlights the effectiveness of the corporative order over the timing of the expansions of both the demand and production of industrial plants. It is only to be noted a not always appropriate matching between the complexity of the premises and the relatively minor results". It is easy, reading between the lines, be aware that: i) Fasiani in fact little has dealt with the corporative economy, ii) that the Commission, for political expediency, had to praise the 'Italian' scientific contribution, since the Fascist regime has been advocating autarky, not only in economics.
} 
group the concepts, developed by various theories ${ }^{109}$ (p. 11). The first concept is Schumpeter's economic development, and in particular the case of new inventions and the construction of large contingents of capital goods (p.13). The second concept is that more capitalist structures may be obtained by lengthening the period of production (von Hayek). The basic idea of Fasiani is that the business cycle is powered by the new capital, as "discontinuous innovations lead to changes and fluctuations of the same type as those described by von Hayek" (p.14). Thus his focus is on "the imbalance between the formation of savings and investments" (p.15). He assumes, however, a closed market for "not to complicate the problems more than it is necessary".

To clarify the concepts, first a communist economy is discussed, where the production cycle is carried out through various processing stages. The advantage is that in communist systems, savings necessarily coincide with investments. In communist systems the problem of development is the formulation of a new plan, in which is expected to divert part of the product from the consumption in order to raise capital. In this way, at the end of the multi-annual productive period, the product available each year can actually increase. The central idea is that, in order to increase capital goods, the decrease of consumer goods must be planned, so that the work force is always occupied in every stage of production. Moreover, at each stage, the whole quantity of semi-finished goods must always find available the work necessary to their transformation. Fasiani uses numerical tables to illustrate, in simple cases, the performance of the production cycle after the decision to increase capital. Then, he recalls a number of conditions for which the plan may "take place smoothly" (p.23-24). Calculations by the planner will be extremely complex and will in-

\footnotetext{
${ }^{109}$ Mitchell, W.C., Business cycles, the problem and its setting, New York, National Bureau of Economic Research ,1927; Egle,W., Saving, Investments and Crisis, i n ournal of Political Economy, 1935, n.6, pp. 721-742; Schumpeter, J.A., Theorie der wirtschaftlichen Entwicklung: eine Untersuchung über Unternehmergewinn, Kapital, Kredit, Zins und den Konjunkturzyklus, München : [s.n.], 1926; Hayek, F., Prices and production, London: G. Routledge, 1931; Hayek, F., Capital and Industrial Fluctuations, in Econometrica, n. 2, 1934, pp.152-167; Fanno, M., Cicli di produzione, cicli del credito e fluttuazioni industriali, in Giornale degli economisti, 1931, May, pp. 329-370; Clark, J.B., Essentials of economic theory: as applied to modern problems of industry and public policy, New York: MacMillan, 1909.
} 
crease with the complexity of the economic systems. Errors lead to disturbances, frictions and discrepancies, even if there is "no plausible reason to believe that ...... they are greater than those present in a society in a liberal regime" ${ }^{110}$ (p.26).

In a liberal economic system, the problem is even more complex because savings do not necessarily coincide with investments in so far as they depend on decisions taken separately by consumers, business and credit intermediaries, while "commands by the central body are replaced by prices". The resulting imbalances: "instead of deviations are normal manifestation of economic life" (p.34). Therefore, there may be phenomena that can not exist in a communist system, including: 1) the abstention from consumption, which can cause unemployment, 2) the drop in consumption may not be enough to free the work necessary for the production of investments, 3 ) the production of capital goods could lead to a rise (incompatible) in the production of intermediate goods, 4) it is possible that, during periods of production of new capital goods, the quantity of consumer goods is lower than demand (p.32-33). To discuss these phenomena, Fasiani considers necessary first to distinguish the savings made from: a) consumers, b) entrepreneurs, c) forced, when inflation prevents consumers to consume.

Secondly, Fasiani deals with Hayek's thesis, according to which the crisis can be explained only starting from a position of equilibrium. In fact, in that way one can have a full explanation of the cycle and, besides, by doing so one is forced to analyze carefully the changes in the techniques of use of existing resources. He notes that, in Hayek's framework, given the definition of stable equilibrium: i) the banking system is unable to raise credits, ii) consumers can not increase savings. Therefore, it would be "impossible to explain the cycles in harmony with the phenomenon of credit that is essentially in agreement with the facts" (p. 43). Thus, the solution proposed by Fasiani is to start from a position of equilibrium in which there is still some possibility of movements. In this situation, banks would not

\footnotetext{
${ }^{110}$ Even if Fasiani does not mention him, this is the conclusion of Barone E., Il Ministro della produzione nello stato collettivista, in Giornale degli economisti, September 1908 pp. 267-93, October, pp. 391-414; The Ministry of Production in the Collectivist State, in F.A. von Hayek. (ed.), Collectivist EconomicPlanning, Routledge, London 1935, Appendix A.
} 
have brought credit to its limit and "the credit will keep flexibility" (p. 44).

According to Fasiani, "the movement towards a more capitalist economy" can start: A) owing to a project of entrepreneurs and bankers, B) per initiative of savers. In case A), it could be for instance a new invention, which being financed by banks with an expansion of credit, which in turn implies the production of new capital goods. Since there is full employment, this implies an increase in prices of the employed goods and factors. This fact requires the other entrepreneurs to comply, first by paying higher price for their factors and then increasing the price of their goods. The higher salaries will lead in turn to an increase in demand for finished goods and therefore to an increase in their prices and ultimately to an increase in profits for the producers of consumer goods. The increase in prices and profits will spread in the productions of other stages up to the raw materials and the process will be accompanied by an increasing expansion of credit: "a new era of prosperity seems opened" (p.49). Firstly, the downturn of the cycle can start if the introduction of new machines, decreases the demand for labour in the long run, which causes a decrease in demand for consumer goods, while the correspondent supply is increasing. Secondly, also the credit will be forced to an actual reduction, and this will stop inflation and will lower the demand for capital goods. The productive structure tends to become less capitalist (p. 53), generating unemployment and falling wages, and even decrease in demand for consumer goods: the economy undergoes a process of "screwing". The crisis is followed by the stagnation of the economy, from which one could get out due to a "positive event" (p. 55), and the process will be much easier than the one that originated from the stable equilibrium, because now there are unemployed inputs, and the possibility of expanding credit.

In case B), the initiative of moving towards a more capitalistic society is due to the savers, which increase the savings and decrease consumption. First, Fasiani notes that "within certain assumptions, the case may also differ very little from that previously considered. Let us suppose that all savings will be provided to the entrepreneurs by banks and ... that there is both own money and bank money. Thus, the increase in savings takes the form of new deposits of own 
money" (p. 57-58) ${ }^{111}$.. "As this occurs, the case B ... does not differ significantly from case A" (p.58). However, this is only one of the possible sequences. In fact, Fasiani devotes pages 59 to 72 to analyze "the movements that follow an increase in savings, when it certainly does not cause an expansion of credit" (p. 59). Following Hayek, Fasiani considers that the capital increase is expressed now as an increase in the average period of production and considers in some detail how the system fits to it, and the issues that may arise. His analysis is "perhaps only worth to show the enormous difficulties that the mechanics of a liberal economy meets in its operation" (p. 72).

About possible interventions to secure control, Fasiani notes that policies can be classified as directed: a) to alleviate the more painful effects of the depression, b) to act on some of the forces responsible for the cycle, c) to change the combination and operation of those forces through coercive actions (communism and corporativism). The policies: a) may consist of small grants to both workers and businesses, and small public works. This is the position of the most reactionary liberals, who believe that, usually, government intervention worsens the economic situation. The interventions of type b) may consist of actions on the credit, especially on the discount rate, or in policies regarding the labour demand, or finally in actions on the demand for final goods. Credit interventions have some effectiveness, but by themselves are not entirely able to control the cycle. Those on the demand for labour may really arise only in the execution of public works during the depression, but can only be financed with the use of debt. Actions on the final demand are designed to increase the spending capacity of the working class through controls on wage levels. All in all, these actions can not be decisive because they are uncoordinated.

About the actions of type c), implemented by the totalitarian regimes, a priori we can say that they might be effective. The corporative state, because it should be based in part on individual choices

\footnotetext{
111 The existence of "own money" in the hands of consumers seems to mean that consumers, in the equilibrium position, are holding liquid money outside the banking system. On the other hand, this seems contrary to the hypothesis that the larger savings would be offset by lower consumptions. In turn, this hypothesis seems difficult to reconcile with the expansion of the system: it is true that investment demand increases, but a crisis will follow in the case that consumption decreases.
} 
(even viewed in the context of collective goals) would appear in the best position to control the cycle. However, its goals are much bigger than that.

The third essay: Potenziale di lavoro e moneta (Potential labour force and the money) (1942) is focused on public action against unemployment basing on the current doctrine ${ }^{112}$, but specifically discusses "the possibility to get to work all the workforce unemployed" (p.75). The scenario considers unemployment in a market where the labour force continues to increase, while the banking system is able to increase the money supply. In fact, the Central Bank follows the rule that "the volume of currency issued ... shall be reasonably proportionate to the volume of production" (p.72) ${ }^{113}$.

The assumptions are: a) that "the working day of the average worker is a measure of the work, b) that the work supply is always measured in such terms", c) that "the individual offer of work remains constant over time despite the change in real wages"(p.76), d) that the work is "of uniform quality ", e) that the production is considered "en bloc" (p.77), since Fasiani considers only a finished goods (consumption) and a capital goods (intermediate), f) that "the marginal productivity of labour remains temporarily constant", g) that the market is closed (p.78).

Given these assumptions, Fasiani states that "the premises seem to contain the basic conditions in order that the quantity theory of money may apply" (p.78). Thus, "an increase in the amount of available work can be employed without price fluctuations until "the amount of money is proportionally increased"(p.78). However, if the policy followed by the Central Bank does not allow the increase of money, "the traditional theory" teaches that wages must be reduced and then also the price of finished goods. Thus, output and employment would be increased. Fasiani argues, however ( $\$ 16$ $\S 19)$ that in reality this is not true, because production does not increase even if the money supply may increase. This is due both to

\footnotetext{
112 Pigou, A.C.: The Theory of unemployment, London: Macmillan, 1933; Hicks, J.: The theory of wages, London : Macmillan, 1932; Keynes, J. M.: The general theory of employment interest and money, London : Macmillan and Co., 1936.

${ }^{113}$ This rule follows from the "recent" reform of the statutes of the Reichsbank, because the previous rule had tied the money supply to the reserves.
} 
the rigidity of wages, and because entrepreneurs act "on their own, with no general vision of the overall phenomenon" (p.82). In fact, generally they increase the production only as a result of an increased demand.

On the other hand, Fasiani feels he can not accept even the usual assertion that the increase in the supply of labour is absorbed by an increase in savings. This statement is based on the fact that the savings flow to the banks, which make it available to businesses.. The latter, in turn, decide to increase production using the labour which has become available (p. 86). On the contrary, following BrescianiTurroni ${ }^{114}$, Fasiani assumes $(\$ 21)$ first of all that savings can occur either before or after the increase in labour supply, and then that savings may be forecast or not. Fasiani considers the four possible cases, and concludes that in none of these cases the "savings alone, either in the form of 'saving of factors', either in the form of 'savings of finished goods' can induce to employ increasing amounts of work. In fact, also the money supply must necessarily grow (p. 90). In order to increase employment it is necessary to increase both the savings and the money supply.

Then, Fasiani considers a monetary system in which there is the possibility of creation of bank money. In this case, monetary expansion finds a limit both in Central Bank's inflationary concerns and in the assessment of banking risks, so that sooner or later the maximum monetary expansion will be reached. In all ways, the interest rate rises until the money keeps growing. This raises two chained questions: A) whether the maximum amount of monetary expansion may allow the employment of the entire workforce. In the case that at the maximum monetary expansion corresponds still a certain level of unemployment, the second question is: B) is it possible that a further monetary expansion may actually allow "an increased use of labour?" (p. 95). Fasiani gives an immediate negative answer to the first problem. About the second, he thinks that there is a general agreement that a further monetary expansion " may permit the absorption of unemployment" under the provisional assumptions that: a) it is possible to create enough money to absorb the unemployment

\footnotetext{
${ }^{114}$ Bresciani-Turroni: The Theory of Saving. Disequilibrium between Saving and Investment during the Trade Cycle, in Economica, New Series, Vol. 3, No. 10 pp. 162-181, 1936.
} 
and to allocate the money conveniently among the entrepreneurs, $b$ ) the marginal productivity of labour does not change. This result, however, "can be obtained with very different economic effects ... depending on the amount of savings that is necessary in order to employ the labour" (p. 96).

The fact is that Fasiani's scenario considers single goods produced in subsequent stages, so that the product of the first stage is a capital good for the next stage. This feature may be close to reality, but the hindrance is that the analysis becomes more complex. For this reason, in $\S \S 33$ through 40, Fasiani, using Clark's tables, shows that oscillating movements would be generated in case the capitalist system is organized in a number of successive stages and if the increase in labour and in savings are constants (p. 99). Even through the analysis of a polar case, Fasiani is able to conclude that, at the same level of wages, it is possible to employ labour provided that: a) savings is not "in excess or deficiency with respect to the quantity required to produce the necessary intermediate goods", b) the money increases by an amount sufficient to remunerate the work of new employees (p. 110).

In $\S 41$, Fasiani waives the hypothesis provisionally assumed that it is possible to create enough money and conveniently distribute it among the entrepreneurs. The fact is that the increase in the money supply is not enough: it is also necessary that entrepreneurs will increase demand. This can happen only if the entrepreneurs expect "a growth in profits and thus higher prices". But there is "little hope that the mere possibility of credit expansion will lead to an increase in employment of labour" (p.112), because entrepreneurs will risk an increase in production only following an increase in demand. In the early stages of expansion of the business cycle an important sign is the increase in the rate of interest, which in that case, however, is owed to the increase in money demand induced by the anticipation of higher prices. In this case, the increase in interest rate "can not fail to act negatively on the employment of labour. It therefore seems that there are no automatic solutions to the problem"(p.113). The conclusion is that, although the increase in income is able to finance the savings which are needed to employ all the work and the money supply is sufficiently elastic, only the command economy (corporative) can lead to a positive solution (end of $\S 41$ ). 
But there is "little hope that the mere possibility of credit expansion will lead to an increase in employment of labor".

From $\S 42$, Fasiani waives the assumption that the marginal productivity of capital is constant, although he believes such an expression inappropriate because, as soon as capital increases, also the other factors of production (beginning with work) increase: "by adopting their most efficient combination". The hypothesis is that productivity is getting lower, and this limits the possibility of absorbing work. In addition, with decreasing productivity, the equilibrium with unchanged prices implies that the payments to inputs will diminish. Unchanged wages would imply a decrease in the cost of production: if the rent remains unchanged, only the rate of interest can decrease. However, this is not possible in a liberal market economy "because the interest rate is determined by the demand and supply of money" (p. 116). By contrast, it is possible in a command economy, and thus in particular in a corporative economy. Nonetheless, the interest rate can not be set below the level at which savings are no longer sufficient to ensure, at the same salary, the employment of workers ( $p$. 119). After reaching this level, it is possible to continue increasing the amount of work only by allowing prices of finished products to go up, because this will induce "forced savings" (p.121). §52, §53 and $\S 54$ are devoted to detailing this forced savings; in $\S 55$ Fasiani reflects on the "theoretical limit" that can be achieved in the formation of forced saving, which stops anyway at the onset of the inflationary process. $\S 56$ and $\S 57$ are devoted to the problem of equity of forced saving, which burdens clearly the workers and benefits the capitalists. In $\S 58$ and $\S 59$, alternatively, Fasiani proposes to recourse to income taxation, because he considers that the recourse to forced savings may only be occasional $(\S 60)$.

In $\S 61$ Fasiani recalls his provisional findings, which are: 1) it is possible to increase the employment of labour at unchanged wage by increasing the money supply provided that voluntary savings increases and productivity of capital remains constant, 2) when marginal productivity starts decreasing, it is still possible to increase labour employment at reduced wages by increasing the money supply, until voluntary savings is able to maintain market equilibrium, 3) further labour can be employed through forced savings until an inflationary process starts, which would be contrary to equity, especially 
in a corporative economy, 4) as a viable alternative to forced savings, Fasiani suggests an income tax.

The following sections are devoted to the discussion of the provisional findings with respect to real economic systems. In particular, Fasiani considers the possibility of intervention in a corporative state, with specific reference to the idea of a monetary policy expressly regulated "according to the needs of labour" ( p. 135).

\section{The corporative economy}

During the decade 1932-1942 Fasiani, like the other university professors, had showed some interest in the theory of the corporative economy. However, Fasiani's interest was perhaps more a matter of words than of real theoretical contributions. Moreover, as regards his discussions of issues in the corporative economy, much of it was political expediency, and it is hard to know whether Fasiani was really trying to bring contributions to the construction of a theory of corporative economy. In fact, while he never assumed political attitudes against the Fascist regime, he was never politically active, and he was interested only in scientific problems. In point of fact, his approach was to treat fragments of the theory of corporative economy within the neoclassical economics, and his interest in the state policies remained well within the neoclassic framework, regarding liberal capitalistic economies.

Fasiani has treated corporative economy specifically in seven paper. In the present bibliographical note, one of them (Fasiani 1942a) has been reported in $\S 2.3$ and three in $\S 5$, i.e. (Fasiani 1935a), (Fasiani 1937a) and (Fasiani 1942b). Thus, it remains to report here only as regards the remaining three papers: Sanctions (1936), A contribution to the theory of the Corporative Man (1932) and On economic autarky (1939).

The first paper is Sanzioni (Sanctions) (1936), which is a brief note that discusses the economic sanctions of the League of Nations. Surely this is a minor work, whose interest is mainly historical and political. Fasiani points out that the economic sanctions have been determined by reasons of politics of power. Therefore, economic 
sanctions do not seem destined to become a system, but rather have an occasional nature. In all ways, if effective, they can push towards war: in this respect Fasiani cites Mussolini. The application of sanctions should be seen as a first step towards the armed conflict, as it helps to weaken the economy. Indeed, the economic structure of the countries may be affected in very different ways, both for the dependence from abroad and for domestic backlash. The foreseeable consequences are both the increasing closure of markets and the formation of political alliances inspired by the need for an economy of war. A possible different consequence is the predisposing for an "economic defence" which "is in part a political issue, partly a purely technical problem and partly an economic problem" (p.133).

The second of the mentioned papers Contributo alla teoria dell'uomo corporativo (A contribution to the theory of the corporative man) (1932) is a clear-cut essay that shows how the neoclassical economic theory is the general case, which includes as special cases the collectivist economic theory and a possible corporative economic theory (p.17, note). Implicitly, in fact, the neoclassical economic theory is considered based on the homo economicus. On the contrary, the corporative economic theory should be based on the homo corporativus. The first one is selfish, while the latter also has "the feeling of the superior interests of the community". First, Fasiani claims that the theoretical formulation of the homo corporativus, as regards the allocation of income among the final goods, is no different from the theoretical formulation of the neoclassical homo economicus. The superior interests implies only a different utility function, but the economic approach remains the same in as much as the problem is still a constrained maximization with respect to income. On the other hand, the behaviour regarding the production of income may change and from that point of view Fasiani considers three possible cases: a) the individual, even if prompted by the interest of the community, acts exactly like the homo economicus, b) the individual behaves differently, c) the individual behaves differently only because there are external constraints. In case c) Fasiani thinks that the external constraints are "intermittent" phenomena, so that they may be treated as "economic policies". The case b) is not denied by the classical and neoclassical theory and it certainly leads to different results, but it regards only: "the method not the substance". In conclusion, Fasiani 
suggests continuing to think in terms of neoclassical theory, considering in a first approximation as non-existent the phenomena of type b) and then correcting the theoretical results "by studying the uniformity of such phenomena b)".

The thrid essay is: Autarchia economica (On economic autarky) (1939). It discusses not only economic autarky, but protectionism and social welfare as well. First, in discussing the current literature on autarky ${ }^{115}$, Fasiani states that the purpose of his writing is neither "to reaffirm a political program" or "to individuate the possible immediate actions in the various fields of economic activity to ensure autarky". On the contrary, his aim is instead "the scientific determination of the phenomenon and its necessary conditions". Then, he distinguishes between "autonomy" and "autarky": the first refers to countries not dependent from abroad, for which there are no international trade relations. By contrast, autarky concerns a country organized in order to steer its economy to achieve its objectives of domestic and foreign policy. In autarky, autonomy is only seen as a means: thus, autarky allows a certain development of foreign trade that does not touch the levers of economic and political life of the country. This assumption seems clearly intended to allow Fasiani to study an autarky that does not exclude in principle the international trade.

Fasiani specifies, therefore, that his analysis concerns the autarky as so defined. He notes that it involves "a certain degree and type of economic independence" (p. 11) and refers to the appropriate Appendix of the paper. In all ways, the degree and type of independence depends on: i) the national policy objectives, ii) the environment with particular reference to the other countries. For Fasiani, in this regard, the analysis must be limited to those few elements that "experimental uniformities" permit (p.13). Thus, for political domestic purposes, he considers that his analysis should be limited to the "general guide-

${ }^{115}$ Mill, J. S., Essays on some unsettled questions of political economy, London : J.W. Parker, 1844; Landry, A. L'autarcie, in Revue d'économie politique, 1936, Jan.; Rossi, L., Commercio estero e autarchia, in Rivista italiana di Scienze economiche, 1937, Aug-Sept.; Keynes, J. M.: Autarchia economica, in Luzzato, G. (Ed.) Storia economica, Nuova Collana Economisti, vol. III, Torino: UTET, 1936; Galli, R.: L'autarchia e il teorema dei costi comparati, in Economia, 1937, Dec.; Cosciani, C., Sull'autarchia economica, in Rassegna bibliografica delle Scienze Giuridiche, Sociali e Politiche, Anno III, Fasc. III, 1937 
lines of the building designed and implemented, piece by piece" by the Fascist regime (p.13). He sets out that building as: a) the corporative and ethical government organization, ii) the creation of the Italian Empire (p. 14). About the international environment, he identifies the relevant facts in: i) the end of the gold standard, ii) the end of liberalism as a system of internal politics of various states, iii) the policy of economic sanctions of the League of Nations (p. 14 ).

The assessment of these three international phenomena converges in indicating that a greater or lesser degree of autarky had been necessarily developed in all countries, albeit with different means. As regards the corporative and ethical organization of the state and the creation of the Italian Empire, Fasiani thinks that the both are leading to "a series of new goals" distinguishable in the categories: i) objectives of peace, ii) objectives of war, the latter intended as "si vis pacem para bellum" [if you want peace, prepare war]. They, in fact, "do not lie in the willingness to make war, but in being prepared to do it" (p. 41, footnote, italics in original). The objectives of peace are analyzed in pp. 20 to 40 , while pp. 41,42 and 43 are dedicated to those of war.

The objectives of peace are: i) the achievement of better social justice, intended both as the change in the distribution of income to the factors of production (equity) and in the control of the negative consequences of economic fluctuations, ii) the strengthening of every productive energies, understood as the defence that protectionism is able to exercise for the nation. Fasiani devotes $\S \S 17$ to 24 to the achievement of greater equity in income distribution: according to him, it comes to increasing the level of wages in the country. The problem is analyzed on the basis of the impact that a policy of high wages necessarily involves on imports and exports, because domestic high-wage acts as a duty on exports.

A first case is analyzed in $\S 17$, when the same policy of high wages is also pursued by foreign countries, and the demand for the goods imported from the country is rigid while exports have elastic demand. Changes in the exchange rate, in prices and in the mix of factors and goods produced lead to the conclusion that at least part of the increase in wages paid abroad reduces domestic consumption. It follows a decline in domestic real wages. Thus, the policy of high 
domestic wages is frustrated and rendered impossible by the fact that the same policy is pursued abroad.

In $\S 18$, Fasiani considers a second case, which differs from the first only because foreign countries do not bother to make a wage policy, but even here he concludes that the domestic policy of high wages is not feasible. The same conclusions applies when foreign countries are pursuing a policy of low wages $(\S 19)$. Transfers of capitals are mentioned in $\$ 20$ to $\S 24$, where also he assumes that imported goods are elastic, noting that this case is very close to the Italian situation at the time. The conclusion is, however, that the achievement of a more equitable distribution is closely tied to the decrease of foreign trade, and thus to the autarky.

The relief of the negative consequences of economic fluctuations is the objective of $\$ 25$. However, Fasiani limits only to examine the case of the introduction of labour-saving machines. and the above considerations lead to the conclusion that, since it is desirable to graduate the introduction of machinery to reduce the amplitude of the fluctuations, this policy is much more difficult to implement when the market is open.

Then, Fasiani goes to the second objective of peace, which he labels "the strengthening of every productive energies". He devotes $\S 27$ to $\S 29$ to discuss List and Patten and thus to a problem that basically regards the history of economic thought, namely the debate free trade / protectionism. Fasiani notes that "in reality there is considerable similarity between the observations of List and Patten and the purest theory of capital, developed by Böhm-Bawerk and Wicksell" (p. 37). The point is that "the concept that the economy evolves from the stage of wilderness to the successive stages of sheepfarming, agriculture,... agricultural and commercial industrialism mentioned by List, is strangely similar to the concept developed by Böhm-Bawerk and Wicksell regarding the lengthening of the average capital investment". So, it seems possible to speak, at least, of "affinity".

In $\S 31$, Fasiani's argument is that if one country at a given moment can make longer the average period of investment, that country will benefit from the increase in productivity and will specialize in the production of goods where productivity is further increased, giving up the production of other products. If other countries have equal op- 
portunities to extend the average period of investment and in any case if the advantage gained from that particular country is shared by other countries - as claimed by the traditional theory - would be all right. By contrast, this is not true because there are obstacles of geographical, geological or informational nature ( $\$ 32$ and $\S 33)$. Moreover, capital tends to move to countries where there is a greater productivity and thus the transformation of the capitalist structure of the other countries begins only when the structure of that particular country has achieved a high level. In conclusion, the pursuit of domestic economic development involves "a high degree of economic independence" (p.40).

In $\S 35$, under "war aims" Fasiani only observes that when wars were "fought with bayonets" (p. 42) the economy of peace might have been easily transformed in the war economy in a short time. By contrast, in modern warfare between capitalist economies that passage becomes "difficult, slow and expensive". If the country has to be prepared for war [World War II had been declared the year of publication of this essay], the economic system must be "able to switch rapidly from the frame of peace to the frame of war" (p. 43).

The conclusions follows in the following 2 sections, in which Fasiani points out that national targets are dynamic: thus, much depends on historical needs, although one should still assume that autarky involves a certain amount of foreign trade. However, the latter should not allow other countries to "materially influence our economic policy" (p. 44). Anyway, it is not possible to say when the autarky can be implemented. The essay concludes with an appendix devoted to clarify the degree and type of economic independence, in which inter alia Fasiani proposes an index of autonomy. The index is essentially the ratio between the value of imports and the value of final consumption, preferably evaluated at constant prices ${ }^{116}$.

\footnotetext{
${ }^{116}$ Repeatedly, Fasiani cites the Fascist Revolution, the Duce [Mussolini] and even the Italian Empire. There is never a critical intent towards the Fascist regime, but it is fair to note that it is always a mere reference, immaterial to the analysis. It is likely that a large part of these cites are basically due to the fact that the work is the revised text of a lecture delivered at the Centre for Corporative Culture and Propaganda in Genoa.
} 


\section{Pubblic Debt}

In three occasions only, Fasiani has treated topics regarding public debt. The last one was in Buoni del Tesoro (Treasury bonds) (1938), which is a voice of the "Nuovo Digesto" that concerns the treasury bonds. It is purely informative and limited to descriptive aspects. More demanding is the article (Fasiani 1936c), which will be reported below in $\S 8$ : in fact, it is the discussion of an antecedent of the Ricardian problem regarding the comparison between public debt and taxation.

The third occasion is: Di alcuni effetti dell'estinzione del debito pubblico mediante un'imposta sul capitale (Some effects regarding the repaying of public debt through a tax on capital) (1929). The starting point of that article is the assertion of the Colwyn Report ${ }^{117}$ that, as regards the PSBR, an extraordinary tax on property aimed at reducing the public debt allows a reduction in the tax income by a smaller amount than the corresponding decrease in interest payments on the debt extinguished.

This depends on the fact that it also decreases the tax base for the taxes levied on the interest on the debt (income tax, super tax and death duties). Fasiani remarks that the contemporary literature from Pigou to Keynes etc.. agrees with this view of the Colwyn Report, and that it is based on the assumptions: i) that we can disregard the effects on the economic equilibrium, and in particular the effects of public policies on credit, prices, savings; ii) that the budget is balanced; ii) that the PSBR has to be financed by income taxes

Firstly, for the case in which there are only capital incomes (i.e. there are no labor incomes) Fasiani shows that the reduction in the expenditure for the payment of interests corresponds exactly to the reduction in taxes obtained with the withdrawal of the debt. In other words, the ordinary tax revenue (without debt service), the incomes (net the tax) and the value of capital (net of taxes) will remain unchanged. Fasiani obtains this result within a financial model and with using numerical tables: see below, in Tables 7.1, 7.2 and 7.3,

${ }^{117}$ Great Britain, Treasury, Report (Cmd. 2800) of the committee on national debt and taxation, London, 1927 (Colwyn Report). 
Tab.7.1: Case 1. No labour income - interest rate: 0.0429 ; income tax rate: i) old: 0.2857 , ii) new: 0.1667; extraordinary Original equilibrium

\begin{tabular}{|c|c|c|c|c|c|c|c|}
\hline \multicolumn{3}{|c|}{ Original equilibrium } & \multicolumn{4}{|c|}{ Equilibrium after the withdrawal of the public debt } & \multirow[b]{2}{*}{ total } \\
\hline \multirow{6}{*}{$\begin{array}{l}\text { gross capital } \\
\text { value } \\
\text { Income } \\
\text { income tax } \\
\text { net income } \\
\text { net capital } \\
\text { value }\end{array}$} & $\begin{array}{l}\text { Priv } \\
\text { capital }\end{array}$ & public debt & total & & old & $\begin{array}{r}\text { public } \\
\text { debt/new }\end{array}$ & \\
\hline & 140.000 & 23.333 & 163.334 & \multirow{2}{*}{$\begin{array}{l}\text { tax) } \\
\text { extraordinary tax }\end{array}$} & 140.000 & 23.333 & \multirow{3}{*}{$\begin{array}{r}163.33 \\
4 \\
23.333 \\
140.00\end{array}$} \\
\hline & 6.000 & 1.000 & 7.000 & & 20.000 & 3.333 & \\
\hline & 1.714 & 286 & 2.000 & \multirow{2}{*}{$\begin{array}{l}\text { capital value (after extraord. tax) } \\
\text { new income }\end{array}$} & 120.000 & 20.000 & \\
\hline & 4.286 & 714 & 5.000 & & 5.143 & 857 & 6.000 \\
\hline & 100.000 & 16.667 & 116.667 & $\begin{array}{l}\text { income tax } \\
\text { net income }\end{array}$ & $\begin{array}{r}857 \\
4.286\end{array}$ & $\begin{array}{l}143 \\
714\end{array}$ & \multirow{2}{*}{$\begin{array}{r}1.000 \\
5.000 \\
116.66\end{array}$} \\
\hline & & & & \multicolumn{2}{|l|}{ net capital value } & 16.667 & \\
\hline
\end{tabular}

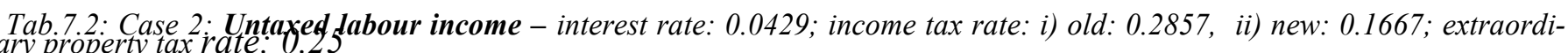

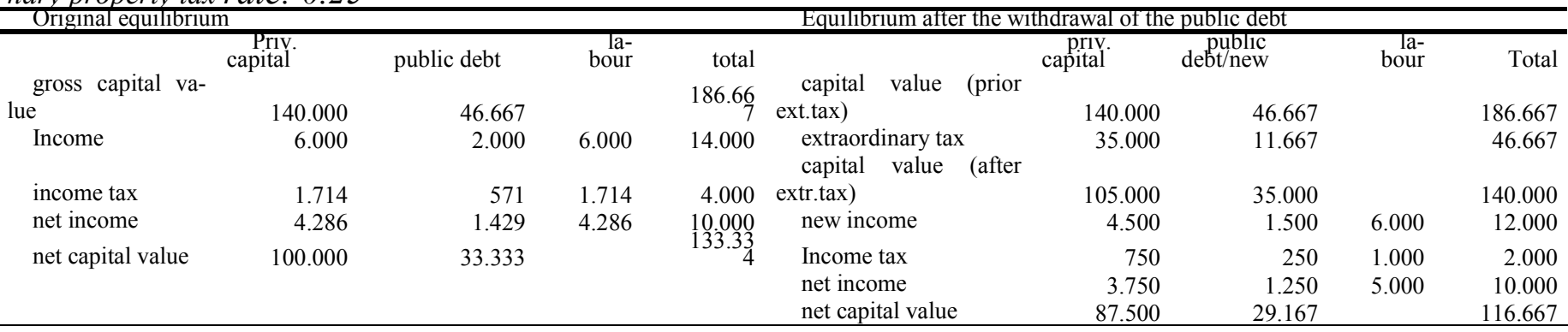


Tab. 7.3. Case 3; Taxed labour income - interest rate: 0.0429; income tax rate: i) old: 0.2857, ii) new: 0.1643; extraordinary

\begin{tabular}{|c|c|c|c|c|c|c|c|c|c|}
\hline \multirow[t]{2}{*}{ Original equilibrium } & \multirow[b]{2}{*}{$\begin{array}{l}\text { Priv } \\
\text { capital }\end{array}$} & \multirow[b]{2}{*}{ public debt } & \multirow[b]{2}{*}{ labour } & \multicolumn{4}{|c|}{ Equilibrium after the withdrawal of the public debt } & \multirow[b]{2}{*}{ bour } & \multirow[b]{2}{*}{ Total } \\
\hline & & & & Total & & $\begin{array}{l}\text { priv } \\
\text { capital }\end{array}$ & $\begin{array}{l}\text { public } \\
\text { debt/new }\end{array}$ & & \\
\hline gross capital value & 140.000 & 46.667 & & 186.66 & $\begin{array}{c}\text { capital value (prior } \\
\text { ext.tax) }\end{array}$ & 140.000 & 46.667 & & 186.66 \\
\hline Income & 6.000 & 2.000 & 6.000 & 14.000 & $\begin{array}{l}\text { extraordinary tax } \\
\text { capital value (after }\end{array}$ & 32.000 & 10.667 & 4.000 & $\begin{array}{l}46.667 \\
14400\end{array}$ \\
\hline income tax & 1.714 & 571 & 1.714 & 4.000 & extr.tax) & 108.000 & 36.000 & & 144.00 \\
\hline net income & 4.286 & 1.429 & 4.286 & 10.000 & new income & 4.629 & 1.543 & 6.000 & 12.171 \\
\hline \multirow[t]{2}{*}{ net capital value } & 100.000 & 33.333 & & & $\begin{array}{l}\text { Income tax } \\
\text { net income }\end{array}$ & $\begin{array}{r}761 \\
3.868\end{array}$ & $\begin{array}{r}254 \\
1.289\end{array}$ & $\begin{array}{r}986 \\
1.014\end{array}$ & $\begin{array}{r}2.000 \\
6.171\end{array}$ \\
\hline & & & & & net capital value & 90.254 & 30.085 & & 120.33 \\
\hline
\end{tabular}


my personal elaborations regarding some numerical values of Fasiani.

On the contrary, in the presence of labor income it is possible that the maneuver diminishes the value of capital in varying degrees, or leaves it unchanged, depending on how the labor income is required to participate to the financing of the withdrawal of the public debt. In such cases, while the total income of the system (exclusive of tax) remains unchanged, the net income shares of the single income categories will change. Specifically, the gross income from labor does not change in absolute value, but its shareincreases because the income coming from the interest on debt disappears.

In contrast, the net income from the "private" capital remains unchanged, but the total capital income will decrease, both in absolute terms and in share, owing to the "disappearance" of the interests on the public debt. The present value of capitals, net of tax, decreases in various ways depending on the participation of the labor income to the extraordinary tax.

Then, Fasiani draws the attention to the fact that the statement of the Colwyn Committee: "the withdrawal of the public debt allows a reduction in taxation less than it might seem at first because the withdrawal shrinks the tax base" is merely a new formulation of the Ricardian view that it is irrelevant whether or not to tax the interest on the debt. Table 7.1 below (case with no labor incomes) shows clearly that the income of $£ 1,000$ coming from the interests on public debt could be replaced by an income of $£ 714$ net of tax. The reasoning of the Colwyn Committee, however, is that the elimination of the debt should halve the rate of the ordinary tax (from $28.57 \%$ to $14.27 \%$ ), whereas it is lowered only to $16.67 \%$ because the tax base is reduced from $£ 7,000$ to $£ 6,000$.

Finally, Fasiani pointed out that in order that the withdrawal of the public debt is neutral, it is necessary not only the static framework ${ }^{118}$

\footnotetext{
${ }^{118}$ I am not sure that Fasiani's hypothesis - that labour income contributes to the financing of the extinction of the debt - is really consistent with his static model. The extinction of debt with a tax on capital is modelled, in fact, through: i) the fact that the private capitalists, in order to pay the extraordinary tax, need selling a portion of their capital, ii) the fact that the owners of the public securities are given in exchange a portion of the existing private securities. If we include the income of labour in the tax base of the extraordinary tax, I am afraid that, in order to represent the capital value of the flow of the tax on the labour income, a financial plan is no more sufficient. In fact, we should perhaps consider a dynamic setting.
} 
but also the closed market assumption. After repaying the debt, the tax rate drops, and - all things equal - foreign capitals come from abroad. In table 7.1 below (case with no labor income) we see that the capital value of $£ 140,000$ had granted a net income of $£ 4,286$, while now the same capital leads to a net income of $£ 5,000$.

\section{History of economic thought}

Fasiani always has had an interest in the history of economics thought. In fact, he collected ancient books on the topic ${ }^{119}$ and especially his early works often cite antecedents in the ancient literature. However, only three essays are directly connected with the topic. They are: The present state of the pure theory of Public Finance in Italy (1932-33); Antecedents of some fiscal theories (1936); Some notes about the Economic Essays of Francesco Fuoco (1937). To these works it must be added also: Pareto's Contributions to the Science of Public Finance (1949).

The first essay was published in German: Der gegenwärtige Stand der reinen Theorie der Finanzwissenschaft in Italien (The present state of the pure theory of Public Finance in Italy) (1932-33). An Italian translation, with a number of changes due to the editor was

\footnotetext{
The portion of the extraordinary tax to be paid by labour incomes should imply the formation of new capital because, by hypothesis, it can not imply the forced expropriation of the existing private capital.

${ }^{119}$ Most of his books are now deposited in the Library of the Bocconi University in Milan; unfortunately, no catalogue has been predisposed at present.
} 
published in 1980 as: La teoria della finanza pubblica in Italia ${ }^{120}$. However, in the papers left by Fasiani, the proofs were found of an Italian version, with original handwritten corrections by Fasiani, titled: Lo stato attuale della teoria pura della scienza delle finanze in Italia. The proofs, however, has been lost in the materials of Aldo Scotto, who was called after Fasian to his university chair. Nonetheless, a photocopy of the proofs is still in the library of the Istituto di Finanza dell'Università di Genova.

The original German version counts 102 pages, and has become a classic in the history of the Italian fiscal doctrines. Fasiani presented the essay as the exposition of the "thought of the greatest and less remote [Italian] writers" with some "critical cues" (p.653). According to Fasiani, the work should be divided into three parts: in the first are considered the "major theories of public finance, in the second ... the most interesting contributions to the theory of the effects of the tax and in the third a number of issues ...regarding 'almost pure theory" " (p.653). As discussed below, however, part III is missing.

It does not seem possible here to review the theoretical developments described by Fasiani: therefore I will limit myself primarily to some information on the documentation, and secondly, to a brief outline merely descriptive. Regarding the documentation, I recall that the work was originally published in three parts in German, respectively translated from Italian by P.Rosentein Rodan, O.Lange and H.Fried.

${ }^{120}$ Massimo Finoia (Ed.) Il pensiero economico italiano (1850-1950), Cappelli editore, Bologna, 1980, p.117-202. 
The above mentioned proofs in Italian are revised of Fasiani's fist, are numbered from p.889 to p.960 and reproduce identically the original German version, including the breakdown in 42 sections, but the headings are missing in print. Moreover, although there is the indication of the footnotes, their text is missing, obviously because they should have been grouped at the end of the paper. Section 27 is also missing, owing to a printmaker error, as noted at the margin by the hand of Fasiani. Sections from 4 to 30 are included under the heading handwritten by Fasiani: " 1 . General theories of public finance". Just before $\S 5$ it is handwritten the subheading "A. Hedonistic theories" which includes the sections up to $\S 10$ inclusive. Before $\S 11$ Fasiani handwrote: "B. Political theories" which groups sections up to $\S 30$ inclusive. The remaining sections from $\S 31$ to the final $\S 42$ are grouped in "Part II. The theory of the effects of the tax" according to the note handwritten just before $\S 31$. These sections are all related to issues affecting the tax shifting and its effects. All sections, their headings and subheadings correspond exactly to those in the original German version.

Taking into account that, according to Fasiani, the distinction: tax shifting / effects of taxation is "a matter of words", and since Part III is missing, it would seem that, at the end, Fasiani had decided to not address the issues of "almost pure theory" as was his initial intent. We do not know what those questions could have been, excepting for the problem of the double taxation of savings. In fact, that topic is cursorily mentioned on page 902 of the proofs, where it is said: "on which, moreover, we shall return in Part III of these notes". The German language version is identical: "wir haben werden noch Ge- 
lengenheit in dritten Teile der vorliegenden Anmerkungen auf diesen Punkt zurückzucommen"121.

The above mentioned version edited in Italian by Finoia is largely taken from the mentioned proofs. However, the title of this Italian version is owed to the editor. The same editor Finoia then changed the partition of the text in new sections and subsections, which are different from those in the two original Fasiani's (German version and Italian proofs). Finally, Finoia gave arbitrary headings and subheadings to these sections and subsections. In particular, it is incorrect the heading "Issues of 'almost pure theory" ", which includes all the matter from p.188 to the end (i.e. the original Fasiani's sections from $\S 35$ to $\S 42$ ). In fact, these sections concern the general analysis of the effects of taxation. Thus, they can not considered as different specific issues. Specifically, in those sections Fasaini considers the general equilibrium approach of Sensini (Fasiani's original §38) and of De Viti de Marco ( $\$ 41)$. Then, there is also included the $\$ 39$ dedicated to the general tax effects highlighted by Einaudi and the $\$ 40$ dedicated to the very general setting of Borgatta that analyzes the effects of the tax "in the sociological theory public finance". Another real source of misunderstanding is the heading "partial equilibrium approach" that Finoia has given to the approach of Einaudi (§39) and Borgatta $(\S 40)$. All this is probably due to the fact that Finoia did not realize that Fasiani's Part III was missing (see above). In conclusion, I regret to say that, despite the fact that Finoia's book constitutes an important instrument for the scholars of Italian economic thought,

${ }^{121}$ Zeitschrift für Nationalökonomie”, 1932, Band III, Heft 5, p.669. 
this Fasiani's essay was treated philologically in questionable manner, which somehow limits its usability.

From the descriptive point of view I recall only that in the first part (pages 891-937) under the original Fasiani's heading "1. The general theory of public finance" and the subheading "The hedonistic theories" are masterfully handled the approaches of De Viti de Marco, Mazzola and Einaudi ${ }^{122}$. Under the subheading "Political theories" Fasiani discusses both the approach that he calls "generically politic" and the one "which is inspired to the sociological theory of Pareto" (page 904). In the first approach are presented Loria ${ }^{123}$ and - with a remarkable depth - Puviani's theory of fiscal illusions ${ }^{124}$. Then, Fasiani discusses the approaches of Conigliani and Murray ${ }^{125}$. As regards the "Paretian sociological approach", he focuses on Borgatta and Sensini ${ }^{126}$ paying particular attention to the last and more de-

${ }^{122}$ De Viti de Marco, A., I primi principî dell'economia finanziaria, Roma: Sampaolesi. 1928; ; Mazzola, U. I dati scientifici della Finanza pubblica. Roma: Loescher, (1890); Einaudi, L.: Osservazioni critiche intorno alla teoria dell'ammortamento dell'imposta, in "Atti della Reale accademia delle scienze di Torino ", vol. 54, 1918-1919, Torino: Bocca, 1919; Einaudi, L.: Contributo alla ricerca dell'ottima imposta, in " Annali di economia ", Università Bocconi, vol. V , Milano, 1929; Einaudi, L., Corso di Scienza delle Finanze; Torino: Tip. E. Bono, 1914.

${ }^{123}$ Loria, A. Le basi economiche della costituzione sociale, Torino: Bocca, 1902;

${ }^{124}$ Puviani, A., Teoria della illusione finanziaria, Palermo : Remo Sandron Edit., 1903

${ }^{125}$ Conigliani, C., (1894). L'indirizzo teorico nella scienza finanziaria, in Giornale degli Economisti, 1894; Conigliani, C. Le leggi scientifiche della finanza, in Rivista di Sociologia, 1895, Feb., pp.108-131; Murray, R., Le nozioni dello stato, dei bisogni pubblici e dell'attività finanziaria, Roma: Atheneum, 1913; Murray, R., Principi fondamentali di Scienza delle Finanze, Firenze: La voce, 1914.

${ }^{126}$ Borgatta, G., Le azioni pseudo economiche, inRivista italiana di sociologia, 1912, Apr.-May, pp.309-353;Borgatta, G., Contributo critico alla teoria finanziaria, in Atti della R. Accademia delle Scienze di Torino, vol. XLVIII, 1912-13, pp.903-925; Borgatta, G., I 
tailed version of Borgatta.

In the second and last part (pages 938-961) Fasiani deals extensively (from pp.938 to 947) with the terminology of the effects of taxation, to conclude that it is inappropriate to "faithfully follow any of the classifications mentioned just now if you want to give an idea of the evolution of the Italian doctrines." His proposal is "to distinguish between two basic types of theories and reasoning: A) those that "relate to the general approach to the problem of the "effects" of taxation", i.e. to all the subsequent changes to the tax induced equilibrium, B) those that "relate to some special effects of the tax: "assuming that no other 'effect' occurs at the same time" (p. 948). Within these issues B), then, "accepting in part the classical terminology" Fasiani proposes to handle three sets of problems, namely those of "the tax shifting..., of the 'effects' of the tax ...; of different 'effects' of the tax and public loan".

About "the general problem of the effects of taxation" Fasiani recalls Pantaleoni's approach ${ }^{127}$, then that of Barone ${ }^{128}$, but discusses

problemi fondamentali della scienza finanziaria, in Atti della R. Accademia delle Scienze di Torino, vol. XLVIII, 1912-13, pp.985-1007; Sensini, G., 1920, La teoria di Ricardo sui diversi effetti del prestito e dell'imposta, in "Giornale degli economisti e Rivista di statistica", February, reprinted in Sensini (1932), pp.252-277; Sensini, G., 1920a, Classificazione generale dei problemi principali della Finanza, in "Giornale degli economisti e Rivista di statistica", July; Sensini, G., 1929, Cenni di finanza teorica, in "Giornale degli economisti e Rivista di statistica".

${ }^{127}$ Pantaleoni, M., L'identità della pressione teorica di qualunque imposta a parità di ammontare e la sua semeiotica, in Giornale degli economisti, March 1910, pp.293-324.

${ }^{128}$ Barone, Enrico, 1912, Studi di economia finanziaria, in Giornale degli economisti e Rivista di Statistica, reprinted in Barone Scienza delle Finanze, 1911-12, cit. , pp.38-42. 
above all (pp. 951-956) Sensini analytic setting ${ }^{129}$, inspired by Pareto. On the "general approach of the theory of shifting" he recalls the contribution of Einaudi ${ }^{130}$, and then goes on to exposing the connection made by Borgatta ${ }^{131}$ between the theory of the effects of taxation and the sociological theory of public finance. Finally, Fasiani remembers "a last recent attempt to basically modify the point of view from which the problem of the "effects' of taxation", namely the discussion of De Viti ${ }^{132}$ on the necessity of considering both the changes in demand and the spending of the tax revenue. The last section contains concluding remarks on the "strong development" that "the general problem of the "effects' of taxation" has had in Italy. The discussion is interrupted without the promised analysis of the issues under B), and, as I warned above, without the third part on "... issues of almost pure theory".

The second article here considered: Precedenti di alcune teorie finanziarie (Antecedents of some fiscal theories) (1936) is a collection of 5 different essays that have in common the fact to indicate the existence of precedents in respect to the modern theoretical approaches. The first long essay concerns the comparison of taxation and public debt (pp. 195-209). The second one examines the problem of the de-

\footnotetext{
129 Sensini, G., 1917, Lo studio scientifico dei fenomeni finaziari, in "Rivista italiana di sociologia", pp.86-97; Sensini, G., 1917a, Prime linee di finanza teorica, in "Scritti vari in onore di Tullio Martello", Bari: Laterza, pp.263-322.

${ }^{130}$ Einaudi, L.: Osservazioni critiche..., cit..

${ }^{131}$ Borgatta, G., I problemi fondamentali..., cit.

132 For a discussion of De Viti's approach, see Fasiani (1943a), §2.1 above and Fasiani $1931-32, \S 2.3$ above.
} 
valuation of money on the economic development (pp. 210-221). Then, three short essays are following, respectively on the idea of optimal taxation (pp. 222-227), the relationship between economics \& social sciences (pp.228-231), and finally on the effects of a general tax (pp. 232-238).

In the first essay on public debt and taxation Fasiani recalls the previous work of Ricardo, Messedaglia, Loria, Pantaleoni \& Ricca Salerno ${ }^{133}$ but considers it essential the work of De Viti de Marco ${ }^{134}$ among the subsequent developments during and after Great War I. However, he suggests that the discussion of De Chastellux ${ }^{135}$ constitutes a forgotten precedent that "that is it worth to be drawn from oblivion because of its qualities of originality and its penetrating force". De Chastellux's work was originally published in 1772, but Fasiani cites the 1822 edition, whose results he compares with those of De Viti.

De Chastellux wonders if the public debt (to finance a war) is "pernicieux" (pernicious) in itself regardless of whether the war is useful or not. In order to give an answer, he has had recourse to the general principle that a static economic system requests that expenditure is constant, in so far as it is based on the specialization of labour and on exchanges. For this purpose it is sufficient that some work and means of production are diverted from normal production and dedi-

\footnotetext{
${ }^{133}$ Messedaglia, A., Dei prestiti pubblici e del miglior sistema di consolidazione, Milano : Francesco Vallardi, 1850

${ }^{134}$ De Viti de Marco, A., Contributo alla teoria del prestito pubblico, in Saggi di economia e finanza, Roma: Giornale degli economisti, 1898.

${ }^{135}$ De Chastellux, F.J.: De la felicité publique, ou considérations sur le sort des hommes dans les différentes époques de l'histoire ,Paris: A.-A. Renouard, 1822. 
cated to the works of war. However, the production of subsistence goods is expected to remain unchanged, while the production of luxury goods should decrease. If the war is financed by taxes, and income distribution favours the privileged (landlords) it seems unlikely that the tax may shift on the privileged, because that would be destabilizing - De Chastellux has in mind a special tax on capital. Thus, if the tax burdens mainly the poor working class, they are doubly bad: first, owing to the tax and second because of the increase in the price of basic necessities. In fact, the rich do not renounce to the consumption of luxury goods, and thus the production of basic necessities diminishes and their prices increase correspondingly. Under these conditions the use of alternative public debt is beneficial, not only because poor workers are not affected by the tax, but also because it is the rich who subscribe to the debt, and therefore he must give up some of his luxury consumption, so that the production of basic consumption goods do not diminish.

As for the payment of interest on public debt, De Chastellux notes, first, that they are largely a double counting in the sense that the landlords pay the tax to finance the payment of the interests on debt and at the same time there are other landlords who receive those interests: but the overall spending remains constant. On the other hand, he recognizes that the presence of this form of wealth tends to divert the rentiers from production, such as diverting the landlords' interest from their land. Finally, about the repayment of the debt, it depends on whether the tax burden is high or low: debt repayment is not advisable if the burden is already high. Also, one has to consider that government spending directed to build infrastructures can be very 
useful to the country. Thus, any available money can be better spent than to repay the debt.

In the second essay on money devaluation and economic development, Fasiani identifies in the 'currency dumping, ${ }^{136}$ the corresponding contemporary phenomenon. He points out that Galiani ${ }^{137}$ had noted that: i) at first, inflation changes the exchange rate and, therefore, lowers imports, ii) domestic prices adjust to inflation slowly ${ }^{138}$. Hume $^{139}$ had agreed with Galiani that domestic prices adjust to inflation slowly, while the change in the exchange rate is immediate: thus, exports increase and imports decrease. However, he maintains that the advantage of the domestic industry only lasts as long as prices are adjusted. It follows that a good public policy should ensure that the money supply increases always, albeit slowly. This would benefit the domestic industry, and the amount of work would increase ${ }^{140}$.

\footnotetext{
${ }^{136}$ With the expression 'currency dumping' it was intended the devaluing of the national currency to foster exports, in order to allow the development of the national economy.

${ }^{137}$ Galiani, F.: Della moneta libri cinque, Napoli: G. Raimondi,1750; Hume, D.: Essays and treatises on several subjects, London : printed for A. Millar; and A. Kincaid and A. Donaldson, at Edinburgh, 1760.

138 As was customary in medieval times, Galiani thinks the money in terms of unit-ofaccount and not of metals, so that 'the elevation' is the state's statement that the unit of account is worth more than the current parity of the metals used for payment up to that moment. The idea of money only used as unit of account, and not for payments, was labelled by Einaudi as "imaginary money". On the imaginary money see: Forte, F., La moneta immaginaria e la moneta manovrata nel pensiero di Luigi Einaudi, in Note Economiche, 1974, n.6; Fossati, A.: L'inflazione nella teoria della moneta immaginaria, in Economia e storia, 1982, pp.219-231.

${ }^{139}$ Hume, D.: Essays and treatises on several subjects, London: Millar, 1760, vol.II, Essay on money.

${ }^{140}$ Hume considers only the increase in money supply. As an example, he suggests to reduce the amount of silver in the coins. In this way, the units of money could increase, and
} 
Also Corniani ${ }^{141}$ states that the increase in the amount of money in circulation is conducive to development. He starts observing that: "from the features allocated to money, therefore, we are forced to acknowledge into it two incompatible ideas: measure and value. The feature of measure requires that it is always equal to itself' (p.215).

Then, he recognizes that "the increase in the numerical value of the currency does not produce a commensurate increase in the domestic prices of food and basic goods. All benefits and justifications of the increase are founded on this result" (p.217).

In that circumstance (rise of the currency) the exchange rate increases, and decreases the price of domestic goods abroad and increases the price of goods imported from abroad. Thus, the national economy is doubly stimulated: the increase in the circulation of money "acts as import duty and as export premium" (p.217) ${ }^{142}$.

The third short essay concerns the principle of tax productivity [principio produttivistico dell'imposta], which Einaudi ${ }^{143}$ introduced in 1927. The principle states that taxes should be distributed "to minimize the burden on the producers, so that the flow of incomes

the prices decrease, so that exports could increase and imports decrease. Hume's inflation, therefore, is caused by a decrease in the weight of silver, keeping the same nominal parity. However, since Hume asserts that this manoeuvre reduces the prices, this means that, like Galiani, he considers the prices are in units of account, and not in coins.

${ }^{141}$ Corniani, G., Riflessioni sulle monete (1796), in Custodi collection, Economisti Classici Italiani, Parte moderna, Tomo XXXIX, Milano: Destefanis, 1805

142 Also Corniani considers units of account and not metals, and his inflation is induced by the state's statement that the unit of account is worth more in terms of coins than the existing parity. See p. 218: 'the increase in the total money'; p. 219: "the above mentioned Parisians academicians had proposed ... to mint anew all coins of the realm, and to raise their title ... so the increased nominal value would have much benefited the state'.

${ }^{143}$ Einaudi, L., La Guerra e il sistema tributario italiano, Bari: ,1927. 
may be maximised" (p.223). According to Einaudi, this principle coincides with the optimal tax. Fasiani observes that a strikingly similar definition is already "in the preface to a small volume published half a century ago and almost forgotten" written by the Duke De Broglie $^{144}$ (p. 227).

In the fourth short essay, Fasiani argues that a precedent of the debate between Einaudi and Griziotti ${ }^{145}$ about the methods of theoretical public finance might be found in an exchange of letters between Dupont de Nemours and J.B. Say ${ }^{146}$. In fact, those letters had discussed the idea of leaving out of the object of study of political economy "la loi naturelle, le droit de l'homme et du cytoyen... pour n'y laisser que la science de richesse" [the natural law, the human rights and the citizen's rights...to leave only the science of wealth] (p.231).

In the fifth and last essay, Fasiani draws attention to the fact that Messedaglia ${ }^{147}$ has obtained before De Viti interesting results about the effects of taxation, particularly on the effects of tax spending on the demand curve ${ }^{148}$. In addition, Fasiani remarks that Messedaglia,

\footnotetext{
${ }^{144}$ Broglie, A.L.V., Le libre échange et l'impôt : études d'économie politique, Paris: Calmann Lévy, 1885.

${ }^{145}$ Einaudi, L. - Griziotti, B.: Sul metodo di ricerca e critica negli studi finanziari, in La Riforma sociale, 1933, pp. 193 ff. \& pp.197 ff.;

${ }^{146}$ Say, J.B., Cours complet d'économie politique pratique, Bruxelles: Société typographique Belge, 1844 (Appendix: Mélanges et correspondance d'économie politique).

147 Messedaglia, A., Scienza delle Finanze, (1878?), in the Fondo Fasiani, Bocconi University Library, Milano.

148 However, it seems that the reasoning of Messedaglia still leads him to believe that even considering the expenditure of the tax revenue, the overall effect on the national economy is negative. See Messedaglia's quote: 'there may still be some sectors which take advantage, but others suffer to an extent incomparably greater, and everything contributes to the downfall of the domestic industry taken as a whole' (p. 237).
} 
in analyzing the effects of a general tax on profits, states that the tax is considered as an increase in overheads costs. Thus, for each business the price increases in different proportions, because the burden of the tax is not in the same proportion.

The fourth essay is: Note sui "Saggi economici» di Francesco Fuoco (Some notes about the Economic Essays of Francesco Fuoco) (1937). Fasiani presents this 131-page monograph as "notes" written on the occasion of the reprint of Fuoco's essay "Application of algebra to political economy" on the Annals of the Faculty of Economic and business of the University of Genoa. That reprint was "supplemented by notes, memos and Appendices designed to illustrate the state of knowledge in Italy at the time when he had written" (p.7).

$\S 2$ contains a brief biography of Fuoco ${ }^{149}, \S 3$ is devoted to his bibliography and $\S \S 4$ to 7 relate how Italian literature up to Fasiani had considered Fuoco. In the very short $\$ 8$ Fasiani warns that information is limited to Fuoco's Essays, does not include other works of him and that his aim is not to discuss Fuocos's thought, but only to draw it to the scholars' attention ${ }^{150} . \S 9$ provides news on the publication of the Essays and $\S 10$ consists in the list of the headings of the Essays. $\S \S 11$ to 19 refer to the first essay, which "marks the first introduction into Italian literature of the Ricardian concept of rent" ( $p$.

\footnotetext{
149 Regarding Fuoco's biography, see A.Bertolini, Fuoco Francesco, in Palgrave Dictionary of Political economy, London: Macmillan, 1896; Dalla Volta, A., Fuoco Francesco, in Encyclopaedia of the Social Sciences, vol. VI, 1931.

${ }^{150}$ However, it is fair to note that Fasiani does much more than being the mere informant: there are no doubts that no critical discussions are lacking.
} 
29). Here Fasiani recalls that it was Marescotti ${ }^{151}$ only in 1856 to recognize this priority, followed by Fornari ${ }^{152}$. Then, Fasiani reports a criticism of Graziani ${ }^{153}$, that he considers, however, "unjustified". In $\S 12$ a summary of the original "Preface" of Fuoco is reported. Moreover, included in a footnote, the bibliography consulted by Fuoco is listed. In $\S 13$ Fasiani provides a summary of Fuoco's reworking of Ricardian theory of rent. $\S 14$ is virtually the statement that "the restatement of Fuoco ... is not only personal but also has a power, precision and a depth certainly not attained by his contemporaries" (p. 41).

In the short $\S 15$, Fasiani warns that the second part of the essay "is less fortunate than the first one in our eyes", even though we are "perhaps doing injustice" (p. 41). In $\S 16$, he summarizes the thinking of Fuoco as regards the consequences of the Ricardian doctrine and in $\$ 17$ he continues in reporting the doctrine of Ricardo on the tax shifting. $\S 18$ is devoted to report the arguments of Fuoco in defence of the Ricardian theory of rent, in particular the refutation of the objections raised by Sismondi, Louis Say and J.B.Say to Ricardo. From those arguments, Fasiani infers that Fuoco had the notion that the absolute level of prices does not matter and had a clear view of the existence of interdependence between the various elements of the economic equilibrium (p. 45). In $§ 19$, Fasiani reports the extension made

${ }^{151}$ Marescotti, A. , Discorsi sulla economia sociale, Firenze, Barbera,1856, vol.II

${ }^{152}$ Fornari, T., Delle teorie economiche delle provincie Napolitane, Milano: Hoepli, 1888. However, Ferrara never mentioned him, while and Cossa and Ricca Salerno referred to him only cursorily: Cossa, L., Introduzione allo studio dell'economia politica, Milano: Hoepli, 1892; Cossa, Luigi Primi elementi di economia politica, Milano: Hoepli1875; Ricca Salerno.G ., Storia delle dottrine finanziarie in Italia, Palermo: Alberto Reber Edit., 1896.

${ }^{153}$ Graziani, A. Storia critica della teoria del valore in Italia, Milano: Hoepli, 1889. 
by Fuoco of the Ricardian concept of rent to industrial production, which concludes the first essay.

The paragraphs $\S \S 20$ to 29 are devoted to the second Fuoco's essay: $\$ 20$ lists some critical assessments of Marescotti, Graziani \& Bertolini ${ }^{154}$. According to Fasiani: "it is already remarkable that Fuoco had been able ... to master [the Ricardian doctrine], in understanding all its importance, without relegating ... [the theory based on the idea of utility] among the scrap iron" (p. 51). In §21 Fasiani states that what Ferrara had said about Senior regarding "the theory of 'cost' and 'utility' " could also be said regarding Fuoco, because he put the premises, but did not arrive ${ }^{155}$ (p. 54) to proof: "that the issue around the «efficient cause of value» "can only be located between Utility and Painfulness»" " (p. 51). In this regard, in §22 Fasiani devotes to highlighting its "degree of approximation" based on the general premises of Fuoco's essay, but also by comparing the positions of Gioja, Condillac, and Ferrara ${ }^{156}$. In all ways, Fasiani reduces Fuoco's argument to 5 propositions (p. 57), the 2 nd and 3 rd of which involve the "rarity", discussed in $\S 23$ at the light of the literature, citing among other Verri, Lauerdale, Purses, Valeriani, Condillac and Galiani.

Fasiani discusses in $\$ 24$ proposition 5, namely that labour depends on the degree of utility, complaining that: "Fuoco was wrong not to highlight the issue particularly, because it was a question not new, of

154 See op. cit. above.

155 See also the long footnote on the views of Gioja (pp. 53-54).

156 Gioja, M., Nuovo prospetto delle scienze economiche, Milano: Pirotta, 1815-17; Condillac, É., Le commerce et le gouvernement, Paris : Baudouin ,1827; Ferrara, Introduzione..cit. 
which writers had not always seen the importance and extent" (p. 66). Among these scholars, Fasiani remembers Galiani, Turgot, Destutt de Tracy and Gioia. In $\S 25$ Fasiani remarks, however, that Fuoco did not take out all the consequences, so that: "his theory of exchange does not depart from those of Condillac, Turgot and Beccaria. Despite some innovation, his theory was actually a construction incomplete and unsafe" (p.70).

The rest of the essay ( $\$ 26$ to $\$ 29)$ "can be considered a brief restatement of the phenomena of production and circulation" (p. 72). In particular, \$27 and §28 consider the relations with public finance and taxation, about which Fasiani cites Einaudi, Marescotti, Fornari and Ricca Salerno ${ }^{157}$, specifically about taxing savings ${ }^{158}$. In $\$ 28$, Fasiani makes the statement that this Fuoco's essay ends with a discussion of the relations between economic systems and law, politics and morals. Fasiani's idea is that those pages "do not have anything original", but he is convinced that in those pages Fuoco "gets the vision of a sociological equilibrium which includes the economic equilibrium, which has stimulated much interest in times closer to us" ( $\mathrm{p}$. 78) ${ }^{159}$.

The third essay is presented in $\S 30$ to $\S 33$ and concerns the theory of limits applied to political economy. In $\S 30$ Fasiani suggests that

\footnotetext{
${ }^{157}$ Einaudi, L., Contributi fisiocratici alla teoria dell'ottima imposta, in Atti della R. Accademia delle Scienze di Torino, vol.LVII, 1931-32; Marescotti, A., Discorsi..., cit.; Fornari, T., Delle teori economiche ..., cit.; Ricca Salerno, G., Storia ..., cit.

158 Fasiani declares "obscure" the thought of Fuoco, and offers his own interpretation of what is meant when Fuoco proposes to taxing savings (see p. 76). Personally, I would suggest that for Fuoco "saving" be might be the excess on the level of subsistence. In that case, Fuoco's thought seems quite clear.

${ }^{159}$ Clearly, the allusion is to the school of sociology inspired by Pareto. 
Fuoco had been inspired by the theory of prices of Canard ${ }^{160}$ and that "the discussion of the maximum and minimum prices of produced goods, implies to discussing the limits in the production, distribution and circulation of wealth" (p. 79). Moreover, according to Fasiani, Fuoco had distinguished between stable and unstable equilibria and suggested a dynamic search of the limits of movements from stable equilibrium (p. 80-81). In addition, Fuoco seeks to build "a theory of the limits of the population, property, production, circulation and wealth" (p. 81). As regards in particular the population, Fasiani recalls Malthus and Cagnazzi ${ }^{161}$. In $\$ 31$, concerning the limits of the property, according to Fasiani the Ricardian theory reappears without any substantial innovation, while in "treating the theory of distribution and its limits, as was pointed out by Loria ${ }^{162}$, Fuoco stands out by his predecessors and contemporaries" (p. 83). "I do not discuss the goodness of the thesis, but the reversal of the traditional position ... is really bold, since it is the germ of a truth that will make its way later on” (p. 84). In $\S 32$, Fasiani refers about Fuoco's ideas on the movement of goods, and in $\S 33$ Fasiani presents a summary of such ideas: the industry is essentially productive, while the distribution and circulation are the means to let consumes match with production. These functions "form necessarily one and the same system" (p. 85). Fasiani comments that "one can think what he wants ...

${ }^{160}$ Canard, N., Principes d'economie politique, Paris: Buisson, 1801.

${ }^{161}$ Malthus, T., An essay on the principle of population, London: Turner, 1872; Cagnazzi, L. Saggio sulla popolazione del regno di Puglia ne' passati tempi e nel presente, Napoli: Trani, 1820.

${ }^{162}$ Loria, A. Italian School of Economics, in Palgrave Dictionary Of Political Economy, London: Macmillan, 1896 
but one can not deny the systematic nature of the doctrine... that permits to distinguish Fuoco clearly from the bulk of his Italian contemporaries". (p. 86).

The fourth essay deals with the applications of algebra to economics, and occupies $\S 34$ to $\S 44$. In $\S 34$, Fasiani reports that Fuoco probably was inspired by the work of two directors of customs of the French empire, namely F. Ferrier and J.M. Du Bois-Aymé ${ }^{163}$, who had discussed the possibility of an axiomatic economic theory, even if not really of a mathematical theory. In addition, Fasiani says that the distinction made by Fuoco between economics and applied economics represents an antecedent over Pellegrino Rossi ${ }^{164}$. In $\S 35$, Fasiani recalls earlier attempts of application of mathematics to economics due to Giovanni Ceva, Beccaria, Silio, Vasco, Frisi, Valeriani, Lloyd, Isnard and Canard. In $\S 36$, Fasiani states that "the most original part ... is the attempt to consider the time factor in the right perspective" (p. 91) and considers that this is a consequence of the results achieved by Fuoco in his previous "The Magic of credit ${ }^{165 "}$. Then, Fasiani quotes a large excerpt that occupies the entire section and merely notes its strong originality, "leaving it to others ... the care to clarify its theoretical value" (p. 96). §37 consists of a single paragraph, in which Fasiani says that in the successive examples of application of algebra to economics, Fuoco "refers to two discus-

${ }^{163}$ Ferrier, F., Du Gouvernement considéré dans ses rapports avec le commerce, Paris : Perlet, 1805; Du Bois-Aymé, J., Examen de quelques questions d'économie politique, et notamment de l'ouvrage de M. Ferrier intitulé Du gouvernement considéré dans ses rapports avec le commerce, Paris: Pelicier, 1823.

${ }_{164}$ Rossi, P., Cours d'économie politique, Paris: Guillaumin, 1854;

${ }^{165}$ F. Fuoco published his Magics of credit under the name of: De Welz,G., La magia del credito svelata, Napoli: Nella Stamperia Francese, 1824. 
sions. The first is his work ... which has obviously such a low value that allows me to dispense with any further analysis. The second is linked to the names of Verri, Frisi and Lloyd and perhaps deserves some more consideration" (p. 96).

Fasiani devotes $\S 38$ to documenting that "it is an error to cite Verri $\ldots$ as the author of the small formulas that explain the theory of value" (p. 96). It is true that they appear in Verri's Meditazioni ${ }^{166}$, but only in a footnote written by Frisi. However, in the subsequent $\S 39$, Fasiani states that this Frisi's small formula: "is simply the translation with symbols ... of an algebraic relationship expressed by Verri" (p. 98). In the remaining part of the section, Fasiani reproduces "in its entirety" the mentioned relationship. $\S \S 40$ to 42 Fasiani presents some evidence about the criticism and the variants of the "Verri-Frisi small formula", recalling G.B.Venturi, Ferroni, Ortes, Valeriani and Gioja, with plenty of citations. $\S 43$ is devoted to Lloyd's formula, to which also Fuoco was interested in: "which is beneficial to express the quantity theory of money" (p. 112). Then, Fasiani actually deals with the formula of Cagnazzi ${ }^{167}$ regarding the speed of the circulation of goods: "that is strangely similar to Marget's formula" 168 .

In $\S 44$ Fasiani states: "I have nothing to add about the content and value of the Essay, because this is not my concern" (p. 115). Then, he continues by pointing out (documenting with long footnotes) that this Fuoco's essay is: "more interesting for the methodological prob-

${ }^{166}$ Verri, P., Meditazioni sulla economia politica, Napoli: Gravier, 1771

${ }^{167}$ Cagnazzi, L. Elementi di economia politica, Napoli, 1813

168 A. W. Marget, The Definition of the Concept of a "Velocity of Circulation of Goods" in Economica, 1932, No. 38, Nov., pp. 431-456 
lem than for the contribution it made to the mathematical theory of political economy. Nevertheless, and although it is perhaps not as strong as many others, has had a very better luck, because it is very commonly cited" (pp. 115-117). Fasiani's opinion is that this fact depends on Scialoja and Cossa ${ }^{169}$. However, Fasiani has the idea that Scialoja's and Cossa's quotes were not actually accompanied by the previous reading of Fuoco's essay (p. 118).

The following $\S \S 45$ to 47 consider Essay 5, that regards the origin and nature of wealth. Fasiani thinks that, perhaps, Fuoco drew from the work of Lauderdale and Bosellini ${ }^{170}$, but he also states that: "it seems to me to find in it no substantial new ideas or views, but rather the refining of a range of issues which were under discussion at the time" (p. 119). In §45, Fuoco's definitions of public and private wealth are recalled, while in $\S 46$ Fasiani reports about "some very important issues" on which Fuoco focuses. Among these issues, there are the following: i) whether "wealth is in the price of things rather than in its value, ii) whether "wealth and its increase are achieved by imports or exports" (p. 121), iii) whether "there may be unproductive work" as stated by Say and opposed by Storch ${ }^{171}$. In $\S 47$, Fasiani recalls that Fuoco was a partisan of free trade and that his views on

\footnotetext{
${ }^{169}$ Cossa, L., Introduzione allo studio dell'economia politica, Milano: Hoepli, 1892; Scialoja, A. I principii della Economia sociale esposti in ordine ideologico, Napoli: Palma, 1840.

${ }^{170}$ Lauderdale, J., An inquiry into the nature and origin of public wealth, London: Longman and Rees , 1804, Bosellini, C., Nuovo esame delle sorgenti della privata e pubblica ricchezza, Modena: Vincenzi e comp., 1816-1817.

${ }^{171}$ Storch, H. Cours d'économie politique, ou, Exposition des principes qui déterminent la prosperité des nations, avec des notes par J.-B. Say, Paris: Aillaud, 1823.
} 
luxury induced him to consider it not harmful to the increase of national wealth.

In $\S 48$ and $\S 49$, Fasiani refers on the sixth essay like a: "violent diatribe against a speech by one of those academicians de' Giorgiofili, who do not seem to enjoy the sympathies of Fuoco" (p. 123). First, Fasiani identifies the Academic in Pietro Colletta, who had really "a very modest standing", and then he states that the merit of the essay is merely in the "large and abundant citations ... to which he sometimes adds remarkable comments" (p. 124). To this essay it is attached an appendix on the use of machines, which Fasiani refers to in $\$ 49$. It appears that the main purpose of that appendix is "to criticize... a memory of another academic", still anonymous. About that identity, however, Fasiani only makes some guesses.

In $\$ 50$, Fasiani refers about the seventh essay, which deals with principles of morality and economics. He states that the essay might be of interest to those who want to investigate the relationship between economic thought and moral thought in the early $1800 \mathrm{~s}$, but there is nothing that may interest the economic theory. \$51 contains the last, brief message that Fasiani leaves it to his readers, i.e. that they may: "penetrate more deeply the thought of Fuoco". In fact, he is confident that it will not be a "wasted effort" because, according to him, Fuoco is "on the top of the greatest thinkers in economic matters that Italy has had in the period that runs from Scialoja to Verri" (p. 131).

Finally, it is here reported Fasiani's: Contributi di Pareto alla scienza delle finanze (Pareto's Contributions to the Science of Public 
Finance) (1949) ${ }^{172}$, which is a 44 -pages essay. The first three sections are devoted to a sort of introduction, in which, first of all, Fasiani recalls the extremely negative opinion, occasionally expressed in his writings, by Pareto in regards of "the science of finance and its scholars". This is primarily in the Trattato di sociologia $^{173}$, in which the science of public finance is defined as a set of derivations, and then in his correspondence, particularly in some letters to Griziotti and to Sensini ${ }^{174}$. In the letters to Griziotti, Pareto states that no taxpayer makes abstruse calculations, that the state is a metaphysical entity, and that public needs do not exist. In addition, it is not possible to know how the state's policies modify economic and sociological equilibria: this is so because, if we know little of the economic equilibrium, essentially ignore all of sociological equilibrium. From the letters to Sensini those judgments are confirmed: the Science of public finance is "labelled science, but it is not even an art"; from the scientific angle, the value of the best public finance treatise "is nearly zero".

At this point it may seem strange that Pareto incites Sensini to deal with public finance, but the reason is: "in that field there is much to

172 The essay was reprinted in: Vilfredo Pareto, l'economista e il sociologo: scritti nell'anniversario della nascita, Milano: casa editrice Rodolfo Malfasi, 1949. English translation: "Pareto's Contributions to the Science of Public Finance", in Michael McLure: The Paretian School and the Italian Fiscal Sociology, Palgrave Macmillan, 2007, pp.266-305. In this paper, the quotes are referred to that translation.

${ }^{173}$ Pareto, V., 1916,Trattato di Sociologia generale, Vol. I and II, Firenze: Barbèra.

${ }^{174}$ Pareto's correspondence with prof. B.Griziotti is published in Griziotti, B., 1943, Sugli effetti dei prestiti e delle imposte e sulla scienza delle finanze (lettere al Prof.Benvenuto Griziotti), in Giornale degli economisti e Annali di economia, pp.133-140; Sensini, G.: Corrispondenza di Vilfredo Pareto, 1948. 
be done". Then, Fasiani recalls that, according to De PietriTonelli ${ }^{175}$, Pareto had indicated the structural lines inherent to the science of finance, and this Fasiani's essay aims essentially to illustrate such lines.

Secondly, in this introduction Fasiani seeks to explain why Pareto attracted on himself a "feeling of peerless aversion" (p.136). This depended primarily on the fact that Pareto had used to communicate in a form "sharp and stinging" (p.271). Secondly, it depended from the substance of his message. In fact, to prove the truth of his claims over those of other scholars who were far away from his experimental-logical world, Pareto could only go in search "for their weak point, where logic is lacking, where their flawed scientific framework reveals the metaphysical or sentimental foundation" (p.271).

The rest of the essay is devoted to the discussion of Pareto's contributions to the science of finance, which Fasiani classified into three groups, namely: A) fragments on some topics in a certain measure connected to public finances, B) the methodological approach of the social sciences, to which also public finance belongs, C) fragments that form an important nucleus of a general theory of public finance.

As regards point A, Fasiani recalls: 1) Pareto's law of the distribution of income, which Barone ${ }^{176}$ and Crosara ${ }^{177}$ used for their attempts to formulate principles of tax distribution, 2) some clarifications on progressive taxation, occasioned by a criticism that Pareto in

\footnotetext{
${ }^{175}$ De Pietri-Tonelli, A., Vilfredo Pareto : 15 luglio 1858 - 19 agosto 1923,Roma: Tip. delle terme, 1935.

${ }^{176}$ Barone, Enrico, 1911-12, Scienza delle Finanze, reprinted in Le opere economiche, vol. III, Principi di Economia finanziaria, Bologna: Zanichelli, 1937.

${ }^{177}$ Crosara, A., Il concetto di redditiere indifferente, Padova: Gregoriana, 1948. 
1895 had raised to his friend Tullio Martello, 3) occasional comments on the public debt (in the Trattato di sociologia, and in the letters to Griziotti).

As for Pareto's law, Fasiani recalls that Barone: "drew an 'objective criterion' for the distribution of the tax burden ... which he called 'economic principle' “ (p. 274). In essence, Barone proposes the tax system that "less hinders the development of the average income". The reason is that, according to Pareto's law, the growth of average income is linked to the increase of the minimum income and to an improvement in the income distribution ${ }^{178}$. Fasiani notes that "the choice of the principle ... is not 'scientific' ... [it is] due to sentiments, judgements, desires that necessarily belong outside the field of logico-experimental research" (italics in the original, p.275) ${ }^{179}$. About the use made by Crosara of Pareto's law, the reference is to Fasiani (1946b), because in that essay, Fasiani takes care of that argument specifically: see above, $\$ 2.1$.

As regards the progressive tax, in a letter written to Martello about his work on progressivity ${ }^{180}$, Pareto: "in particular he proves (a) that a tax can be progressive without getting to the point... of absorbing the whole income, and (b) that with such a tax... the state can earn,

${ }^{178}$ Barone, Scienza delle Finanze, cit. p.46.

${ }^{179}$ From this, Fasiani concludes that Barone has made use of the concept of Pareto in contrast with the "teachings of its discoverer" (p.275). In reality, Barone's principle seems designed to achieve an efficient equilibrium: see Fossati, A. Vilfredo Pareto's influence on the Italian tradition in public finance: A critical assessment of Mauro Fasiani's appraisal. Forthcoming in European Journal of the History of Economic Thought, vol.20:2, May 2013.

${ }^{180}$ Martello, T. L'imposta progressiva in teoria ed in pratica, Torino: Utet, 1895. 
by surcharging the more substantial incomes, as much as, and more than, what is lost by raising lower incomes" "(p. 276).

On public debt, Fasiani notes that Pareto has never directly dealt with the Ricardian problem of choosing between debt and taxation. In the Trattato di sociologia, public debt is considered only as a transfer of income from the rentier class to other classes, even though some Pareto's expressions "could well lead one to suppose that he thought, through public debt to transfer on future generations part of the burden deriving from expenses that have been met" (p. 277). In the correspondence with Griziotti, first of all Pareto confirms that the problem of the burden is unimportant, because in reality the redistributive aspect is preminent. Secondly, he stresses that the effects of debt and the tax should be compared mostly under the sociological approach. And so the choice between debt and taxes is made not according to their different burden, "but in accordance with some position of sociological equilibrium" (p. 279).

With regard to point $\mathrm{B}$, Fasiani notes first that "the hints, the criticisms, the exhortations that appear here and there in his works and in his letters" show that Pareto could conceive no specific methodological problem as regards the science of public finance, because: "there could only exist the problem of the methodology of social science" (p.279). From Pareto one can only take the general idea that the investigative key of the science of public finance can be found only in the methodology of social sciences, i.e. of sociology.

At this point, Fasiani considers it important to report some essential features of the Pareto methodology of social sciences. Recalling that Pareto was attempting to build a social science with the basic characteristics of logico-experimental sciences or, as others prefer to say, 
physical-natural sciences (p.280), Fasiani uses his pages from 280 to 293 to recall its essential principles, and to draw inferences regarding the possible construction of a science of public finance consistent to such principles. Cornerstone is that: "perceptive propositions, categorical imperatives, consequences drawn from arbitrary principles which do not show the characteristics of mathematical hypotheses" (p.280) must be excluded ${ }^{181}$. The Paretian approach also implies that the premises must be clear and that judgments can only regards the capability of means to reach an end. If, as often happens in economics (and public finance) judgments end up by entailing the selection of goals, the activity is no longer scientific (p.283). The science of public finance must move away from what is emotion, passion or interest, because attention must be paid on 'that which is' rather that 'which should be' (p. 284) ${ }^{182}$.

For this reason, even if Fasiani considers Ferrara as the first great Italian economist, the way in which the latter regards public intervention in the economy, is deeply far from the Pareto concept of science. His thought "was the sublime manifestation of a mind thinking under the power of a passion ... [but] it was not, nor could it be, the systematic and - alas! - cold knowledge, of those who only looks for uniformity" (p.285). That of Ferrara was a science non-experimental, regarding "a wish, an aspiration or, better still, a faith" (p. 286), emphasis in the original). The non logico-experimental theories are mastered by "scattered principles, that are accepted a priori, independently from experience...they do not depend on the facts, but the

\footnotetext{
${ }^{181}$ Here, Fasiani is quoting Borgatta, G., Vilfredo Pareto, in La Riforma sociale, 1924, p.388.

182 This seems to hint to the controversy with Einaudi: see below, $\S 9$. 
facts depend on them; they govern the facts" [Pareto, Trattato di sociologia, cited by Fasiani, p.286]. In contrast, in logico-experimental theories the principles are abstract propositions tentatively accepted only as are consistent with the facts.

In summary: "elimination of preconceptions, prejudices, judgements of good and evil, moral sentiments are, according to Pareto, the fundamental presuppositions, for the creation of a social science, and therefore also of a science of public finance" (p.289).

Pareto, however, also gave to Sensini two tips on how to investigate in the field of public finance: the first is to distinguish between pure science and the study of concrete phenomena. According to the latter one should try "to find out if there are uniformities, which will then be in aid of science". The second suggestion is: "the tax-payer is not aware of many effects of the taxes, or... of many fiscal measures. His actions, therefore, are not of the logical type, with which political economy deals, and whose theory is less difficult, they are instead actions of the non-logical type, whose theory is far more difficult" [Pareto, Letters to Sensini, cited by Fasiani, p.290].

According to Fasiani, the main methodological lesson to be learned from Pareto is that the actions that are the subject of study of the science of public finance are largely non-logical actions. Their explanation depends on the identification "of relationships of interdependence that exist between residues, interests, derivations and the circulation of elites", i.e. on a design of the theoretical representation of human actions which are for the most part non-logical (p. 291). In conclusion, Fasiani believes that "the notion of the existence of a non-logical activity in the fiscal phenomenon can and must be of great relevance in the future developments of the science of public 
finance" (p. 292). However, even if "something in this sense was carried out by Borgatta, Sensini and Murray ... these writers [could not] go beyond the boundaries marked by the current knowledge of sociology" (p. 292).

As far as point C), there are three topics of "substantial importance in a general theory of public finance: the concept of public need, the concept of hedonistic maximum and the idea of the content of fiscal activity" (p.293).

The concept of public need is indeterminate (it is a derivation), can not be satisfied by logical actions, albeit it plays a major role in the circulation of elites. It follows that, according to Pareto, in a logicoexperimental science of public finance there has no place for the concept of public need. It is simply the need that it is satisfied by government intervention. Fasiani notes, however, that the doctrine in general has not received this Paretian message, with the exception of Barone, Murray and Borgatta ${ }^{183}$.

On the concept of hedonistic maximum, Pareto has far outpaced the approach of Pantaleoni, because he makes the distinction between maximum "for" and maximum "of" the community, that Fasiani specifically used in the definition of his polar cases of state, i.e. the "cooperative state" and the "tutorial state" 184 (p.167). In particular, while in the Pantaleoni's maximum one must first evaluate and then

\footnotetext{
${ }^{183}$ Of course, Fasiani must be added to the scholars who are no longer basing on the concept of public need.

${ }^{184}$ Regarding the Paretian maxima for and of the community see: Fossati, A., Pareto's influence on scholars from the Italian tradition in public finance, in Journal of the History of Economic Thought, forthcoming in the spring 2013 issue, vol 45, no. 1. On Fasiani's polar cases of state, see specifically Fasiani (1941) and Fasiani (1951).
} 
add up the individual preferences, in the Paretian maximum "of" the community, the ruling class in some way "weigh" the individual assessments. In other words, it applies its own system of weights to its assessment of individual preferences. However Fasiani notes that the current doctrine still does not use this Paretian contribution because it is: "grounded in Sax's and Seligman's hedonistic doctrines" (p. 298).

The last contribution of Pareto refers to what Fasiani has called the "idea of the content of the fiscal activity", i.e. to the consequences that the Paretian scientific approach had caused "to the extreme optimism of theories of the 1800's", regarding public finance (p.300). The fact is that Ferrara saw the history of taxation as a history of abuse, but his philosophy of taxation induced him to consider taxes not only as legitimate, but also as voluntary. Similarly, De Viti had tended to confuse his cooperative state with the modern state of his day, based on democracy, and Emil Sax ${ }^{185}$ had shared the tendency to voluntarism, marginalism and idealism which are the core of the dominant science of public finance still in early 1900. "The results of the incomplete theory ... are at once presented as the logic and complete explanation of the concrete phenomenon. Here the artifice lies in eliminating through hypothesis the facts that contradict the theory, in order then to conclude that therefore the theory is true!... what kind of man will ever be able to accept with diffidence and caution a theory that demonstrate the logicality of what he hopes and wishes for? "(p.302). It is "against these conventional distortions of reality

${ }^{185}$ E.Sax, La teoria della valutazione dell'imposta, in Giornale degli economisti, May 1924, pp.276-312 
that Pareto's reaction manifested itself" (p.302), firstly in the "Systèmes socialistes", then in the "Manuale" and finally in the "Trattato di sociologia."

Fasiani concludes that Pareto has indicated "the path of the new research ... in the midst and against the optimism of his times" (p. 304). This path begins with the rejection of idealism and considers public needs neither predetermined nor chosen by economic criteria. It is the: "path followed with blind faith by Sensini, with limited faith by Borgatta and with many uncertainties by Murray. And it is a path that we have all touched upon, even those of us who do not yet believe in the possibility of a real sociological science"(p. 304).

\section{The dispute with Einaudi}

The dispute with Einaudi originated from the publication of Fasiani's manual Principles of Public Finance (1941), because of the general criticisms that Einaudi addressed to that book with the review article on his own journal ${ }^{186}$. Then, Einaudi rejected "the indictment $\ldots$ indeed very serious' concerning the state-factor of production" 187 . Next, he attacked the concept of "public group"188. Then,

\footnotetext{
${ }^{186}$ Einaudi, L.: Scienza e storia, o dello stacco dello studioso dalla cosa studiata, in Rivista di Storia economica, 1942, pp.30-37

${ }^{187}$ Einaudi, L., Del concetto dello 'stato fattore di produzione' e delle sue relazioni col teorema della esclusione del risparmio dall'imposta, in "Giornale degli economisti e annali di economia", 1942, July-August, pp.301-331.

${ }^{188}$ Einaudi, L., Di alcuni connotati dello stato elencati dai trattatisti finanziari, in Rivista di Diritto finanziario e Scienza delle Finanze, 1942, December, pp.191-200 .
} 
Einaudi criticized Fasiani's polar cases of state ${ }^{189}$. The last argument of Einaudi, was his reply to the arguments of Fasiani ${ }^{190}$.

To the original review article, "a correspondence followed, in particular about the connection between the monopolistic state and a general tax"191. On the other hand, Fasiani confirms: 'this time my reply is published in a journal, rather than in a private letter, as happened last time" [Fasiani 1942d, p.491, footnote]. And, on the other hand, in [Fasiani 1943b, p.62] he mentions 'three' Einaudi's criticisms to the Principii, "two or maybe three polemical replies of mine ....and a fourth very cordial dispute.. on other points of my manual, with writings and replies, not intended for print". Of this controversy the point of view of Einaudi has been detailed in [Einaudi, 1943, footnote p.26-28] $]^{192}$.

Fasiani replied to the original Einaudi's review article with one or more letters (see above), and to the Einaudi's criticism concerning the state-factor of production with the first paper reported here (Fasiani 1942c), which was followed by an Einaudi's short note ${ }^{193}$ published as an appendix to the same Fasiani's essay. Then, Fasiani replied to the criticism regarding the characteristics of public groups with the second paper here reported [Fasiani 1943b], which was fol-

\footnotetext{
${ }^{189}$ Einaudi, L., Ipotesi astratte ed ipotesi storiche e dei giudizi di valore nelle scienze economiche, Torino, R.Accademia delle Scienze, 1943, 78, II: 57-119.

${ }^{190}$ Einaudi, L., Discutendo con Fasiani e Griziotti di connotati dello Stato e di catasto e imposta fondiaria, in Rivista di Diritto finanziario e Scienza delle Finanze, 1943, pp.178190.

${ }^{191}$ Einaudi, L., Ipotesi astratte ed ipotesi storiche..., cit., p.26, footnote.

${ }^{192}$ Einaudi, Ipotesi astratte....,cit..

${ }^{193}$ Einaudi, Postilla critica, Giornale degli Economisti, 1942, pp. 512-517
} 
lowed by a replica of Einaudi ${ }^{194}$ that enclosed a further Fasiani's note [Fasiani 1943c], which is the third essay here reported. Finally, to the criticism regarding the polar cases of state ${ }^{195}$ Fasiani replied only with the second edition of his Principii, published posthumously.

Thus, here are reported the three Fasiani's papers: Of the theory of tax productivity, of the concept of 'state factor of production' and of the theorem of the double taxation of savings (1942); Of some characters of the public group and of a definition of public needs (1943); A Note added to L.Einaudi, Discussing with Fasiani, Griziotti about the characters of the public group and about the cadastre and land taxes (1943).

The first one is: Della teoria della produttività dell'imposta, del concetto di 'stato fattore della produzione' e del teorema della doppia tassazione del risparmio (Of the theory of tax productivity, of the concept of "state factor of production" and of the theorem of the double taxation of savings) (1942). There, firstly Fasiani summarizes the position of Einaudi in three points: A) the old theory of reproduction contains the simple truth that there is a relationship between taxation and public services; B) the state is still a factor of production, although sui generis and C) Fasiani does not recognize to the state the feature of factor of production, only because he [Fasiani] wants to reject a theorem of De Viti that denies the double taxation of savings.

\footnotetext{
${ }^{194}$ Einaudi, Discutendo con Fasiani...cit.

${ }^{195}$ Einaudi, Ipotesi astratte.... cit.
} 
About point A), Fasiani concisely summarizes Stein's reproductive theory noting that one can not, as Einaudi does, reducing it either to the mere declaration that there is "necessary link between all the public services and the payment of taxes" (p. 495), or to the statement that to talk about tax productivity "in earnest, public services need not even exist". Thus, Fasiani claims that De Viti has perfected Stein's theory of productivity by applying it to the case of the cooperative state. Finally, he confirms that the old theory of productivity is contained in De Viti's assumption of state-factor of production.

About point B), Fasiani reiterates that the state is not an input like the other factors that contribute to production processes, even though it may be a factor in the generic sense, namely in the sense that it somehow affects the productive processes. However, he believes that De Viti had used the word factor in the strict sense. For the latter, the assumption of the state-factor of production means that: "work, land and capital are combined in certain ways in order to obtain services that are complementary ... to all acts of production and consumption. And it is this set of work, land and capital, combined by the state, which requires a payment, a portion of the total production, exactly as required by the labour, land and capital that are combined in the production of private goods" (pp. 500-501).

By contrast, Fasiani believes that public services are not complementary to private goods, and therefore he rejects the argument of De Viti. Also, for him the fact that public services are useful to everybody has nothing to do with the concept of state-factor of production in the strict sense. For Einaudi, on the contrary, all public services are factor of production "because of the influence ... exerted on the activities of entrepreneurs and workers" (p.502). On the other hand, 
for Fasiani the very idea that the state, with maintaining security, creates the enabling environment for production, may not permit to consider the state as a factor in the strict sense: at most, it would be a prerequisite. Anyways, the same Einaudi states that the state is a productive factor 'sui generis': then, Fasiani can argue that it is only "the sound of the words we use, not the view of things" that separates him from Einaudi (p.508).On the other hand, in the 'Postilla critica', Einaudi seems to agree: "I have the impression that the dispute is solving itself, not because of me, in a mere matter of words" (p.512).

On point C), namely on Einaudi's statement that Fasiani denies the state-factor of production only to reject De Viti's thesis of the double taxation of savings, Fasiani notes: that for Einaudi the double taxation remains still valid, even accepting De Viti's premise that the state is a factor of production. Thus, Fasiani may argue that Einaudi only by denying the very idea of state-factor, may maintain his point. ${ }^{196}$.

The second paper: Di alcuni connotati del gruppo pubblico e di una definizione dei bisogni pubblici (Of come characters of the public group and of a definition of public needs) (1943) is Fasiani's second public reply to the criticism raised by Einaudi to his Principii.

Firstly, Fasiani summarizes his own position about the characters of public groups in the form of proposition A, and summarizes as proposition $\mathrm{B}$ his position as he thinks that Einaudi perceives it. No

\footnotetext{
${ }^{196}$ I have no doubt that Fasiani is right: in fact, in order to make his assertion Einaudi had to say that that the state is a productive factor 'sui generis', i.e., it is not a true factor.
} 
doubts that proposition $\mathrm{B}$ is less nuanced and less detailed than proposition A. Thus, Fasiani is formally correct by observing that proposition B may induce the reader to think that Fasiani did not consider all the possible states, but only those with the four characters. It is also true, however, that this point does not have great importance, given that "Einaudi's criticism seems to turn to topics far more substantial" (p. 64). In all ways, according to Fasiani, his proposition A should be always considered together with his following thought, in the sense that "the choice of the public needs ... varies with the changes in the political life" (p.65) and in his opinion this necessarily leads to the scientific study of polar cases of the state $^{197}$.

Fasiani continues by noting that "the criticism of Einaudi contains two propositions": 1) the four characters are not appropriate to characterize the public groups, 2) it is irrelevant say that public needs are the needs satisfied by the state really, because what matters is why and how the state satisfies some needs. To Fasiani, the first proposition seems "a pure and simple premise to get to the second proposition " (p. 66), so that he devotes the last and most meaningful part of the essay to the latter topic.

About the first proposition, both authors acknowledge that the matter of the litigation is very thin, and the differences of positions

\footnotetext{
197 This specification contains the core of the primary criticisms raised by Einaudi in his first review of the Principii, which has mainly dealt with Einaudi's allegation that Fasiani had failed his unifying design regarding Public Finance. Thus, Fasiani's Principii would only be the assembling of three separate essays, not particularly consistent with each other [Einaudi, Scienza e storia...,cit. p.65-66].
} 
are rather modest. In short, Fasiani believes he can identify the public group when the characters of universality, coercion, heterogeneity and variability are all co-present. Einaudi, in a historiographical perspective, notes that these characters are not always present in all real states, with particular reference to coercion. However, he does not believe that this observation constitutes a criticism to the list of Fasiani's characters. Fasiani recognizes that one or more of the characters proposed by him may have not been present historically, but still believes that the point of view of Einaudi is peripheral, i.e., it is relative to small fringes, and that it does not invalidate scientifically his claims .

Fasiani considers the second proposition as the most significant, if understood as "implicit claim that, in any time and at any space, the state may arbitrarily declare public all the needs that any whim can suggest" (p.76). In that case, as regards the discussion of choice of public services, the question would shift to: "whether it is more or less reasonable to talk of tendencies, as described in the polar cases considered, as if they were merely the manifestation of the will of the ruling class" (p.77) (emphasis in original). For Fasiani, the key question is whether "the ruling class has a very limited ability to vary the choice of public services", as Einaudi thinks, or whether it can move in very broad limits (p.77). Although Fasiani is not sure whether he has really understood Einaudi's position, he thinks it appropriate to clarify his own point of view, because "these notes are primarily intended to clarify positions and problems" (p.77).

In point of fact, Einaudi is very close to the position that the modern state is an ethical state, that provides useful services to the community, except for small fringes in fact negligible, so that "the ruling 
classes ... can not but operate marginally as regards the public expenditure" (p.78), since they have few degrees of freedom. To the contrary, as regards Fasiani, the ruling classes can "move within very broad limits" (p.79).

In all ways, Fasiani believes that there is no way to prove whether it is strictly correct any of the two propositions, because: "they are based on 'impressions' " (p.79). Therefore, from his point of view, Fasiani cannot but to "take as a given the little that I know really. There are forces which push the state towards the monopolistic form ... forces that push toward the cooperative form and forces ...that push towards the modern form, in which prevails the interest of the group considered as a unit" (p. 82).

The paper: Postilla" a L. Einaudi, Discutendo con Fasiani e Griziotti di connotati dello Stato e di catasto e imposta fondiaria (A Note added to L.Einaudi, Discussing with Fasiani, Griziotti about the characters of the public group and about the cadastre and land taxes) (1943) is the last public reply to the criticism raised by Einaudi to the Fasiani's Principii. As always, the dispute is among gentlemen, but it is more and more difficult to ascertain the real reasons of the dispute. In this occasion, Fasiani observes that the dispute concerns the different way of thinking about science: as regards Einaudi, is looking for "the tasks which should be attributed to the state in a given historical moment. To that end, a theory which does not take into account all the nuances with which all the characters occur is certainly inadequate". By contrast, Fasiani in his Principii is pursuing a "much more modest goal" because is "trying to investigate that little that I am able to do. So I must eliminate deliberately all the vari- 
ables ... that characterize the state in a given historical moment" (p.191).

Still, the reader may have the impression that the "key" statement of Fasiani is that he pretends to discuss systems merely economic, i.e. he has no political implications in mind. In point of fact, indeed, his literal expression is "with respect to economic activity, the only which I am interested" (emphasis in original) (p.191).

As regards Einaudi, the following statement seem perhaps even more revealing: "Must I confess that my interest in science was born, as always in the social sciences, from a moral or political sympathy? And in particular from the hope ... to see gradually disappear the fact (and its dogma) of the absolute sovereignty of the state, of the leviathan state, which is the absolute master of life, and can issue every rule?" . Even more significant, perhaps, is the fact that, a few lines below, Einaudi says that the relevance of the study of the institutions that do not have all the characters indicated by Fasiani (which is to say, without the character of coercion) "has grown to one thousand double because in the present moment the fate of mankind depends on the choice that men have to make between the state with full sovereignty and the type of fragmentation of the same sovereignty between many states, coexisting in the same area" 198 .

It seem fair to me to conclude this report of the Einaudi-Fasiani dispute with a short comment. The controversy, albeit at a formal level of great courtesy between gentlemen, might seem rather specious, and the reasons for disagreement sounds quite paltry, even if the discussion appears deeply felt. The reader may perhaps find the

${ }^{198}$ Einaudi, Postilla critica, cit., p.181. 
debate somewhat pretentious, since he may have the impression that the contention is flowing underground, and that it can have metaeconomic reasons.

At the time Einaudi was seventy years old, and perhaps had little sympathy for the bold claim of his pupil Fasiani (then forty-three years old) to have completed the unifying work which had not succeeded to him: "Many years ago I flattered myself to build a manual of public finance based upon the simple idea of equality. I must confess that I am now convinced that from our scribbled subject of public finance it is not possible to deduce logically a doctrine by a principle ... it is vain the hope of being able to do in public finance something that has even a faint track of the bright jewels that have emerged from the workshops of Senior or Pantaleoni" ${ }^{199}$.

On the other hand, Fasiani in order to get his university chair after winning the competition for a professorship, had had difficulties owing to a political veto of the Fascist regime, which had been then passed just for the direct intervention of Einaudi, who had to write to Mussolini, head of the Fascist regime. Perhaps, therefore, such experience had induced Fasiani to remain close enough to the political lines of the country, albeit he was never involved in politics. By statements emerging here and there in his writings, however, it might seem that in fact he thought that the corporative fascist regime could be a third way, best of capitalism and communism.

What is true, is that Fasiani had not produced even a minimal outline of his third polar state, where the ruling class is in the search of a sociological maximum of the community in the Pareto meaning of

${ }^{199}$ Einaudi, Scienza e storia ...,cit., p.33 
the term. However, in referring to it as either "national", "modern" or "corporative", Fasiani seems convinced that the real tendency was moving towards this type of state. In the second edition of his Principii, however, the final name is "tutorial state", returning to the original terminology of De Viti de Marco (1888).

On the contrary, Einaudi had realized that such an abstract state, endowed with an absolute sovereignty can degenerate into a state of absolute moral evil. Thus, he may have thought to be authorized to distrust it, given the reality of the fascist state, characterized by totalitarianism and racial laws. Thus, behind the discussion it is possible that there be the different conception of "the modern state". Perhaps Einaudi had the idea that Fasiani's "modern state" might have identified the Fascist regime, which was rapidly degenerating from the original simple corporative state. Actually, the Italian racial laws were issued in 1939 and we are on the eve of 1943 when the war was raging, and Einaudi was on the verge of escaping in his Swiss exile.

\section{The Principles of Public Finance}

Like the ideal archetype of manuals, the two volumes of Mauro Fasiani's Principii di Scienza delle Finanze (Principles of Public Finance) (1941) are formally devoted to the students, but it is a work that really marks the foundations of public economics, at least as it was intended by the Italian tradition. The second edition, published posthumously in 1951, was edited on the basis of a fairly definitive 
manuscript which regarded, however, only the first volume ${ }^{200}$. Thus, volume II of the 1951 edition is only a reprint, with very few modifications, mainly printing errors ${ }^{201}$.

I think it possible to give here only a brief outline, merely descriptive of the main lines of the theoretical developments and pragmatic views described in the Principii. Firstly, however, I shall give some brief information regarding the modifications made in the second edition of volume I.

The revision covers removals, modifications and additions to the text, but even to many footnotes, as it happens in these occasions. Although numerous, these changes do not substantially alter the overall exposition, but are intended to make it even clearer. Moreover, a chapter on tax shifting in imperfect competition was added, and the original chapter on tax evasion has been divided into two new chapters, dealing, respectively, with the "legal" and with the "illegal" tax evasion.

The first volume of the Principii opens ${ }^{202}$ with two chapters devoted to the general theory of Public finance, i.e. to a discussion of the main methodological problems. Specifically, Fasiani discusses the object of scientific investigation, which he intends as the study of

\footnotetext{
${ }^{200}$ As editor, acted Aldo Scotto, who, after Fasiani's death, had been called to his university chair. As regards the criteria - exemplarily correct from the philological point of view followed by the editor, see Scotto's warnings on pp. xiii-xv of volume I, 1951 edition.

${ }^{201}$ For the exhaustive list of the modifications, see Aldo Scotto's warnings on pp. v-vi of volume II, 1951 edition.

${ }^{202}$ In this short outline, I am following the text of the 1951 edition, because it represents the last evolution of Fasiani's thought.
} 
the statistical uniformities regarding part of the economic activity of public groups.

With Pareto, he considers a clear separation between science and politics, science and morals, science and arts, and thinks that successive approximations are the necessary basis for scientific explanation. Drawing on Seligmans ${ }^{203}$, he defines a group as public when it presents the four characters of: i) universality (the group includes all the members of the community); ii) coercion, intended as indissolubility; iii) heterogeneity and variability of the needs satisfied by the public group; iv) indefectibility, or the inexistence of limits to its duration. As recalled above in $\S 9$, this was the object of Einaudi's criticism and of a sharp Fasiani's reply in (Fasiani 1943b).

The crucial idea, however, is that the economic activity of the public group is only a part of the general political phenomenon, but, as a first approximation, the political elements may be limited to the methodological assumption of three polar cases, i.e. the Monopolistic state, the Cooperative state, and the Tutorial state, in each of which it is defined differently the behaviour of the political elite ${ }^{204}$.

It is true that De Viti de Marco had considered already the very same three kinds of $\operatorname{state}^{205}$, but Fasiani made a very important quality change under two profiles. First, he considered them as polar

${ }^{203}$ Seligman, R.A., Theorie sociale de la Science des Finances, in Revue de Science et Législation financières, Paris: Marcel Giard, 1927. Originally published as The social theory of public finance, in Political Science Quarterly, 1926.

${ }^{204}$ This was the object of a second criticism of Einaudi: see above, $\S 9$.

205 De Viti had mentioned the Tutorial state only in his 1888 booklet, and in his subsequent analysis he -de facto- considered only the Cooperative state with only fleeting allusions to the Monopolistic state. In fact, De Viti had considered the modern state as almost coincident with the Cooperative state. 
cases, and not as historical states like De Viti, whose main idea was that the Cooperative state could have been identified with the current democratic state. Secondly, Fasiani had used the Paretian concepts of maxima for and maxima of the community in order to define or identify his polar cases.

Specifically, in De Viti's Cooperative state the general idea is that the public group behaves as a cooperative firm, so that the average cost is the basic price of the goods, public services included. By contrast, in Fasiani's Cooperative state the public choices are made in order to get a Paretian maximum for the community. Thus, in this polar case only economic efficient points of equilibrium should be reached, and the fundamental principle is: "no benefit to anyone, which may cause expense to others". The basic price of goods is marginal cost, public services included.

On the contrary, in the Tutorial state the governing elite is pursuing a Paretian maximum of the community, i.e. a sociological maximum for which individual utilities are weighted. Finally, in the Monopolistic state, the governing elite is pursuing their interests only ${ }^{206}$, but it is constrained by the political and economic reactions of the governed people.

Fasiani has devoted the first volume of his Principii to the Monopolistic State, and the second volume to the Cooperative state: in both such polar cases, the prices are determined by the market. He had no occasion to developing the theory of the Tutorial state, in

${ }^{206}$ In case there is a dictator, this notion is perfectly clear. When there is a class of politicians, it is not clear, however, if the politicians are pursuing a maximum for or of their limited community. My opinion is that Fasiani intended a sociological maximum relative to the governing elite. 
which, however, the system of prices should be modified or forced by the public policies.

The remaining chapters of the first volume of the Principii are devoted to the analysis of the polar case of the Monopolistic state. As recalled above, the governing elite in the Monopolistic state is constrained by the political and economic reactions of the governed people. But in point of fact, Fasiani develops the Monopolistic state mainly as the theory of the economic limits induced by the reactions of the governed class, even if the initial four chapters of Book I (Public finance in the Monopolistic state) are devoted to the phenomenon of fiscal illusion, drawing on Puviani ${ }^{207}$.

The fact is that the choice of public services is important only as a political constraint to the production of services, which are public only in so far as are useful to the governing elite. But the latter follows a maximising behaviour, which induces it to act in the manner that might reduce to a minimum the reactions of the governed class. From that, the huge relevance of fiscal illusions will follow, which may regards both the "public" services and the state taxing activity. Thus, Fasiani devotes one chapter to discuss the concept of fiscal illusion, and then two chapters to the fiscal illusions related respectively: i) to public expenditure, ii) to taxation. The fourth chapter is devoted to the limits incurred by fiscal illusions, because the latter may become even "negative".

Then, in the remaining chapters of Book I, Fasiani analyses the theory of the economic effects of taxation intended as constraints to

${ }^{207}$ Puviani, A., Teoria della illusione finanziaria, Palermo : Remo Sandron Edit., 1903. 
the predatory attitude of the governing elite. Chapter $\mathrm{V}$ is devoted to the related methodological problems, chapters VI to VIII to the shifting of special taxes, respectively in monopoly markets, competitive markets and in imperfect competition ${ }^{208}$. Chapters IX, X and XI regard respectively the backward tax shifting, the problem of time in the tax shifting process ${ }^{209}$ and to some effects of a general tax. The following two chapters are devoted to tax evasion, respectively "illegal" and "legal".

In summary, Fasiani's thought followed the path that in the Monopolistic state the governing elite uses public activity in order to satisfy its own wants as much as it is possible. It behaves in large part in a non-logical manner and according to the lines of least resistance. Thus, the fiscal system has the character of exploiting as possible fiscal illusions of the governed classes. However, limits exist to fiscal illusions, and other limits are determined by the economic reaction of the markets, so that tax shifting, and in general the effects of taxation, may limit the capability of burden the governed classes. Other important limits are determined by the legal and illegal recourse to tax evasion.

Fasiani's idea was that the analysis of the effects of taxation is not confined to the Monopolistic state case, in so far as it determines disturbances to the fiscal aims that any law-maker may want to realize. In Paretian terms, fiscal activity is non-logical, in as much as its ends do not coincide with its objective results. Thus, the effects of taxation also interest the Cooperative and the Tutorial states: in fact, Fasiani

\footnotetext{
${ }^{208}$ This chapter is based on Fasiani (1942a): see above, $\$ 2.3$.

209 As regards the work of Fasiani about time and tax shifting, see above, §2.2.
} 
considered them as a prerequisite for the analysis of both such polar cases. However, he discussed special taxation within the Monopolistic state, because it seems to him that their logical location can not be but there, where they play a dominant role. By contrast, the systematic analysis of the effects of the general tax is located in the second volume, because it belongs typically to the cooperative state.

The second volume of the Principii contains Book II (Public finance in the Cooperative state) and also seven Appendices ${ }^{210}$. The first chapter is devoted to the problems regarding the choice of the public services; chapter II discusses how to take the decisions that regard the quantity of the public services. The next two chapters discuss how to distribute the cost of the public services, that have, respectively the character of divisibility and indivisibility ${ }^{211}$. Then, owing to the fact that income taxation is necessary to fund the indivisible public services, the following chapters from V to VIII discuss the basic problems of taxing income. These are: the problems of the qualitative and quantitative discrimination of income, technical problems regarding taxes and the definition of the taxable income. In chapter IX the overall economic effects of the existence of taxation are considered in a framework in which monetary flows are circulating among the economic agents. Chapter $\mathrm{X}$ is devoted to the phe-

\footnotetext{
${ }^{210}$ See above, at the end of the present section. In the 1951 edition there is also the Appendix VIII, which, however, is due to the editor, and not to Fasiani. There, the editor discusses two pages, handwritten by Fasiani, that might be the object of a possible revision regarding the tax burden of a capitalist and of a labourer.

211 An indivisible service corresponds to the Samuelsonian public goods $Y=Y_{1}=$ $\mathrm{Y}_{2} \ldots=\mathrm{Y}_{\mathrm{n}}$. By contrast, for a divisible service the citizens are able to formulate a demand schedule.
} 
nomenon of the capitalization of the general tax and to the shifting of the special taxes. In chapter XI the limits to the tendencies of public finance in the cooperative state are discussed.

As this list highlights, the governing class is facing mainly information problems, because it has to implement its general political principle in a world as near as possible to the real world. Since Samuelson, we know that economic efficiency implies to provide public goods at individual prices ${ }^{212}$. But the governing class of the Cooperative state does not know the utility of the citizens, and thus it must have recourse to pragmatic rules in order to overcome its difficulties.

As regards the choice of the public services, the first pragmatic principle is that goods may be publicly provided if the state is able to produce it at a lower cost, or with a higher quality level. However, the state may provide certain services at a cost higher than the private in the case that the private provision may be a menace to the very existence of the Cooperative state. For example, a private army may be refused even in case it has a lower cost, and a natural monopoly may be advocated to the state even with a cost higher than that of a private, provided that the public price be lower than the price of the private monopolist.

Another pragmatic important principle is that the state may provide services that: i) are useful to everybody; ii) are useful to a part of the community but are indifferent to the others. In general, no service may be produced by the state if it benefits to somebody, but harms

\footnotetext{
${ }^{212}$ Samuelson efficiency condition for public goods was anticipated in De Viti de Marco's 1888 booklet: see Fossati, A. Public goods in the Italian tradition, in Il Pensiero economico Italiano, 2003, pp.99-122.
} 
other citizens. However, the exception is when the harmed minority is small and the majority will exit the community if the service is not provided. For example, a prison is harmful for robbers, but the large majority of the citizen wants its provision as a condition for remaining in the community.

In general, Fasiani's way of handle the matter of financing indivisible public services is to lean on traditional theory. In fact, he discusses the current literature pervasively, often making recourse to long and comprehensive quotations. However, he is using a framework such as to render the traditional arguments quite reasonable in the contest of his Cooperative state. For instance, in the chapter regarding the quantitative discrimination of income, he arrives to the progressive income tax by successive steps. First of all, he recalls that the incomes lower than a certain threshold must be exempted, in the interest of the overall community. Such a threshold is determined by politicians: the "minimum social income" is a fact, as far as the science of public finance is concerned.

Then, for the incomes higher than the threshold, Fasiani excludes that the governing class may know individual utilities. However, he argues that that the governing class can not but have certain rough ideas regarding the sacrifice caused by subtracting income to the generic taxpayers. Thus, the concept of proportional sacrifice worked out in the traditional theory seems to be conform to the fundamental principle of the Cooperative state "no benefit to anyone, which may cause expense to others", at least in the mind of the governing class. Moreover, they have the general idea that the higher the income, the 
lower is the sacrifice. It follows that the income tax will be progressive, i.e. the tax rate rises with income.

Fasiani's point might seem naïve: he does not pretend to provide scientific evidence, but only to explain fiscal phenomena, in a first approximation, by observing the behaviour of the politicians. Of course he cannot observe the real politicians of the Cooperative state, which is a polar case that do not exist. Nonetheless, all the governing classes have largely the same characters: only their aims are different.

It is not possible to discuss here the content of the single chapters regarding the Cooperative state; however, I would like to remark that much of that analysis may be relevant also in other frameworks, different from the polar case. The difference between it and the Liberal state seems very thin, and considering Fasiani's pragmatic approach, the conclusion might be that the real explicative content is much more important than what may seem at a first sight. To that end, Fasiani's pragmatism may play an important role; anyways, his conclusion is that: "the will [of the governing class] to model public finance second the ultimate principles of equality and individual utility is very often forced to deviations and compromises" (p.177, vol.II).

Finally, I conclude by giving some information regarding the Appendices to the Principii. The first Appendix regards the supply schedules at constant, increasing and decreasing costs, largely based on Sraffa's article ${ }^{213}$. In the second Appendix Fasiani, in a monopoly market, discusses the shifting of an excise under the assumptions of

213 P. Sraffa, Sulle relazioni fra costo e quantità prodotta, in Annali di Economia dell’Università Bocconi, 1925. 
rising and decreasing costs. The third Appendix regards the effect of a lump-sum tax, still under the assumptions of rising and decreasing costs. The fourth Appendix is devoted to the concepts of savings, investment and capitals, based on Clark ${ }^{214}$. The fifth and the sixth Appendices regard respectively the indifference curves and the determination of public/political prices, i.e. the prices concerning the divisible services, for which individuals make real demand ${ }^{215}$. The last Appendix is devoted to the problem of the double taxation of savings $^{216}$.

The Principii may or may not, depending on the point of view, be considered to have accomplished his author's ambitious task of building a general unified framework for the theory of public finance. At any rate it is here suggested ${ }^{217}$ that it represents the highest point of evolution of the general theory of public finance in the Italian tradition, considering that its characterizing features are:

i) from the assumption of polar cases of State, a number of logical developments follow that give a unitary character to the whole analy-

\footnotetext{
${ }^{214}$ J.B. Clark, Essentials of Economic Theory, New York: Macmillan, 1909; Clark, J.B.: The distribution of wealth, New York: Macmillan, 1899.

${ }^{215}$ Political prices correspond to the prices of the Musgravian mixed goods. Public prices correspond to the prices of publicly provided private goods, and are equal to the average cost. In the case that costs are rising, actually, pricing at marginal cost engenders a profit, and thus a non efficient equilibrium. Fasiani does not mention Barone, but this problem had been solved in Barone E., Il Ministro della produzione nello stato collettivista, in Giornale degli economisti, September 1908 pp. 267-93.

${ }^{216}$ See above, $\$ 4$ and Fasiani (1936a) in $\$ 2.2$. above.

${ }^{217}$ This final comment is taken from Fossati, A., Pareto's influence on scholars from the Italian tradition in public finance, in Journal of the History of Economic thought. Forthcoming in Journal of The History of Economic Thought, spring 2013 issue (vol. 45, no. 1).
} 
sis of the single aspects of public finance; ii) the Paretian characteristic of excluding value judgements from reasoning; iii) the fact that there is no solution of continuity with the thought of the preceding scholars of the Italian tradition, as proved by the constant critical discussion of previous contributions; iv) the pragmatic approach, which allows obstacles to be overcome without any ad hoc assumptions that lead far from reality; v) the fact that descriptive aspects of the fiscal system are excluded, unlike other previous Italian manuals.

\section{The minor works}

In this section, it remains only to report on the nine remaining known works of Fasiani. Three of them have only didactical scope, since they are the text of lecture notes: Elementi di economia (Elements of Political Economy) (1934), Appunti di Scienza delle Finanze, (Lecture notes on the Science of Public Finance) (1939-40) and Lezioni sulle riforme tributarie fasciste (Lecture notes on the Fascist fiscal reform) (1933-34). I have not been able to consult the first two: I recall that they have had only local diffusion and the $\mathrm{Li}$ brary of the Faculty burned out during the World War II.

As regards the lectures about the Fascist fiscal reform ${ }^{218}$, it is a booklet of 131 pages, the first half of which examines "the Italian tax system as it was on the eve of war, and as it became during the war" (p. 10), and describes its evolution until the post-war period, includ-

\footnotetext{
218 The only copy I was able to consult is the original copy of Fasiani, with printed his $e x$ libris, conserved among his books in the Library of the Bocconi University.
} 
ing the Meda reform project. In the remaining pages, Fasiani describes: i) the successive Government's regulations relating to direct taxes, ii) the elimination of extraordinary taxes imposed in wartime, also providing some data on revenues, iii) the "new laws of 1929-30" related to the taxes on exchanges and on consumption, iv) the reorganization of local finance and public debt. In the final remarks, Fasiani shows a clear satisfaction with the fiscal achievements of the regime, even though he recognizes that it started from "a frightening and chaotic confusion".

Other four works present only a very small scientific interest: it is the Introduction to the Italian translation of A.C. Pigou: The economics of welfare (1934), the Foreword to N.Pisani, La teoria finanziaria di Maffeo Pantaleoni (1940), the obituary regarding his collegue Emanuele Sella (1949) and the review article to two books of A. Da Empoli ${ }^{219}$.

As regards the Introduction, there is no comment on the merit of Pigou's book: the approach is learned but detached. Fasiani points out that from the original Wealth and Welfare (1912) have been derived not only the successive editions of The Economics of Welfare, but also A Study in Public Finance (1928), Industrial Fluctuations (1927) and The Theory of Unemployment (1933). Thus, "the entire work could be called a 'treaty on the state' " (p. VIII), while "the solutions offered by the author... are those that may be dictated by his scientific approach and by the economic-political environment in

${ }^{219}$ A.Da Empoli, Teoria dell'incidenza delle imposte, Reggio Calabria: Vitalone, 1926, and Riflessioni sull'equilibrio economico, Reggio Calabria: Vitalone, 1926 
which he lives" (p. IX). For the rest, Fasiani simply suggests two insights: a) whether from a survey of first approximation is permissible to draw practical lessons for a liberal political-economic system, as the U.K. of the time, b) the extent to which the assumptions of Pigou and the conclusions drawn by him could be applied to the Italian situation, which at the time wanted to be a corporative economic system. It is evident that both of these questions have answers implicitly negative. Regarding the first, it is known that Fasiani distrusted practical applications of the theoretical solutions: see below what has been said about Fasiani (1940). Regarding the second, the answer is a fortiori negative, at least to the extent that there was a real difference between the two economic systems. It follows a synopsis of the material presented in the five books mentioned above, and a detailed bibliography.

The second mentioned work is a heartfelt foreword to the doctoral thesis of Nicola Pisani on Pantaleoni's fiscal theory, that Fasiani was publishing on the Annals of the Faculty, after his death. Pisani had been practically the only real Fasiani's pupil, who, called to the front, was dead on the third day of war. The original thesis still stands between the material of Fasiani's library at the Bocconi's library.

The obituary of Emanuele Sella is the initial lecture of the course in Economics of the Faculty of Law at the Genoa University, which was previously held by Emanuele Sella. In that lecture, Fasiani has outlined the scientific and human figure of Professor Sella. The latter was a close friend of Luigi Einaudi, who was Fasiani's teacher.

Finally, the review article is a fair comment on Da Empoli's books, that highlights Fasiani's early scientific maturity. 
The remaining two works are: Problemi tributari inglesi (English fiscal problems) (1935) and A proposito dei recenti provvedimenti tributari italiani (On recent Italian fiscal measures) (1940).

The first work is the text of the lecture that Fasiani has read at the Bocconi University under the auspices of the "Serena Foundation" of London. The exposition is very plain and easy to follow. He provides a brief description of the English tax system and some essential clues on the basis of the technical principles of Adam Smith. Fasiani recalls that the British income taxes were the income-tax, the sur-tax and the three inheritance tax. Then, he comments on the evolution of tax revenues since before World War I, and how the Labour has moulded the British fiscal system between 1925 and 1932, namely the "no taxes on food" and "free breakfast" with respect to consumption taxes, and the strong characterization of the progressive income tax more and more pronounced until 1933-34, combined with a significant qualitative discrimination.

As regards A. Smith's criteria, Fasiani doubts that the British fiscal system may be in compliance with the first one (equality or equity) and the fourth (economy). The reasons are both the height of progressive rates and the excessive role played by the inheritance taxes in the tax progression. He notes that British reaction to the crisis of 1929 , initially has been to increase the tax on high incomes, but this policy had to be corrected in the subsequent years, because, before the crisis, average incomes were already subject to the maximum possible tax burden.

In conclusion, Fasiani recalls that the consequences of taxation in the real world are not those stated by the Colwyn Committee, so that 
it is not necessarily true that by reducing indirect taxation and by increasing income taxation, the aggregate demand may rise. In other words, nobody may be sure that in order to "meet the decrease in total tax revenue" the best solution necessarily is to rise the tax burden on "the income earners hit by the income tax" (p.364).

The last work here considered is: "On recent Italian fiscal measures", which does not seem to me a very important scientific essay, but is interesting because highlights Fasiani's approach to concrete phenomena. At the very beginning, Fasiani claims that, in his opinion, research should not be applied to concrete phenomena. Nonetheless, the essay attempts applying the theoretical scientific uniformities to concrete phenomena, which Fasiani, however, affirm to consider a "scientific adventure". Nevertheless, he examines the "major structural lines" both of the tax on wealth and of the tax on general exchanges (IGE), at the time newly introduced in Italy. The idea is to consider the two taxes in the historical context and in view of the entire tax system to which they belong. About the historical background, Fasiani quotes Mussolini according to whom there was no distinction between the economy of peace and the economy of war and also Pantaleoni who had stated that the war is endemic ( $p$. 215). As a result, the traditional distinction between ordinary and extraordinary finance seems to disappear and the tax system should have the feature to function both in time of peace and in time of war. It seems fair to note, however, that in 1940 Italy was at war.

On the ordinary tax on wealth, Fasiani recalls that the tax achieves the qualitative discrimination of incomes, using a large quotation from Meda. Moreover, he quotes Einaudi according to whom that tax might also "exacerbate" the progressivity of taxation. In addition, he 
notes that the qualitative discrimination carried out by the Italian complementary tax is inadequate. In fact, as regards mixed incomes, that tax did not make any distinction between salaries and capital incomes. From this point of view, then, the wealth tax may actually improve the desired level of discrimination.

About the general exchange tax (IGE) "the comment can only be uncertain" (p. 222). In all ways, it was a transformation of the previous tax on trade, which have been changed into a general tax, by extending the tax base both to retail trade and to professional and craft services. From a technical standpoint, compared to the previous tax on exchanges, the main innovation has been that the retail trade is assessed by subscription. The subscription fee is calculated on the basis of: i) taxable income both from the mobile wealth tax [imposta di ricchezza mobile] and the license fee [imposta di licenza], ii) the population of the Municipality. Regarding its incidence, the discussion is complicated because the Corporative state is presumed able to control prices, which interferes with the tax shifting, although it seems likely that in the long run the tax may raise prices. Thus, the burden shifts to the consumed income and to the productive factors, excluding labour. These considerations, however, seem to refer only to the part of the tax assessed by subscription.

Overall, the role of the two taxes is in accordance with the desired characteristics of the tax system, because they: a) affect the consumed income, also achieving a qualitative discrimination in favour of labour income, b) have a high elasticity, which allows them to automatically adapt the tax revenue to the market dynamics, which is very important in financing a war. Then, Fasiani makes a long quote from Flora, who in 1912 called for similar characters. 
Finally, Fasiani believes that the Italian tax system has acquired many reasonably positive characters, if compared with the one that has got out of World War I, thanks to these two new taxes, that he believes permanent, and not just temporary. Among these positive characters, Fasiani also includes the building of the Register of taxpayers (Anagrafe tributaria), which became operative, however, only with the fiscal reform of 1971.

\section{The works of Mauro Fasiani}

1926 Sulla teoria dell'esenzione del risparmio dall'imposta, in "Memorie della R. Accademia delle Scienze di Torino", Serie II, Tomo LXVI (1926), offprint of pp. 38.

1927 Review article to A.Da Empoli, Teoria dell'incidenza delle imposte, Reggio Calabria: Vitalone, 1926, and A. Da Empoli, Riflessioni sull'equilibrio economico, Reggio Calabria: Vitalone, 1926, in "La riforma sociale", 1927, pp.184-186.

1928a Sulla doppia tassazione del risparmio, in "Riforma Sociale", March-April (3-4), 1928, pp. 123-40.

1928b Review article to Irwing Fisher "The income concept in the light of experience», in "La Riforma sociale", May-June 1928, pp. 293-95

1929a Riflessioni su di un punto della teoria dell'illusione finanziaria, in "Atti della R. Accademia delle Scienze di Torino", Vol. LXIV, 1929, pp. 333-45. English translation: Some notes on an aspect of the theory of fiscal illusion, in Pasinetti, L. Italian Economic Papers, Il Mulino/Oxford University Press, 1998, vol. III, pp.89-97 
1929b Di alcuni effetti dell'estinzione del debito pubblico mediante un'imposta sul capitale, in "La Riforma Sociale", May-June (5-6), 1929, pp. 213-24

1929c Elementi per una teoria della durata del processo traslativo dell'imposta in una società statica, in "Giornale degli Economisti e rivista di statistica", vol.XLIV, August 1929, pp. 557-83, and September 1929, pp. 687-714. English translation: Materials for a theory of the duration of the process of the shifting, in "The Review of Economic Studies", February 1934, pp. 81-101, e February 1935, pp. 122-37 (see Card n. 19)

1930 Di un particolare aspetto delle imposte sul consumo, in "La Riforma Sociale", January-February, (1-2) 1930, pp. 1-20. English translation: On a Particular Aspect of Consumption Taxes, in International Economic Papers, vol.6, 1956.

1931a A proposito di una divergenza di opinioni fra alcuni scrittori di finanza, in "Rivista di Politica Economica", fasc. VI, June 1931, pp. 67788.

1931b A proposito degli effetti dell'esenzione dall'imposta delle case di nuova costruzione, in "La Riforma sociale", July-August (7-8), 1931, pp. 337-63.

1931-32 Contributo ad alcuni punti della teoria della traslazione delle imposte sui "profitti» e sui "redditi», in "Studi Sassaresi", vol. IX, 1931, Fasc. III, pp. 173-207, e vol. X, Fasc. I, pp. 1-51

1932a Contributo alla teoria dell' «uomo corporativo», in "Studi sassaresi”, fasc. IV, vol. X, 1932, pp. 317-335.

1932b Di un fenomeno di attrito, in "Rivista Italiana di Statistica, Economia e Finanza", year IV, n. 2, June 1932, pp. 248-81.

1932c Schemi teorici ed "exponibilia» finanziari, in "La Riforma sociale", July-August (4), 1932, pp. 481-514. 
1932d Velocità nelle variazioni della domanda e dell'offerta e punti di equilibrio stabile e instabile, in "Atti della R. Accademia delle Scienze di Torino", vol. LXVII (1932), pp. 383-425 (with 9 graphs out of text)

1932-33 Der gegenwärtige Stand der reine Theorie der Finanzwissenschaft in Italien, parti I, II e III, in "Zeitschrift für Nationalökonomie", Band III, Heft 5, pp. 651-91; Band IV, Heft 1, pp. 79107; band IV, Heft 3, pp. 357-88 (1932-33). Italian translation, with a number of changes due to the editor: La teoria della finanza pubblica in Italia, in Massimo Finoia (Ed.) "Il pensiero economico italiano (18501950)", Cappelli editore, Bologna, 1980, p.117-202.

1933-34 Lezioni sulle riforme tributarie fasciste, edited by the student Ettore Schiavina, G.U.F, Genova, a.a. 1933-34

1934 Introduction to the Italian translation of A.C. Pigou: The economics of welfare, vol. X of the "Nuova Collana di Economisti", Torino, Utet, 1934, pp. I-XVI

1934a Elementi di economia, Genova: Università degli studi, Scuola sindacale Dario Guidi, Gestione dispense

1935a Fluttuazioni economiche e economia corporativa, in "Annali di Statistica e di Economia", R. Istituto superiore di Scienze Economiche e Commerciali, Genova, Laboratorio Statistico Economico, year II, vol. III (1935), pp. 1-70.

1934-35 Materials for a theory of the duration of the process of the shifting, in "The Review of Economic Studies", February 1934, pp. 81-101, e February 1935, pp. 122-37 . It is the translation, with some changes, of Fasiani (1929c).

1935b Problemi tributari inglesi, in "Annali di economia", dell’Università Bocconi , 1935, vol. X, n. 2 (July), pp. 333-65.

1935c Imposta e rischio, in "Studi in onore del prof. Salvatore Ortu Carboni”, Roma, 1935, Tipografia del Senato, pp. 139-202. 
1936a Di un elementare problema di tempo e di alcune sue applicazioni finanziarie, in "Annali di Statistica e di Economia", R. Università degli Studi - Genova, Facoltà di Economia e Commercio, Laboratorio Statistico Economico, 1936, year III, vol. IV, pp. 68-114.

1936b Sanzioni, in "Annali di Statistica e di Economia", R. Università degli Studi - Genova, Facoltà di Economia e Commercio, Laboratorio Statistico Economico, 1936, year III, vol. IV, pp.125-137

1936c Precedenti di alcune teorie finanziarie, "Annali di Statistica e di Economia", R. Università degli Studi - Genova, Facoltà di Economia e Commercio, Laboratorio Statistico Economico, 1936, year III, vol. IV, pp. $195-240$

1937a Principi generali e politiche delle crisi, in "Annali di Economia" dell'Università Bocconi, vol.XII, 1937, pp.5-87

1937b Note sui «Saggi economici» di Francesco Fuoco, in "Annali di Statistica e di Economia" della R. Università, Facoltà di Economia e Commercio, Laboratorio di Scienze economiche, Genova, Year IV, vol. V, 1937, pp.1-131

1938 Buoni del Tesoro, in "Nuovo Digesto Italiano", 1938, Torino, UTET, offprint of pp.1-7

1939 Autarchia economica, in "Annali di Statistica e di Economia", R. Università, Facoltà di Economia e Commercio, Laboratorio di Scienze economiche, Genova, Year V, vol. VI, 1939, pp.1-52

1940a A proposito di un recente volume sull'incidenza delle imposte, in "Giornale degli Economisti e annali di economia", year II (Nuova serie), Fasc.1-2, 1940, pp.1-23

1940b Foreword to N.Pisani, La teoria finanziaria di Maffeo Pantaleo$n i$, in "Annali di Statistica e di Economia", R. Università, Facoltà di Economia e Commercio, Laboratorio di Scienze economiche, Genova, Year VI, Vol. VII-VIII, 1940, pp.1-2 
1940c A proposito dei recenti provvedimenti tributari italiani, in "Annali di Statistica e di Economia" della R. Università, Facoltà di Economia e Commercio, Laboratorio di Scienze economiche, Genova, Year VI, Vol. VII-VIII, 1940, pp.209-235

1939-40 Appunti di Scienza delle Finanze, Genova, G.U.F., a.a. 193940

1941 Principii di Scienza delle Finanze, Giappichelli, Torino, 1941

1942a La traslazione dell'imposta in regime di concentrazione industriale e in regime corporativo, in "Studi economici finanziari e corporativi dell'Università di Napoli”, 1942, pp.1-26

1942b Potenziale di lavoro e moneta, in "Annali di Statistica e di Economia”, R. Università di Genova, Facoltà di Economia e Commercio, Laboratorio di Scienze economiche, Year VII, vol. IX-X, 1942, pp. 70-137

1942c Appunti critici sulla teoria degli effetti dell'imposta sull'offerta individuale di lavoro, in "Annali di Statistica e di Economia", R. Università di Genova, Facoltà di Economia e Commercio, Laboratorio di Scienze economiche, Year VII, vol. IX-X, 1942, pp.142-223

1942d Della teoria della produttività dell'imposta, del concetto di «stato fattore della produzione», e del teorema della doppia tassazione del risparmio, in "Giornale degli Economisti e annali di economia", year IV (Nuova serie), Fasc.11-12, novembre-dicembre 1942, pp.491-511

1943a Sulla legittimità dell'ipotesi di un'imposta-grandine nello studio della ripercussione dei tributi, in "Studi in memoria di Guglielmo Masci", Milano, Giuffrè, 1943, pp.261-279

1943b Di alcuni connotati del gruppo pubblico e di una definizione dei bisogni pubblici, in "Rivista di diritto finanziario e Scienza delle Finanze", giugno 1943, pp. 62-83

1943c Postilla a: L. Einaudi, Discutendo con Fasiani e Griziotti di connotati dello Stato e di catasto e imposta fondiaria, in "Rivista di diritto finanziario e Scienza delle Finanze, 1943, pp.178-190", pp.190-191. 
1946 L'imposizione degli incrementi patrimoniali, in: Ministero per la Costituente, "Rapporto della Commissione economica", V Finanza, II Appendice alla relazione, 1946, Roma, Poligrafico dello Stato, pp.427-451.

1949a Emanuele Sella, in "Economia internazionale",vol. II, n.1 febbraio 1949, pp.50-67.

1949b Contributi di Pareto alla scienza delle finanze, in "Giornale degli economisti e annali di economia", year VIII (Nuova serie), Fasc. 3-4, March-April, pp.129-173. Reprinted in: Vilfredo Pareto, l'economista e il sociologo: scritti nell'anniversario della nascita, Milano: casa editrice Rodolfo Malfasi, 1949. English translation: Pareto's Contributions to the Science of Public Finance, in McLure, M, The Paretian School and Italian Fiscal Sociology, Houndsmill: Palgrave Macmillan, 2007, pp.266-305.

1949c La distribuzione dell'imposta e la «legge di Pareto» in una recente indagine teorica, in "Economia internazionale", vol. II, n.2, maggio 1949, pp.299-321. English translation: Tax distribution and Pareto's law in a recent theoretical study as Supplement to the same number of the Journal.

1950 Sull'equivalenza fra imposte sui redditi e imposte di successione, in "Finanza pubblica contemporanea, Studi in onore di Jacopo Tivaroni", Bari, Laterza, 1950, pp. 155-190

1951 Principii di Scienza delle Finanze, II edizione, Giappichelli, Torino.

\section{Bibliography about Mauro Fasiani}

B.Griziotti, Recensione ai Principî di scienza delle finanze (1941), in Rivista di diritto finanziario e Scienza delle Finanze", dicembre 1941, pp.274-275 
J.Tivaroni, Recensione ai Principî di scienza delle finanze (1941, in Diritto e pratica tributaria, 1942 gennaio-febbraio, pp.16-20

A.De Pietri Tonelli, Recensione ai Principî di scienza delle finanze (1941), in Rivista di Politica economica, febbraio 1942, pp,122-25

L.Einaudi, Scienza e storia, o dello stacco dello studioso dalla cosa studiata, in Rivista di storia economica, marzo 1942, pp.30-37

G.Capodaglio, Recensione ai Principî di scienza delle finanze (1941), in Economia, maggio-giugno 1942

E.D’Albergo, Recensione ai Principî di scienza delle finanze (1941), in Rivista bancaria, 1942, pp.187-88

L.Einaudi, Ipotesi astratte ed ipotesi storiche e dei giudizi di valore nelle scienze economiche, Torino, R. Accademia delle Scienze, 1943

L.Einaudi, Discutendo con Fasiani e Griziotti di connotati dello Stato e di catasto e imposta fondiaria, in "Rivista di diritto finanziario e Scienza delle Finanze", 1943, pp.178-190, with Postilla by M.Fasiani, pp.190-191.

L.Einaudi -A.Scotto, Mauro Fasiani. Gli scritti con bibliografia, in "Rivista di diritto finanziario e scienza delle finanze", 1950, fasc.3, pp.199218.

F.Chessa, In memoria di Mauro Fasiani, commemorazione tenuta alla presenza del Presidente della Repubblica Italiana il 17 Marzo 1951 nell 'aula Magna dell'Università di Genova, Roma: Tipografia delle terme, pp.16-35, 1951

E.D'Albergo, Mauro Fasiani, in "Rivista Bancaria", ottobre-novembre 1950, estratto di 6 pagine

C.Cosciani, Mauro Fasiani, in "Economia Internazionale", 1950, pp.913-919

J. M. Buchanan, La scienza delle finanze. The Italian tradition in fiscal theory, in Fiscal theory and political economy-Selected essays, Chapel Hill 1960, pp. 24-74. Italian translation: La scuola italiana di finanza pubblica, 
in M. Finoia (ed.), Il pensiero economico italiano, 1850-1950, Bologna: Cappelli, 1980, pp. 203-242

F.Forte, Il pensiero finanziario in Italia fra le due guerre, con particolare riferimento a Pesenti, Pugliese, Fasiani e Fubini, in "Quaderni di storia dell'economia politica", VIII , 1990, 2-3, pp. 197-221

D.Da Empoli, Fasiani, Mauro, in "Dizionario Biografico degli Italiani", Volume 45, 1995, http://www.treccani.it/enciclopedia/maurofasiani_(Dizionario-Biografico)

M.McLure, 2007, The Paretian School and Italian Fiscal Sociology, Houndmills and New York: Palgrave Macmillan.

A.Fossati: Schede relative alle opere scientifiche di Mauro Fasiani, 2009, http://130.251.147.253/schede\%20Fasiani.html

A.Fossati, The idea of State in the Italian tradition of Public Finance, in "European Journal of the History of Economic thought", 2010, vol.4, pp.881-908

A.Fossati, Pareto's influence on scholars from the Italian tradition in public finance, in "Journal of the History of Economic thought". Forthcoming in Journal of The History of Economic Thought, spring 2013 issue (vol. 45 , no. 1$)$.

A.Fossati, Vilfredo Pareto's influence on the Italian tradition in public finance: A critical assessment of Mauro Fasiani's appraisal, Forthcoming in "European Journal of the History of Economic thought", vol.20:2, May 2013.

A.Fossati, The double taxation of savings: the Italian debate revisited, Forthcomin 


\section{Working Papers recently published}

(The complete list of working papers can be found at http.//www.disefin.unige.it)

n.7/2011 Amedeo Fossati, Marcello Montefiori, "Adverse Selection in Elderly Care", November 2011

n.6/2011 Paolo Cremonesi, Enrico di Bella, Marcello Montefiori, Luca Persico, "A self-reported work sampling to assess the Emergency Department's costs", October 2011

n.5/2011 Enrico di Bella, Luca Persico, Matteo Corsi, "A Multivariate Analysis Of The Space Syntax Output For The Definition Of Strata In Street Security Surveys", September 2011

n.4/2011 Elena Briata, "Marginal tax rates, tax revenues and inequality. Reagan's fiscal policy", July 2011

n.3/2011 Francesco Copello, Cristiana Pellicanò, "Esemplificazione della Data Envelopment Analysis per la valutazione di efficienza in una grande azienda ospedaliera universitaria"

n.2/2011 Stefano Capri, Rosella Levaggi, "Shifting the risk in pricing and reimbursement schemes? A model of risk-sharing agreements for innovative drugs"

n.1/2011 Cinzia Di Novi, "The Indirect Effect of Fine Particulate Matter on Health through Individuals' Life-style"

n.4/2010 Angelo Baglioni, Andrea Monticini, "Why does the Interest Rate Decline Over the Day? Evidence from the Liquidity Crisis"

n.3/2010 Amedeo Fossati: "The double taxation of savings: the Italian debate revisited" 
n.2/2010 Andrea Monticini, David Peel, Giacomo Vaciago: "The impact of ECB and FED announcements on the Euro Interest Rates"

n.1/2010 Amedeo Fossati: "Vilfredo Pareto and the methodology of the Italian tradition in public finance" 